BBAREV 85387
Review

\title{
Techniques and concepts in exocytcsis: focus on mast cells
}

\author{
Manfred Lindau ' and Bastien D. Gomperts ${ }^{2}$ \\ 'Biophysics Group, Department of Physics, Free Unicersity Berlin, Berlin (Germany) \\ and ${ }^{2}$ Department of Physiology, Rockefeller Building, Unicersity College London, London (U.K.)
}

(Received 5 March 1991)

\section{Contents}

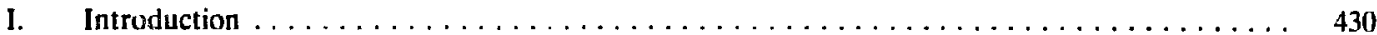

A. First considerations $\ldots \ldots \ldots \ldots \ldots \ldots \ldots \ldots \ldots \ldots \ldots \ldots \ldots \ldots \ldots \ldots$

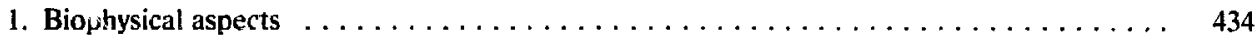

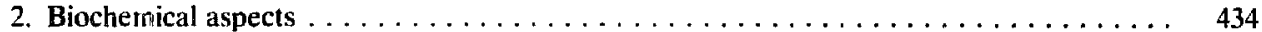

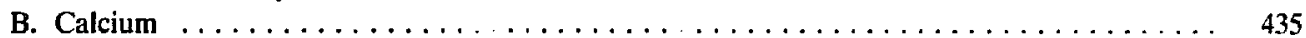

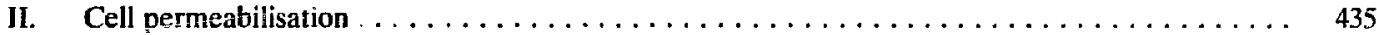

A. Quantitative description of permeability lesions $\ldots \ldots \ldots \ldots \ldots \ldots \ldots \ldots \ldots \ldots \ldots$

III. Permeabilisation of cell suspensions $\ldots \ldots \ldots \ldots \ldots \ldots \ldots \ldots \ldots \ldots \ldots \ldots \ldots \ldots \ldots \ldots$

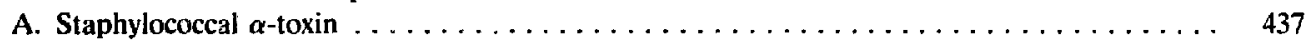

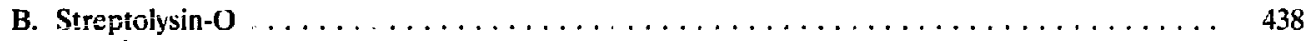

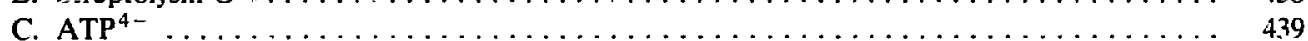

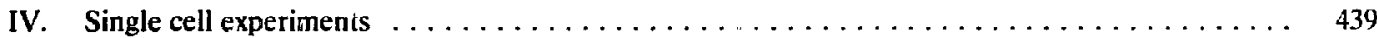

A. Single cell microinjection $\ldots \ldots \ldots \ldots \ldots \ldots \ldots \ldots \ldots \ldots \ldots \ldots \ldots \ldots \ldots \ldots$

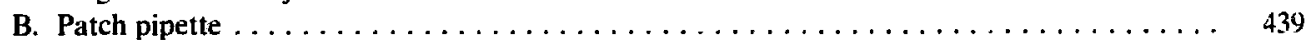

C. Measurement of secretion from single cells $\ldots \ldots \ldots \ldots \ldots \ldots \ldots \ldots \ldots \ldots \ldots \ldots$

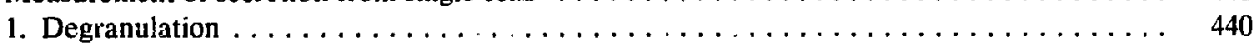

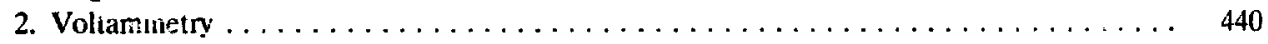

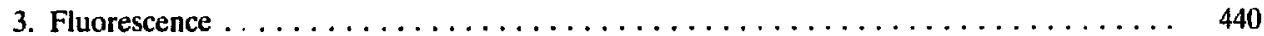

4. Measurement of membrane capacitance $\ldots \ldots \ldots \ldots \ldots \ldots \ldots \ldots \ldots \ldots \ldots \ldots 440$

5. Slow-whole-cell configuration of the patch-clamp technique $\ldots \ldots \ldots \ldots \ldots \ldots \ldots \ldots$ 44

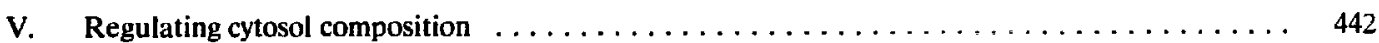

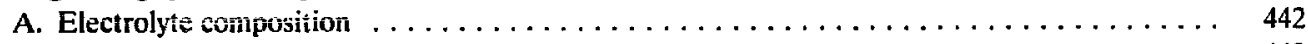

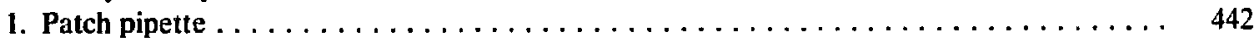

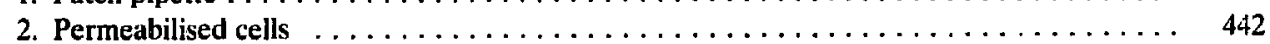

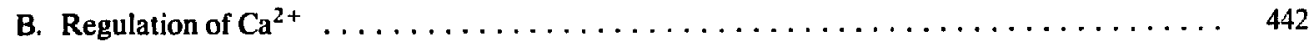

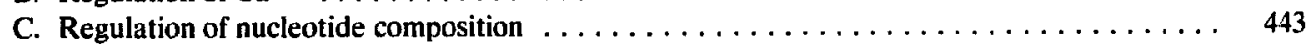

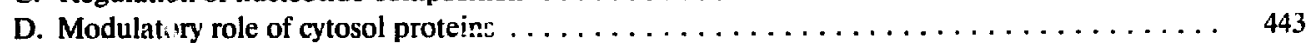

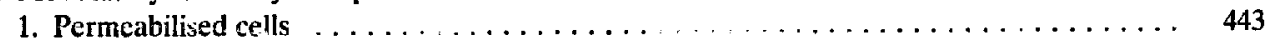

Leakage of cytosol proteins $\ldots \ldots \ldots \ldots \ldots \ldots \ldots \ldots \ldots \ldots \ldots \ldots \ldots \ldots \ldots$

Introduction of exogenous proteins $\ldots \ldots \ldots \ldots \ldots \ldots \ldots \ldots \ldots \ldots \ldots \ldots \ldots \ldots$

VI. Dual effectors for exocytosis $\ldots \ldots \ldots \ldots \ldots \ldots \ldots \ldots \ldots \ldots \ldots \ldots \ldots \ldots \ldots . \ldots \ldots$

A. $\mathrm{Ca}^{2+}$ and a guanine nucleotide, together, are necessary and sufficient $\ldots \ldots \ldots \ldots \ldots . \ldots 44$

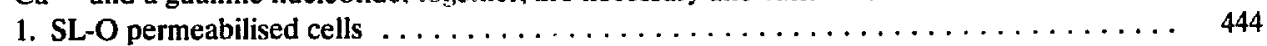

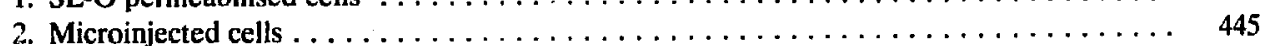

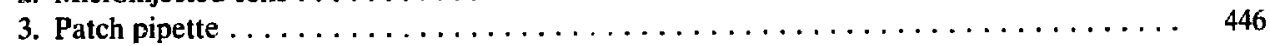

Correspondence: B.D. Gomperts, Department of Physiology, Rockerfeller Building, University College London. University Street. London WC1E 6JJ, U.K. 
B. The meaning of effector concentration-response relationships $\ldots \ldots \ldots \ldots \ldots \ldots \ldots$

C. Exocytosis in zwitterionic electrolyte solutions $\ldots \ldots \ldots \ldots \ldots \ldots \ldots \ldots \ldots \ldots \ldots \ldots \ldots \ldots \ldots \ldots$

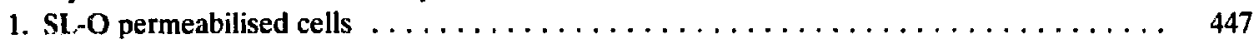

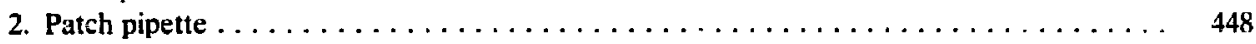

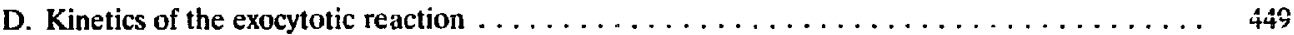

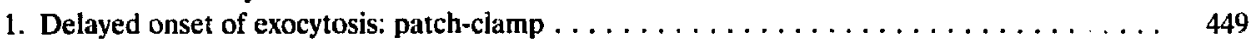

E. Delayed onset of exocytosis: SL-O permeabilised cells $\ldots \ldots \ldots \ldots \ldots \ldots \ldots \ldots \ldots \ldots .450$

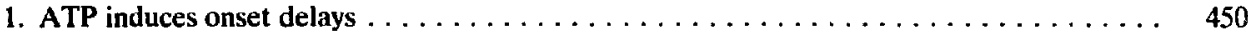

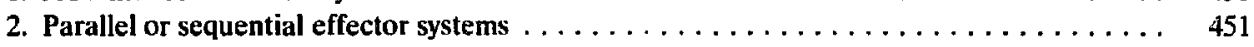

3. Abrupt onset in the absence of ATP $\ldots \ldots \ldots \ldots \ldots \ldots \ldots \ldots \ldots \ldots \ldots \ldots \ldots$

VII. Evidence for a G-protcin mediated dephosphorylation as an enabling reaction for exocytosis . . 452

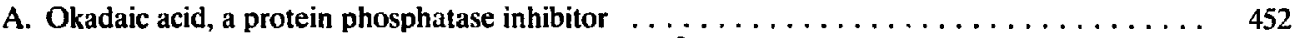

B. SL-O permeabilised cells lose responsiveness to $\mathrm{Ca}^{2+}$ and $\mathrm{GTP}-\gamma-\mathrm{S} \ldots \ldots \ldots \ldots \ldots \ldots \ldots$

C. Okadaic acid ensures dependence on guanine nucleotice $\ldots \ldots \ldots \ldots \ldots \ldots \ldots \ldots, 453$

D. Evidence for protein dephosphorylation as an enabling step in other secretory ce $\ldots \ldots \ldots 454$

E. Evidence for a late-acting GTP-binding protein $\left(G_{\mathrm{E}}\right)$ mediating secretion in other cells $\ldots \ldots, 454$

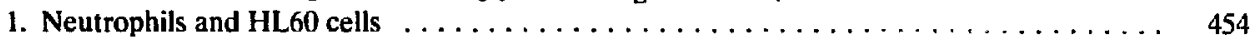

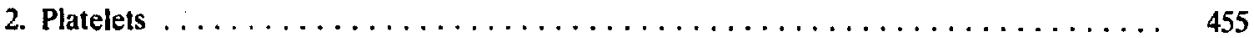

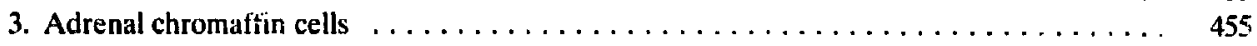

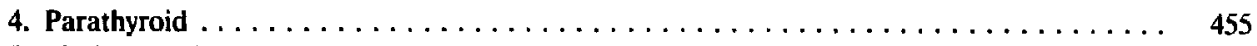

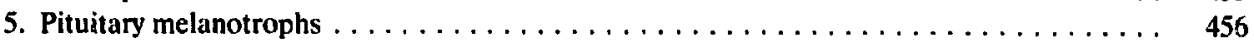

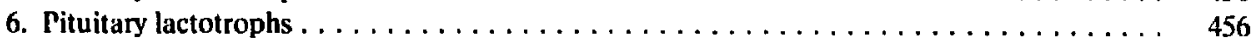

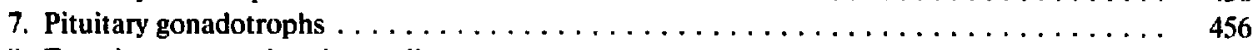

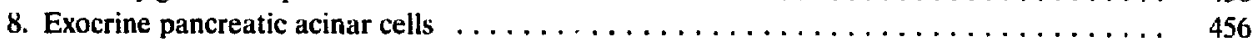

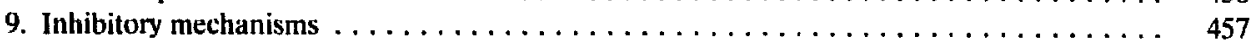

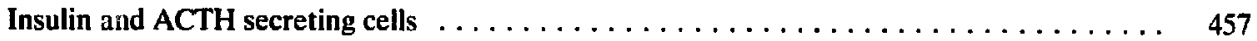

F. Classification of $G_{E}$, the GTP-binding protein mediating exocytosis in myeloid cells $\ldots \ldots \ldots$

1. $G_{\mathrm{E}}$ : an argument ior a heterotrimeric signal transducing $G$-protein $\ldots \ldots \ldots \ldots \ldots \ldots 45$

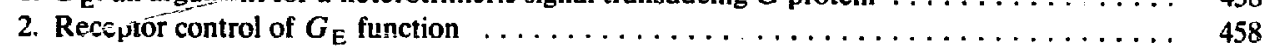

VIII. The exocytotic event $\ldots \ldots \ldots \ldots \ldots \ldots \ldots \ldots \ldots \ldots \ldots \ldots \ldots \ldots \ldots \ldots \ldots \ldots$

A. Exocytosis of single granules $\ldots \ldots \ldots \ldots \ldots \ldots \ldots \ldots \ldots \ldots \ldots \ldots \ldots \ldots \ldots \ldots \ldots$

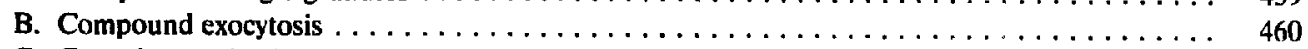

C. Granulogenesis: the formation of secretory granules $\ldots \ldots \ldots \ldots \ldots \ldots \ldots \ldots \ldots \ldots \ldots \ldots$.

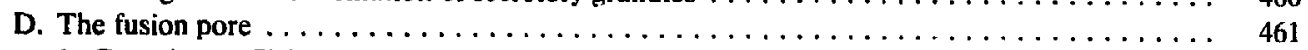

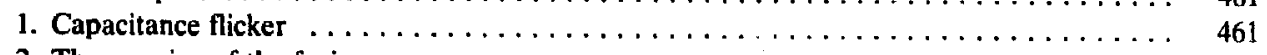

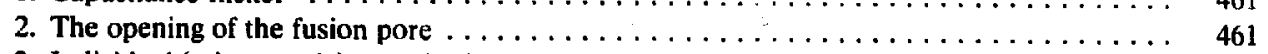

3. Individual (microscopic) steps in the exocytotic event $\ldots \ldots \ldots \ldots \ldots \ldots \ldots \ldots \ldots \ldots . \ldots \ldots$

4. Is non-osmotic membrane tension the driving force for fusion? $\ldots \ldots \ldots \ldots \ldots \ldots \ldots \ldots$.

IX. Envoi $\ldots \ldots \ldots \ldots \ldots \ldots \ldots \ldots \ldots \ldots \ldots \ldots \ldots \ldots \ldots \ldots \ldots \ldots \ldots \ldots$

Acknowledgements $\ldots \ldots \ldots \ldots \ldots \ldots \ldots \ldots \ldots \ldots \ldots \ldots \ldots \ldots \ldots \ldots \ldots \ldots \ldots \ldots \ldots$

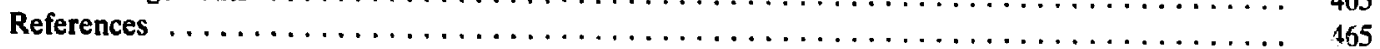


....'One mechanism involves binaing of the hormone to the receptor, resulting in a rise of the intracellular level of $\mathrm{Ca}^{2+}$ and after a series of ill-defined steps, in stimulation of secretion'

from Molecular Cell Biology. Darnell, Lodish \& Baltimore (Scientific American Books, 1986)

'The final truth came io me as we stood there, trembling, searching between all our past and all our future; at at moment when the difference between fission and fusion lay in a nothing, a tiniest movemeni, betrayal, further misunderstanding'

(from THE MAGUS (C) John Fowles, first published by Jonathan Cape Ltd., 1966)

\section{Introduction}

The term exocytosis [99] describes the mechanism by which eukaryotic cells secrete prepackaged materiais contained in membrane-bound vesicles or granules to the exterior. The substances released by exocytosis range from relatively small compounds such as neurotransmitters to enzymes, antibodies, micellar phospholipids (i.e... in the type II cells of the lung epithelium) and heparin (mast cells). Depenüing oni the particular requirements they are packed in vesicles having diameters ranging from $50 \mathrm{~nm}$ in the case of synaptic vesiclec to more than $1 \mu \mathrm{m}$ in the case of horse eosinop the mucin containing granules of epithelial cells. Intrinsic to this process is the attachment of the granules to the plasma membrane and the subsequent fusion of the vesicle membrane with the plasma membrane so that the vesicle contents can be released through a fusion pore which then develops [71-74,269] (Figs. 1 and 2). In many cells (ranging from microorganisms to tissues such as the mammalian liver) secretion occurs constitutively, not appearing to depend on specific signals. There is also a wide variety of cell types (again ranging from unicellular organisms such as Paramecium to mammalian tissues) which undergo secretion in response to snecific signals: this is called regulated exocytosis and forms the topic of this article. Well investigated examples among animal cells include the release of neurotransmitters at synapses and neuromuscular junctions, the release of peptide hormones from the pituitary and pancreatic glands and catecholamine reiease by the adrenal medulla. These are

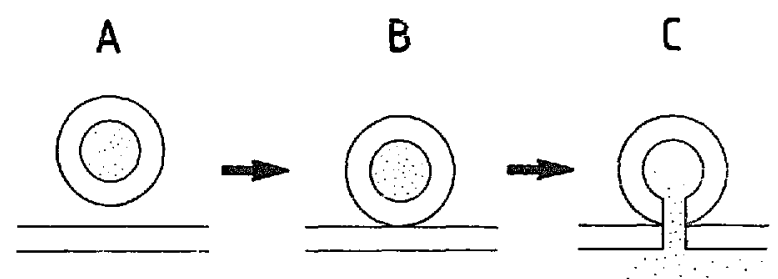

Fig. 1. Schematic representation of membrane-membrane interaction in exocytotic fusion. Cytoplasmic granules (A) need to attach to the plasma membrane (B) before a fusion pore can open $(C)$ allowing the granular components to be released. In neuronal cells, some of the secretory vesicles are in close contact (docked) with the plasma membrane in the resting state in a state of readiness. This allows for very rapid release. In other secietory cells, docking comprises a stage in the stimulus-secretion sequence. all electrically excitable systems in which exocytosis is triggered by action potentials. The action potential leads to the opening of voltage dependent calcium channels and it is the consequent elevation of cytosol $\mathrm{Ca}^{2+}$ which is believed to trigger the fusion of the secretory vesicles with the plasma membrane by a still unknown mechanism.

Exocytosis also occurs in non-excitable ceils in which secretion occurs in response to specific receptor directed agonists and in these systems the regulatory pathway varies widely. Secretory cells are thus equipped to execute a wide multiplicity of physiological tasks. Presynaptic membranes, nerve terminals and chromaffin cells release neurotransmitters or hormones within milliseconds oî depolarisation $[8,114,217,253]$; parathyroid $[60,255,326]$ (and some other peptide releasing cells $[00,78,120,147,279])$ release hormone in response to a decrement in cytosol $\mathrm{Ca}^{2+}$; parotid cells can release amylase in response to $\beta$-adrenergic activation leading to elevation of cyclicAMP $[170,231,295]$ and this allows independent regulation of fluid release in response to elevation of cyiosol $\mathrm{Ca}^{2+}$ by muscarinic cholinergic activation. Nor does exocytosis necessarily occur in response to a change in the concentration of a conventional water soluble second messenger. Thus, activation through the protein kinase $C$ pathway induces secretion from platelets and neutrophils under conditions in which cytosol $\mathrm{Ca}^{2+}$ is maintained at or even below resting levels [102,292,300,301]. There exist alternative second messengers and also signalling systeins in which the concentration of intraceliular effectors remain constant, but the affinity for their binding increases.

The historical investigations of the secretory process which provided many of the concepts with which we are still concerned, came from experimental work on glands [278] or those single cells which release into a closed environment (i.e., nerve endings) $[184,185]$. Some of the best and most lasting insights have concerned the pathway for synthesis, modification and storage of secretory materials rather than the exocytotic event itseif [175]. One reason for this is that the rlands (and this is equally true of the synapse) necessarily release only a very small proportion of their stored material in response to stimulation [319]. Release all your amylase or insulin and you can't, or shouldn't eat your next pudding; release more than a few percent of your 

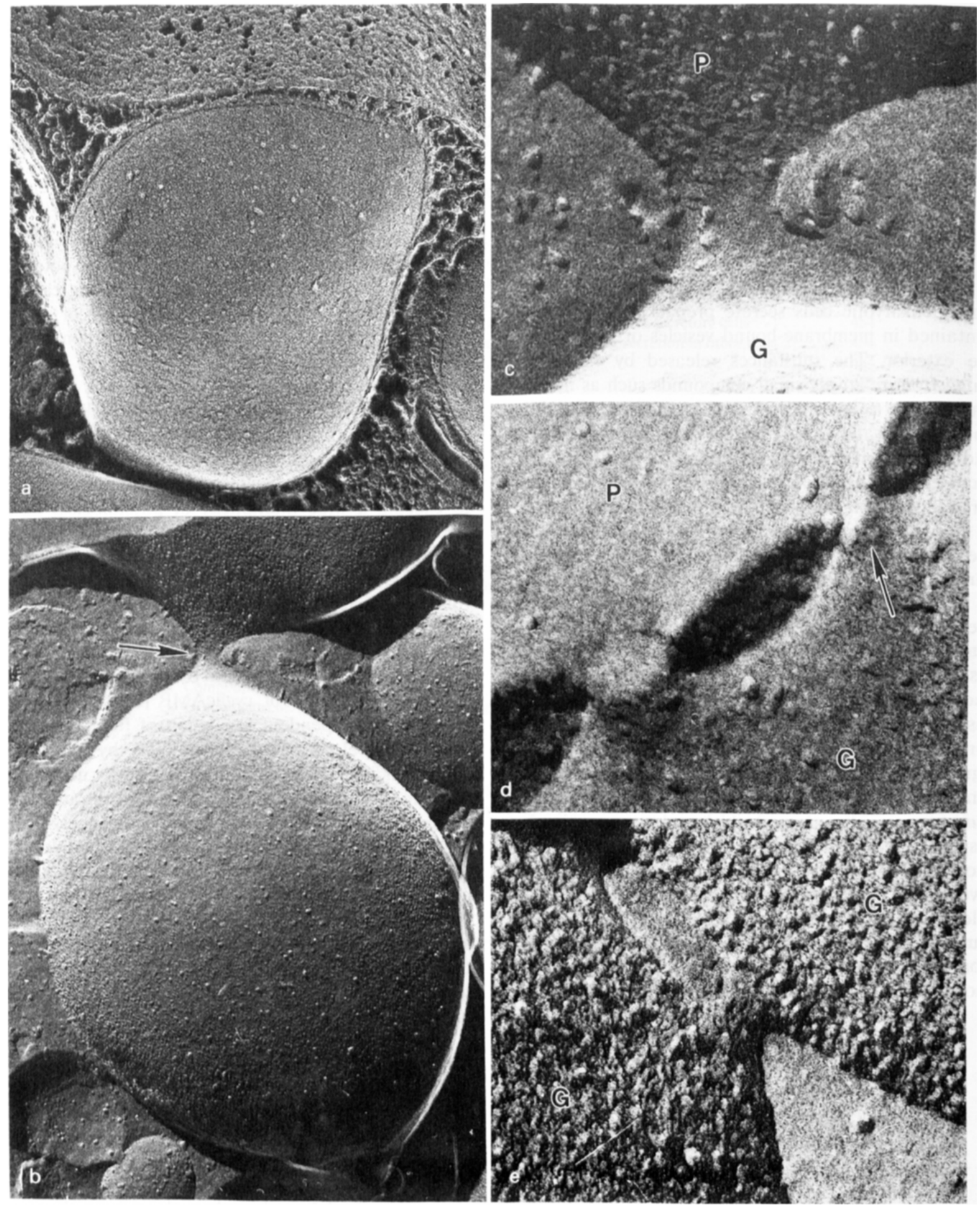

Fig. 2. Freeze-fracture images of exocytosis in mast cells and neutrophils. (a) Freeze fracture replica of an un timulated rat mast cell. A secretory granule lies just under the plasma membrane. The specimen was quici-irozisi on a liquid helium-cooled co per biock, fractured and replicated with platimum/crston. $\times 90000$. (b) The beginning of exocytosis in rat mast cells stimulated with compound $48 / 80$. A small pore has formed between the plasma membrane and the gransle (arrow). $\times 75000$. (c-e) Exocytotic pores in stimulated rat mast cells during ihe early stages of pore growth. (c) The pore depicted in (b) is seen here joining the $E$ face of the plasma membrane (P) with the $E$ face of the granule membrane (G) $\times 280000$. (d) Some pores. as small as $27 \mathrm{~nm}$ in diameter (arrow), appear to be pedestals that may still contain a singl: bilayer diaphragm. $\times 360000$ [73]. (e) Small pores are also seen joining granules. $\times 350000$. (f\&g) The pore grows as the granule matrix expands allowing exit of the granule contents. $\times 58000$ (f) and $\times 48000$ (g). (g) reproduced from [71]. (h\&i) Exocylusis in rabbit neutrophils treated with cytochalasin B and 

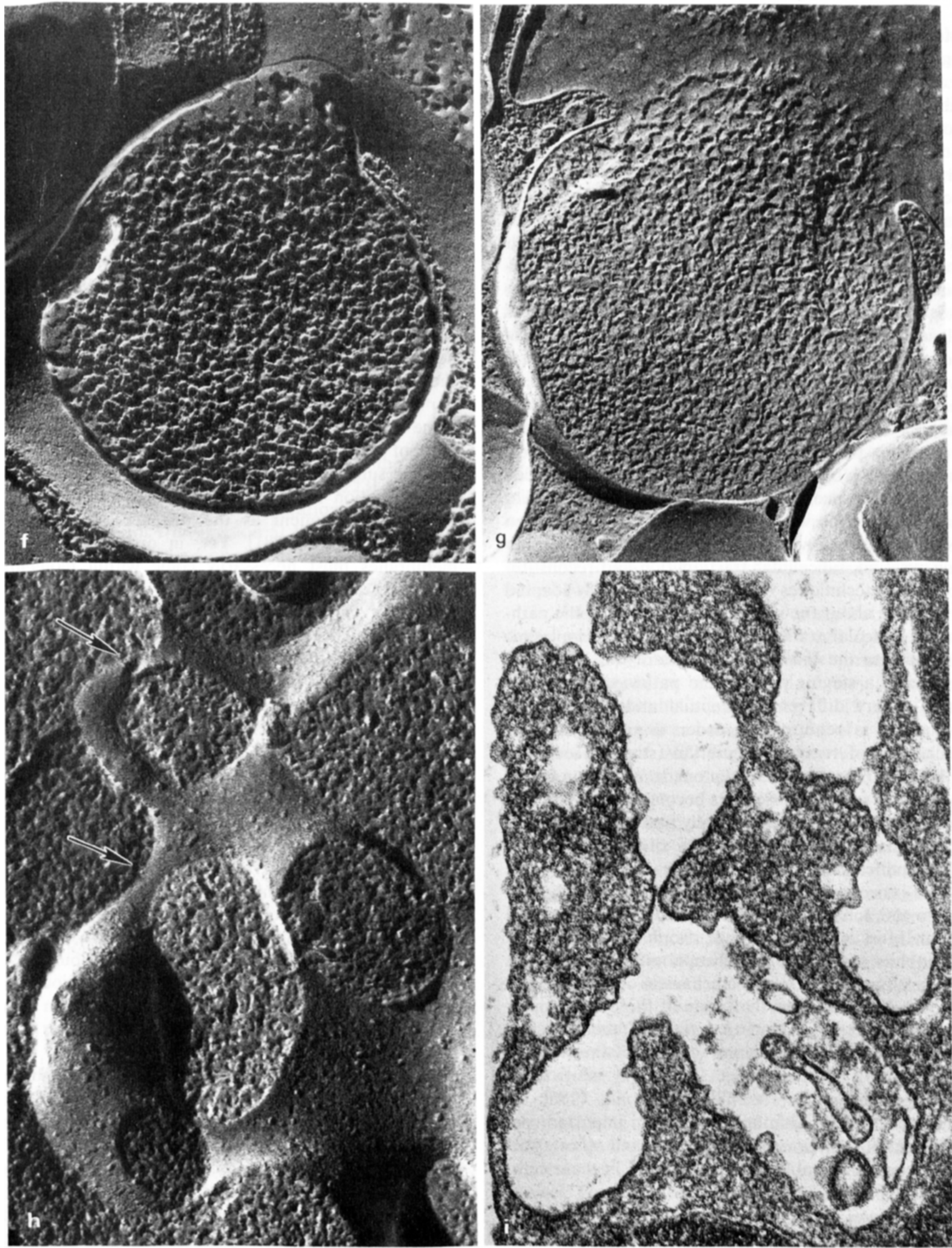

stimulated with fMetLeuPhe. The granules are interconnected by narrow diameter tubular structures (arrows). Specimens were fixed in glutaraldehyde and either quick-frozen and freeze fractured (h) or embedded in epoxy resin and thin-sectioned (i). $\times 170000(\mathrm{~h})$ and $\times 110000$ 
catecholamines and you can forget all about fight and flight - better call in the undertaker (mortician).

Many of the secretory systems which are now contributing so strongly to understanding of the release mechanism were hardly recognised or understood as such in the earlier times. In the main these are secretory cells which occur as isolated entities, many of them (but not all, e.g., platelets) associated with the immune system in the blood (neutrophils, eosinophils, basophils) or the tissues (mast cells). Operating as single cells, a significant contribution to the local environment can only be achieved if the extent of exocytosis is considerable: in a number of instances substances released from these cells go on to recruit other cells of the same class so actually amplifying the response. Even so, if a large proportion of the platelets or basophils are simultaneously stimulated the consequences are often fatal (i.e., thrombosis, anaphylaxis).

There is possibly another reason why biochemical understanding of the exocytotic step has so far eluded us and this concerns people. Many of the early pioneers in secretion were the biochemists who had been instrumental in devising the techniques of tissue homogenisation, subcellular fractionation and reconstitution. These techniques were and remain ideally adapted to learning about the non-regulated stages of the pathway of vesicular traffic leading from the endoplasmic reticulum to the formation of secretory vesicles. This represents a staging post on the pathway; thence onward, a very different conceptual and experimental framework is required. In order to understand the mechanism of regulated secretion (stimulus-secretion coupling [103]), agonists, receptors, transduction mechanisms and second messengers become paramount and the pioneers in this field generally regarded themselves as pharmacologists. Today, these distinctions are of little significance.

The process of regulated secretion is certainly centrat action of the effector cells of the immune system. Mast cells, basophils, neutrophils, macrophages, eosinophils and cytotoxic T-lymphocytes all release a variety of mediators by the mechanism of exocytosis. It is now well established that none of these cells generate action potentials and that none of them possess voltage dependent calcium channels (mast cells [212,213,284]; macrophages [125,385]; neutrophils $[126,186]$; basophils [186,358]; eosinophils [186]; Tlymphocytes [98]). Although $\mathrm{Ca}^{2+}$ is an important determinant of secretion, other effectors and other effector mechanisms enable exocytotic fusion in these cells.

\section{I-A. First considerations}

\section{I-A-1. Biophysical aspects}

Exocytosis has been described as the controlled interaction of perigranular membranes with the plasma membrane which results in their fusion and subsequent fission to release the granular contents to the exterior [278]. This was based mainly on thin-section and freeze-fracture electron microscopic evidence of cells fixed while undergoing exocytosis. The fusions are absolutely specific and as far as we know there is no leakage of granule contents into the cytosol. While this portrayal remains valid in a macroscopic sense, and has indeed been weil substantiated by more recent developments [206,267,269,273,268], it also conceals a number of problems which must be faced if we are ever to understand the molecular mechanisms involved. We should consider some problems of temporal and spatial resolution. Membranes are regarded as being in close apposition and hence in a pre-exocytotic state when the fixed and stained thin section reveals a pentalaminar structure. It is at this point, a hydrated surfaces come within about $2 \mathrm{~nm}$ of each ofiler (i.e., close to the limi: of resolution in electron microscopy), that they become subject to an overwhelming force of repulsion (the hydration force) which increases according to a high oris exponent as the distance of separation diminishes [207,280,281]. Yet, in order to fuse, the membranes must necessarily come within molecular feeling distance of one another.

Next, it must be realised that the phospholinid bilayer of which membranes are composed is a stable structure in the biological environment in which water provides the buik phase (i.e., at $55 \mathrm{M}$ ). It is hydration which maintains phospholipids in this arrangement [34] and the polar surfaces of the bilayers have a high affinity for water [207]. In order to disorganise the bilayer organisation experimentally, to induce fusion between cells it is common practise to deliydrate the environment, though this in itself is insufficient. Thus, a high concentration of polyethylene glycol, sufficient to remove all traces of free water is commonly used as a fusogen in the formation of cell hybrids, but the propensity to fuse ceils varies greatly between polyethylene glycols from different sources [164,328] depending on the presence of destabilising impurities in the commercial material [377]). It must be obvious that biological fusions occur by mechanisms other than those which simply involve the removal of bulk water from membrane surfaces.

In fact it is very unlikely that biological membrane fusion involves an extensive interaction between surfaces. When freeze fracture images are prepared from cells quick frozen in the act of exocytosis (i.e., caught in a kind of membraneous in flagrante delicto), the extensive apposition between the fusing surfaces, familiar as the pentalaminar membrane depicted in images of thin sections, is no longer evident (see Figs. $2 b-g$ ); indeed they approach no closer than about $2 \mathrm{~nm}$ except at focal points of contact. Here, as fusion is initiated and develops, there forms a structure which has been 
called the fusion pore. The surface lining this structure has the characteristic morphology (a fracture surface interrupted with intramembraneous particles) and fluidity (see VIII-D-4) of an extension in continuity with the fusing membranes.

\section{I-A-2. Biochemical aspects}

In the light of experience with artificial systems it becomes axiomatic that the controlled fusions which occur in biology are catalytically mediated and proceed on a molecule by molecule basis. In seeking to understand the mechanism of exocytosis we are searching for a fusogenic catalyst; in effect, what we discover is a sequence of control steps the last of which, so far unidentified, being that which regulates the activity of the fusogen.

\section{1-B. Calcium}

Calcium has been directly associated with the secretory process for at least 50 years $[148,223]$ and less directly (i.e., throug!. the demonstration of a requirement for $\mathrm{Ca}^{2+}$ tor transmission at the frog neuromuscular junction) for close on a century [218]. Today, it still remains central to any discussion of the secretory process. Following the initial demonstration that secretory activities $[119,293,322]$ could be indwod by the calcium carrying antibiotic (ionophore) A23187, similar effects were obtained for nearly all the well recognised secretory systems $[86,131]$ and with other ionophores such as ionomycin [41] and the synthetic compound 'fod' (a chemical-shift reagent widely used in NMR spectroscopy) [137]. Activation of secretion by ionophores depends on the concentration of the lipid soluble ( $\mathrm{Ca}^{2+}$.ionophore) complex and thus on the rate of entiry of the $\mathrm{Ca}^{2+}$ ion into the cytosol [41]. Since this occurs against the homeostatic mechanisms which normally maintain $\mathrm{Ca}^{2+}$ at a low resting level, the effect is to establish a new elevated steady state level.

Fig. 3 illustrates the dependence of histamine secretion by RBL-2H3 (rat basophilic leukaemia) cells on

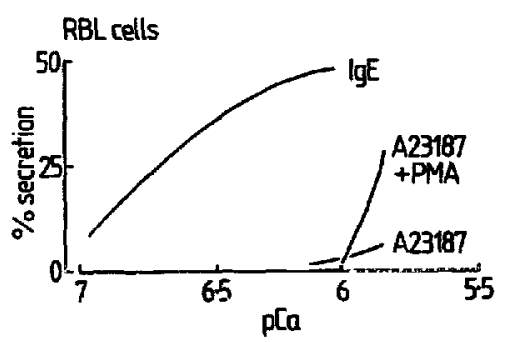

Fig. 3. Dependence on the concentration of intracellular $\mathrm{Ca}^{2+}$ for secretion of histamine from rat basophilic leukaemia cells. Intracellular $\mathrm{Ca}^{2+}$ was measured in a suspension of RBL-2H3 cells (a mast cell line) loaded with quin-2, following stimulation with: (a) a calcium ionophore; (b) a calcium ionophore applied in combination with the protein kinase $C$ activator PMA; and (c) by an antigen which activates these cells by cross-linking the receptors for $\mathrm{lgE}$. Redrawn and adapted from Beaven et al. [39]. the level of intra-cellular calcium following stimulation with: (a) a calcium ionophore; (b) a calcium ionophore applied in combination with the protein kinase $C$ activator PMA; and (c) by an antigen which activates these cells by cross-linking the receptors for IgE [39]. It is apparent that the $\mathrm{Ca}^{2+}$-sensitivity of these cells when subjected to a $\mathrm{Ca}^{2+}$-only stimulus of this kind, or with concomitant activation of protein kinase $\mathrm{C}$, fails to match the sensitivity achieved by stimulating the cells through the normal receptor mechanism. Clearly, elevation of calcium and phosphorylation of kinase $\mathrm{C}$ substrates is only a part of the story. This conclusion has been reinforced by the finding that cells treated with an inhibitor of protein kinase $C$ (staurosporine, at a concentration sufficient to obliterate the response to ionophore-plus-phorbol ester) remained responsive to stimulation to an antigen [94]. In addition to the well recognised pathway of activation mediated by the hydrolytic products of phosphatidylinositol bisphosphate, the cross-linking of the receptors for $\operatorname{IgE}[234,320]$ (and presumably the activation of more conventional receptors on other secretory cells) must initiate further signals to the system so that exocytosis can occur in response to $\mathrm{Ca}^{2+}$ at intracellular concentrations well below $10^{-6} \mathrm{M}$.

In addition to a possible requirement for $\mathrm{Ca}^{2+}$, these cells (and nearly all other cell types) fail to secrete in response to stimulation by normal receptor directed ligands, or ionophores, if they have been treated with metabolic inhibitors [112,119 178]. This is generally accepted as being indicative of a reliance on the presence of ATP but it leaves unanswered all questions about what the role or roles of ATP might be.

Nobody seriously thinks that you could find out about the workings of a motor car by measuring what comes out of the exhaust pipe. Much better to open up the bonnet (hood), tariper with the works and get your hands dirty. Similarly, you don't learn about the mechanism of exocytosis simply by measuring the release of secreted products in response to a stimulus. Indeed, the statements offered in the above paragraphs summarise nearly all that can usefully be gleaned by the study of intact cells (i.e., $\mathrm{Ca}^{2+}$ is surely important, but under normal circumstances not sufficient, and at some point in the process there is likely to be a requirement for ATP). To obtain information about the chain of events linking stimulation of the cell surface to the final fusion event and about the nature of the fusion process itself, it is necessary to gain access to the cytosol. To some extent the use of calcium ionophores, by markedly decreasing the barrier for calcium ions and so permitting $\mathrm{Ca}^{2+}$ to enter the cell across the plasma membrane, already represents an attempt to achieve this. Methods which permeabilise the plasma membrane enable us to control the composition of the 
cytosol with precision. There is a very wide range of techniques by which this can be achieved.

\section{Cell permeabilisation}

Broadly the techniques of membrane permeabilisation divide into two main strategies. One may either look at single cells which can provide information which is highly resclved in time and dimensions. Alternatively one might look at cell populations. These provide the possibility of pursuing a flexible approach which allows application of an extensive range of conditions, concentrations, timing of operations etc. at the cost of averaged data.

There are many techniques which allow the selective permeabilisation of the plasma membrane of cells while maintaining their general structural integrity and their ability to respond to appropriate effectors. Those which have been most widely applied include the use of high voltage electric discharges (HVD) [196], application of bacterial cytolysins (streptococcal $\alpha$-toxin ( $\alpha$-tox [4,210]) and streptolysin-O (SL-O [4,168])), application of plant glycosides (saponin [306] and digitonin [201]), and for susceptible cell types, ATP (as its tetrabasic free acid, ATP $^{4-}$ ) [84]. All these different methods have particular, and importantly, quite distinct characteristics. The cell type and the permeabilisation method thus have to be considered jointly as an experimental system and it is necessary to have a good understanding of the nature of the damage inflicted in terms of the duration and dimensions of the lesions formed. While the proponents of the various methods have, from time to time, claimed particular advantages for their own favoured technique [196], the real benefits accrue from recognising that there is a repertoire of techniques, each of which offers its own special features. In this way it is possible to design experimental $s$ rategies with much greater flexibility and to analyse results appropriately.

The basic characteristics of these various techniques are set out in Table I. It should be stressed that the characteristics of lesion formation vary among different cell types for all of these different techniques; thus, while HVD treatment of adrenal chromaffin cells [27], platelets [195] and pancreatic (exocrine [193] and endocrine [383]) cells has the effect of generating semipermanent $(>1 \mathrm{~h})$ permeability lesions, those formed in red blood cells [188], macrophages and Hela cells reseal rather rapidly [30]; also, while SL-O permeabilisation is a very effective way of permeabilising cells in suspension, monolayers of cultured cells are sometimes obstinately resistant (e.g., hepatocytes in primary culture; J.D. Judah, personal communication). The range of available methods for cell permeabilisation now allows one to opt for methods which will permit the selective dialysis of ions and low molecular weight solutes (e.g., HVD, $\alpha$-tox); alternatively by application of plant glycosides or SL-O it is possible to induce exchange of most, if not all cytosol proteins. At the extreme, the use of the patch pipette (in the whole-cell mode: see below, section IV-B) imposes a single permeability lesion having the dimensions of cytoplasmic organelles.

\section{II-A. Quantitative description of permeability lesiuns}

To describe the characteristics of a particular permeabilisation method a quantitative description of the permeability lesions is clearly required. It is obvious that only those molecules smaller than the size of individual pores can leave or enter the cells. However,

\section{TABLE I}

\section{Methods of cell permeabilisation}

The filtration dimensions are given only as a very rough guide. For any reagent or method there will be wide variation depending on membrane composition and other conditions. Furthermore, the different methods used to assess the filtration properties of membrane lesions must necessarily give different results.

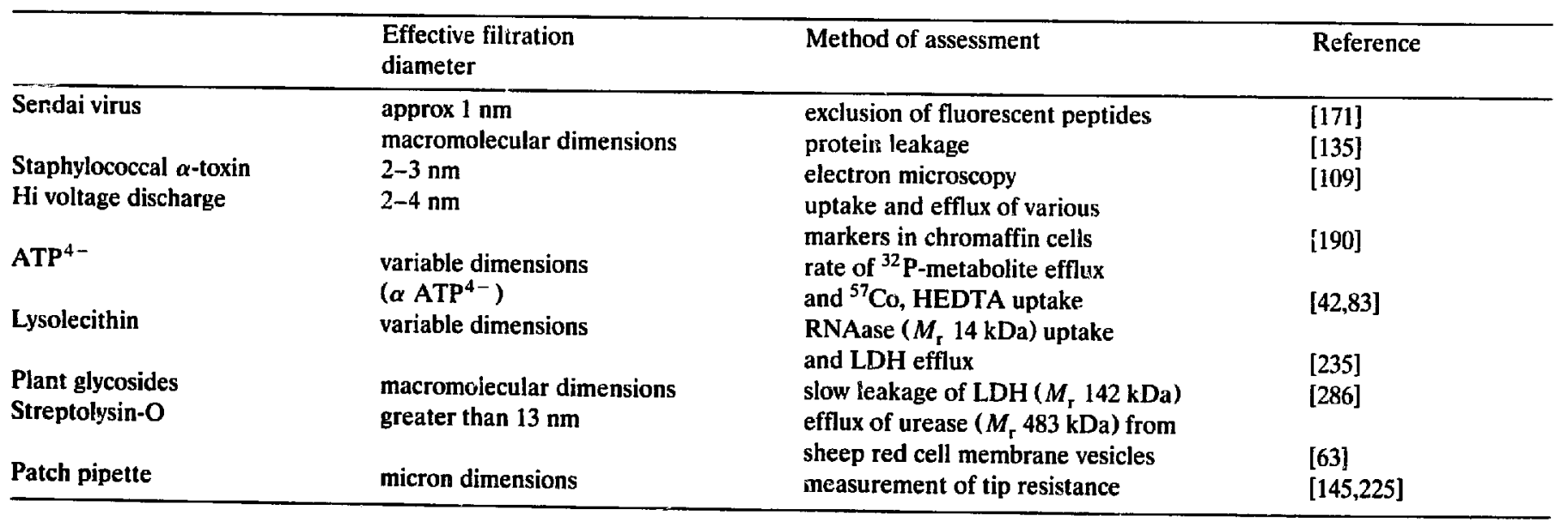


the flux rate through the lesions for any permeant substance will depend on its diffusion constant, which in timin is related to the molecular weight. As long as the membrane represents the main diffusion barrier and the cytoplasm can be assumed to be well stirred, the rate of exchange will be proportional to the number of pcres.

The time constant $\tau$ for diffusional equilibration between the extracellular medium and the interior of a spherical cell having radius $r$, permeabilised by a single pore of length $l$ and cross-sectional area $a$, is expected to be

$\tau=\frac{4}{3} \pi \cdot r^{3} \cdot l /(\mathrm{a} D)$

where $D$ is the diffusion constant for a particular substance [318].

For a cylindrical pore the cross-sectional area is given by

$a=\pi \cdot(d / 2)^{2}$

where $d$ denotes the diameter of the pore. The time constant for the exchange of mol cules having a diffusion constant $D$ will thus be

$\tau=\left(16 r^{3}\right) /\left(3 d^{2} D\right)$

and as long as the plasma membrane remains the limiting diffusion barrier the time constant $\tau$ in the presence of $n$ pores will be

$\tau=n \cdot\left(16 r^{3} l\right) /\left(3 d^{2} D\right)$

The diffusional equilibration time constant is thus inversely proportional to the diffusion constant of a particular substance, which for large molecules is in turn proportional to the third root of the molecular weight, $M^{-1 / 3}$. It also varies with the third power of the size of the cell, $r^{3}$, indicating that any given method of permeabilisation may have quite different consequences in large and small cells. Finally the $\tau$ is inversely proportional to the square of the pore diameter $d^{2}$ which means that changing the pore diameter from 1 to $3 \mathrm{~nm}$ alters the equilibration time by an order of magnitude.

\section{Permeabilisation of cell suspensions}

\section{III-A. Staphylococcal $\alpha$-toxin}

The pores formed by the $\alpha$-toxin of Staphylococcus aureus have been characterised by measuring the electrical conductance of the channels formed by the toxin in planar phospholipid bilayer membranes [233]. The opening of single channels was found to occur in steps of rather uniform magnitude which indicates that the toxin forms individual pores of well defined size. The single channel conductance increases linearly with the conductivity of the solution suggesting a diameter of approx. $1 \mathrm{~nm}$ for an aqueous pore. The unit conductance is weakly voltage dependent and the channels display a slight anion selectivity. $\mathrm{Ca}^{2+}$ and other divalent cations are permeant as might be expected for a large pore but as with many other pore forming agents (e.g., haemolytic viruses, complement), the induced permeability is also inhibited by divalent cations (i.e., including $\left.\mathrm{Ca}^{2+}[233,282]\right)$. The inhibition of $\alpha$-toxin induced permeability by divalent cations is voltage dependent [233]. Very similar properties of the $a$-toxin pores generated in rat mast cells have been recorded in whole-cell patch-clamp experimenis as shown in Fig. 4. (Lindau and Troeger, unpublished data).

The rate of flux through the lesions generatec by $\alpha$-toxin is very slow. Therefore, if meaningful results are to be obtained, great care and special precautions have to be taken to ensure adequate equilibr:tion of solutes such as nucleotides and $\mathrm{Ca}^{2+}$ buffers (e.g., EGTA). For example, in a recent investigation concerning the exocytotic mechanism ir. primary pituitary gonadotrophs [369], the cells were first permeabilised at $37^{\circ} \mathrm{C}$, then loaded with $\mathrm{Ca}^{2+}$-buffers for $30 \mathrm{~min}$ at $0^{\circ} \mathrm{C}$ and only then returned to a temperature permissive for secretion $\left(37^{\circ} \mathrm{C}\right)$. In addition it was found necessary to use the Ca.EGTA buffers at high concentrations $(20 \mathrm{mM}$ : in most work with permeabilised cells $3 \mathrm{mM}$ is generally considered sufficient) in order to ensure equilibration of $\mathrm{Ca}^{2+}$.

\section{III-E. Streptolysin-O}

The size of pores generated by streptolysin-O allows for leakage of proteins like actin (43 kDa) $[198,199]$, phosphoglycerate kinase (PGK, $40 \mathrm{kDa}$ ) [139] and lactate dehydrogenase (LDH $140 \mathrm{kDa})[139,168]$. Following addition of streptolysin- $O$ to rat mast cells at $0.4 \mathrm{iU}$ $\mathrm{ml}^{-1}$ the release of cytosol marker enzymes (PGK and LDH) commences after a lag period of approx. $20 \mathrm{~s}$ and then proceeds with a time constant $\tau$ of 60 and $100 \mathrm{~s}$ for the two enzyme proteins, respectively. Whole-cell patch-clamp experiments on HL60 cells have revealed conductance steps having a widely variable conductance. Typically the first step has a conductance of 10 to $20 \mathrm{nS}$ which corresponds to a pore diameter of 8 to $11 \mathrm{~nm}$. Such a pore is just large enough to allow for permeation of enzymes such as PGK and LDH. These initial conductance steps are usually followed by smaller steps indicating subsequent dilation of the first pore or possibly the fusion of two small pores into one large pore [258].

If we assume a mast cell radius $r$ of $6-8 \mu \mathrm{m}$, a pore length $l$ of $8 \mathrm{~nm}$, a diffusion coefficient for LDH and PGK of approx. $5 \times 10^{-7} \mathrm{~cm}^{2} \mathrm{~s}^{-1}$ and a pore diameter 
of about $10 \mathrm{~nm}$ then Eqn. 3 (see section II-A) yields a diffusion time constant $\tau$ of approa. 30-80 min. The large discrepancy between this, and the actual measured time constants indicates that the individual cells must be peppered $w$ th approx. 50 pores of this size (Eqn. 4) or that a fevi much larger pores are formed. From estimates based on the diffusion constants, the equilibration times of low molecular weight solutes such as $\mathrm{Ca}^{2+}$, EGTA or GTP- $\gamma-\mathrm{S}$ can be assumed to be about 10-times faster than those for the proteins. These will thus enter the cells within 5-10 s.

\section{III-C. $A T P^{4-}$}

For cells having appropriate receptors $[44,352]$, the application of ATr provides a particularly versatile approach to membrane permeabilisation since the dimensions of the lesions can be regulated by changing the concentration of the free acid form, ATP ${ }^{4-}$ $[83,357]$. Cells susceptible to $\mathrm{ATP}^{4-}$ include renal tubules [304], transformed 3T3 cells [155], T-lymphocytes [246], haematonoietic stem cells [375], macrophages $[341,143]$ and rat peritoneal mast cells $[83,84]$.

A

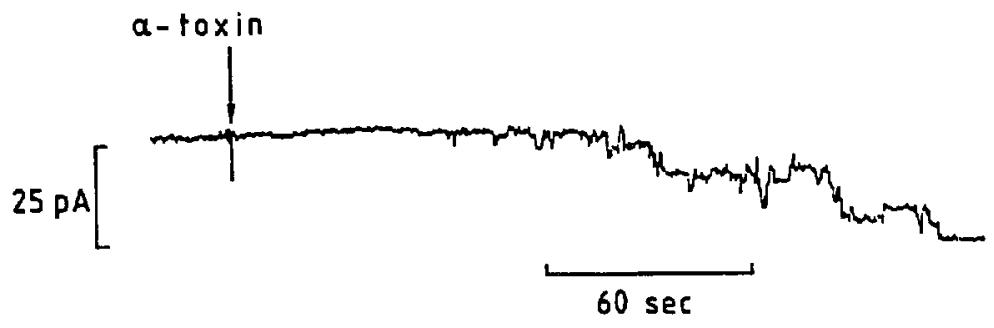

B
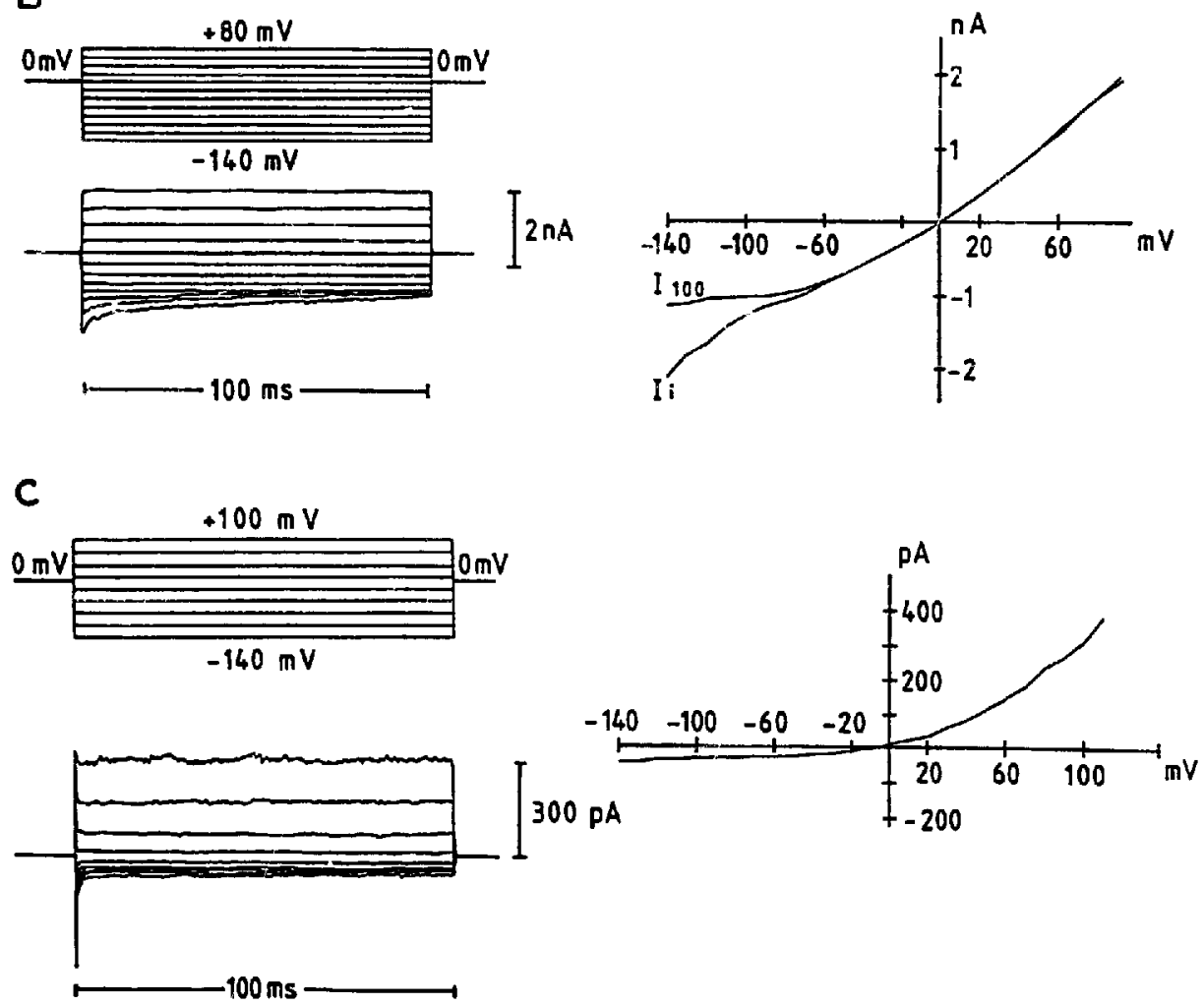

Fig. 4. Whole cell patch-clamp experiment illustrating the formation of plasma membrane pores in mast cells by $\alpha$-toxin. (A) A continuous current record using symmetric solutions $(150 \mathrm{mM} \mathrm{NaCl}, 5 \mathrm{mM} \mathrm{KCl}, 10 \mathrm{mM}$ Hepes/ $\mathrm{NaOH}, \mathrm{pH} 7.25)$. At $-50 \mathrm{mV}$ the conductance increases upon addition of $\alpha$-toxin showing reversible openings of ion channeis having a unit conductance of approx. $80 \mathrm{pS}$. (B) Under these conditions the currents at different potentials (left) show slight inactivation at negative potentials. Whereas the current voltage relationship (right) is nearly linear for the instantaneous current 1 , inactivation is apparent for the current $I_{i \in 0}$ measured at the end of the $100 \mathrm{~ms}$ pulses. (C) Using 'physiological' solutions (inside $135 \mathrm{mM}$ potassium glutamate, $20 \mathrm{mM} \mathrm{NaCl}, 1 \mathrm{mM} \mathrm{MgCl}, 0.5 \mathrm{mM} \mathrm{Na}_{2}$ ATP, $0.1 \mathrm{mM}$ BAPTA. $10 \mathrm{mM}$ Hepes/NaOH, pH 7.24; outside, $140 \mathrm{mM} \mathrm{NaCl}, 5 \mathrm{mM} \mathrm{KCl}, 2 \mathrm{mM} \mathrm{CaCl}, 1 \mathrm{mM} \mathrm{MgCl}, 10 \mathrm{mM}$ Hepes/ $\mathrm{NaOH}$, pH 7.25 ) the inward cữüeñts (left) are very small throughout the $100 \mathrm{~ms}$ pulse. The current-voltage relationship (right) shows that the reversal potential remains close to $0 \mathrm{mV}$. The voltage dependent block is thus due to the presence of high concentrations of the divalent cations $\mathrm{Ca}^{2+}$ and $\mathrm{Mg}^{2+}$. 


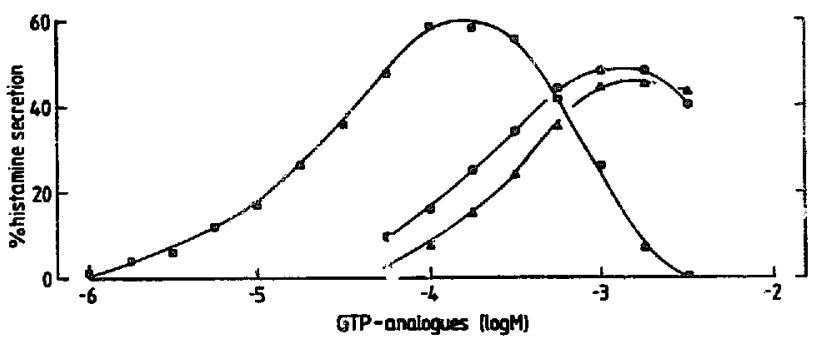

Fig. 5. $\mathrm{Ca}^{2+}$-induced secretion of histamine from permeabilised-resealed mast cells loaded with guanine nucleotides. Mast cells in divalent cation-free buffered salt solution were permeabilised by $\mathrm{ATP}^{4-}(6 \mu \mathrm{M})$ in the presence of guanine nucleotides at the concentrations indicated. After $5 \mathrm{~min}, \mathrm{Mg}^{2+}(2 \mathrm{mM})$ was added to chelaie the ATP and allow the permeability lesions to seal. $10 \mathrm{~min}$ later, $\mathrm{Ca}^{2+}(5 \mathrm{mM})$ was added and the incubation carried on for a further $10 \mathrm{~min}$. GTP- $\gamma-\mathrm{S} ;{ }_{1}, \mathrm{GppNHp} ; \Delta, \mathrm{GppCH}_{2}$ p. From [130j.

Dialysis of the cytosol of mast cells can be achieved by permeabilisation with $\mathrm{ATP}^{4-}$ at concentrations less than $5 \mu \mathrm{M}[42,83]$; at higher concentrations $(50 \mu \mathrm{M})$ ATP $^{4-}$ permits the slow leakage of actin and presumably other soluble proteins [198]. Moreover, removal of the tetrabasic acid form of ATP (e.g., by chelation following addition of excess $\mathrm{Mg}^{2+}$ ) allows the lesions to reseal [130], re-es ablishing within milliseconds the initial barrier properties of the membrane [357]. This technique has been used to load and trap normally impermeant aqueous solutes such as the calcium sensing dye quin2 [141], guanine nucleotides, cyclicAMP [130] and neomycin $[85,307]$ into mast cells. It was by the use of this method that a role (rather, roles) for guanine nucleotides in the control of regulated exocytosis were first perceived [130] (see Fig. 5).

\section{Single cell experiments}

\section{IV-A. Single cell microinjecticn}

At the single cell level access to the interior has been attained by microinjection and by intracellular dialysis using patch pipettes. The microinjection method is somewhat distinct from real permeabilisation methods since a small volume (in our experiments, approx. $1 \%$ of the cytosol water space [356]) of a highly concentrated solution is introduced into the cell while endogenous compounds are retained [36,356]. For small cells, however, the membrane leak at the impalement site leads to significant exchange between the cytoplasm and the external saline and this can include an influx of large amounts of $\mathrm{Ca}^{2+}$ when it is present at millimolar concentrations on the outside [356].

\section{IV-B. Patch pipette}

The whole-cell patch-clamp configuration avoids this complication since a tight seal between the pipette tip and the cell membrane is established before gaining access to the interior. There is thus no significant exchange between the cell interior and the extracellular medium. The pipette solution however, exchanges rapidly with the cytoplasm. Tie volume of solution loaded in the pipette is typically around $20 \mu \mathrm{l}$, whereas the volume of spherical cells having a diameter of 6-20 $\mu \mathrm{m}$ is as small as $0.1-4 \mathrm{pl}$. Any soluble component present inside the cell will be infinitely diluted into the lumen of the pipette, a phenomenon known as 'washout'. The inner diameter of a patch pipette tip is approx. $1 \mu \mathrm{m}$ and is quite sufficient to allow exchange of the largest proteins and also potentially, the intracellular organeiles and secretory granules. In practice though, this does not occur, since such large structures move very slowly due to their very small diffusion coefficient and may possibly be restrained by the cytoskeleton. At the same time, substances included in the pipette solution enter the cell interior by simple diffusion. This diffusion into the cell has been characterised in some detail for fluorescent compounds covering a wide range of molecular weights [294].

The size of the orifice linking the lumen of the patch pipette to the cell interior can be estimated by measuring its electrical resistance. This access resistance, $R_{A}$, is usually in the range of 2-20 M $\Omega$. The diffusion time constant for a given compound has been found to increase in proportion to the value of $R_{\mathrm{A}}$. For soluble substances which do not exhibit significant binding to intracellu'ar membranes or to other structures, the diffusion : ate (i.e., the reciprocal value of the time constant) is proportional to the diffusion coefficient $\bar{D}$. For chromaffin cells having a mean volume of approx. $2 \mathrm{pl}$ the diffusion time constant with a $5 \mathrm{M} \Omega$ pipette is less than $10 \mathrm{~s}$ for $\mathrm{Na}^{+}$or $\mathrm{K}^{+}$and is approx. $20 \mathrm{~s}$ for the $\mathrm{Ca}^{2+}$-sensing dye fura-2 (MW 637). For organic substances like fura-2, nucleotides or proteins the time constants were found to approximate the relationship:

$\tau=80 \cdot R_{\mathrm{A}} / D$

[294] where $\tau$ is in seconds, $R_{A}$ in $M \Omega$ and $D$ in $10^{-7}$ $\mathrm{cm}^{2} / \mathrm{s}$.

If we treat the connection between the bulk pipette volume and the cell interior as a cylindrical tube of length $l$ and cross-sectional area $a$, then the access resistance of this connection can be written as

$R_{\mathrm{A}}=1 / \sigma \cdot l / a$

where $\sigma$ is the conductivity of the pipette solution (approx. 10-15 mS cm$~_{-1}$ for physiological saline). With this relationship Eqn. 1 can be rewritten as

$\boldsymbol{\tau}=\boldsymbol{V} \cdot \boldsymbol{\sigma} \cdot \boldsymbol{R}_{\mathrm{A}} / D$ 
The same expression has been derived for more complex geometries by Oliva et al. [266]. The theoretical prediction of Eqn. 7 yields diffusion time constants which are about 3-times longer than the experimentally determined values (Eqn. 5). Given the large scatter in the experimentally determined exchange time constants [294], the reduction of the actual free volume within the cytoplasm due to the presence of granules and other organelles and uncertainties about the cytoplasmic diffusion constants, this is a rather small difference. Provided that the cell is approximately spherical and does not exhibit particularly complex geometry, then, as expected, the equilibration time constant increases roughly in proportion to the cell volume. For this reason neurons having dendrites and axons are much less efficiently equilibrated by simple diffusion.

For organic compounds, the diffusion constant $D$ is roughly proportional to the inverse third root of the molecular weight $M^{-1 / 3}$. Eq. 5 can thus be rewritten as

$\tau=0.6 \cdot R_{\mathrm{A}} \cdot \mathrm{M}^{-1 / 3}$

where $R_{\mathrm{A}}$ is again in $\mathrm{M} \Omega$ and $\mathrm{M}$ is in Daltons [294]. For a typical pipette $\left(R_{\mathrm{A}}=5 \mathrm{M} \Omega\right)$ the diffusion time constants are very close to those measured in SL-O permeabilised cells (see above, section II-A). The rate of entry and also the rate of leakage from the cell is thus very similar in the SL-O permeabilised and the patch pipette system.

Although the cell interior is efficiently dialysed by the patch pipette, the intracellular and extracellular compartments remain isolated from each other and so they may be independently controlled. In particular, the $\mathrm{Ca}^{2+}$ concentration on the outside can be raintained in the millimolar range while clamping $\mathrm{Ca}^{2+}$ at submicromolar levels inside the cell.

\section{IV-C. Measurement of secretion from single cells}

\section{IV-C-1. Degranulation}

When working with single cells, an important problem that has to be solved is how to measure secretion. For sea urchin eggs [31] or for mast cells which have granules of diameter approx. $770 \mathrm{~nm}$ [153], this may be detected as the degranulation which is clearly visible under the microscope as shown in Fig. 6, - an approach which does not allow the measurement of the time-course and extent of exocytosis. For most other cell types (e.g., chromaffin cells and neutrophils which have much smailer granules (diameter $<300 \mathrm{~nm}$ )) no clearly observable morphological change associated with degranulation is evident under the light microscope.

\section{IV-C-2. Voltammetry}

An alternative approach is to detect oxidisable or reducible secretory products by voltammetry. For ex-

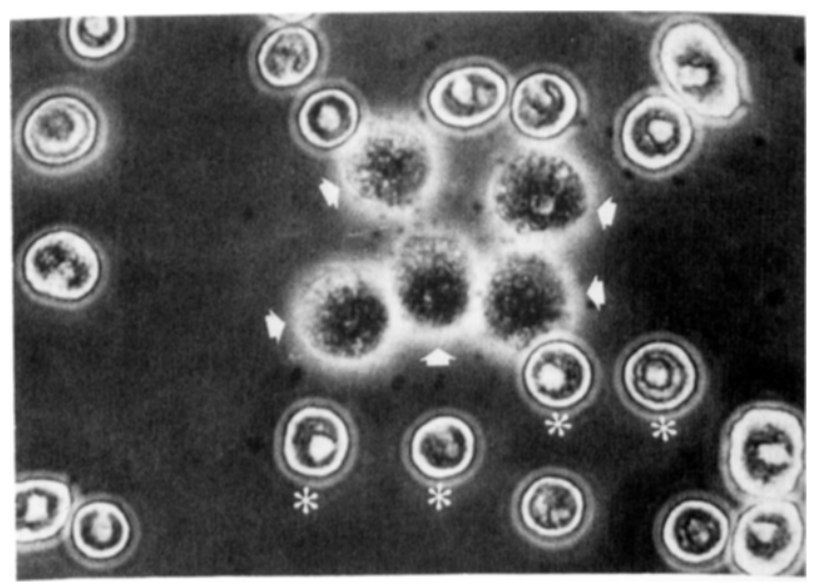

Fig. 6. Phase contrast image of microinjected rat mast cells. Adherent cells were injected with $1 \mathrm{mM} \mathrm{GTP-y-S}$ (arrows) or a similar volume of water (asterisks). The remaining cells were not injected. From [356].

ample it is possible to monitor the release of catecholamines from small numbers of adrenal chromaffin cells using a carbon fibre electrode placed in close proximity $[104,187]$. The method is sufficiently sensitive to allow monitoring of the release of serotonin from individual rat mast cells [353]. (NB histamine is not amenable to voltammetric analysis since it is not readily oxidisable).

\section{IV-C-3. Fluorescence}

Secretion from cell populations [141] and from single cells [55] can also be followed by measuring the release of a fluorescent reporter substance which can be loaded into the secretory granules and then released alongside the nurmal secretory products. In general, such indicators are weak bases such as aminoacridine or quinacrine $[101,181]$ which are able to penetrate the plasma membrane and then the granule membranes in their non-protonated form and become trapped at high concentration following protonation in the acid environment pertaining within the secretory granules (in mast cells, the intragranular $\mathrm{pH}$ is about 1 unit below that of the cytosol $[181,205]$ ). Following exocytosis the fluorescence of the dye both within and around the cell changes due to the dilution and the change to neutrality.

\section{IV-C-4. Measurement of membrane capacitance}

As the granule fuses with the plasma membrane, the area of the plasma membrane is enlarged by the accretion of the granule membrane. Since biological membranes have a remarkably constant specific electrical capacitance of approx. $1 \mu \mathrm{F} / \mathrm{cm}^{2}[90]$ the increase in membrane area is associated with a proportional increase in membrane capacitance. A capacitance change of sea urchin egg membranes at fertilization was first measured by Cole in 1935 [89] using extracellular electrodes in a suspension of eggs but it was more than 20 


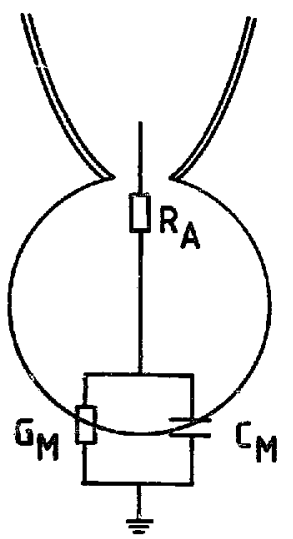

Fig. 7. Schematic represcatation of the whole-cel! patch-clamp configuration and minimal equivalent circuit. The circuit consists of the access resistance $R_{\mathrm{A}}$, the membrane capacitance $C_{\mathrm{M}}$ and the membrane conductance $G_{\mathrm{M}}$.

years before it was realised that this might be a manifestation of the increase of membrane area associated with cortical granule fusion $[1,305]$ which had by then been observed in electron micrographs.

Fig. 7 shows a schematic representation of the whole-cell patch-clamp configuration together with the minimal equivalent circuit which consists of the access resistance $R_{\mathrm{A}}$, the membrane capacitance $C_{\mathrm{M}}$ and the membrane conductance $G_{\mathrm{M}}$. The high sensitivity of recently developed techniques for measurement of capacitance in this configuration now allows the detection of the fusion of a single granule having a diameter as small as $200 \mathrm{~nm}$. The variety of capacitance measuring methods which have been used to follow exocytosis are reviewed in detail elsewhere [211]. Time-resolved admittance measurements under voltagc-clamp conditions allow the simultaneous recording of membrane capacitance and conductance ${ }^{1}$. In excitable cells it is thus possible to relate exocytosis directly to the opening of voltage dependent calcium channels in response to depolarisation $[114,253]$. The simultaneous capacitance and conductance measurements provide a powerful tool for the direct investigation of the role of ion channels in the activation of exocytosis. It also allows for an analysis of the temporal aspects of fusion pore formation. With the development of the patch-clamp technique such experiments can now be performed on virtually all cell types and even on single isolated vertebrate nerve endings $[114,217]$.

\footnotetext{
The admittance $(Y)$ can be considered as the complex conductance of a passive electrical circuit which relates the current $(I)$ and voltage $(V)$ according to

$I=Y \times V$.

so $Y$ is formally similar to a conductance. Note, however, that the admittance is a complex function of $R_{\mathrm{A}}, C_{\mathrm{m}}$ and $G_{\mathrm{m}}$ and it converts the sine wave voltage into a sine wave current with a certain amplitude and phase shift.
}

In the patch-clamp whole-cell configuration, second messengers, activators and inhibitors of exocytosis can be introduced into the cytosol and the capacitance measurement provides an on-line record of exocytotic activity. This approach has recently provided a powerful technique for the study of second messenger systems regulating the activation of ion channels and exocytotic granule fusion [250].

\section{IV-C-5. Slow-whole-cell configuration of the patch-clamp technique}

The intracellular dialysis of a mast cell with a patch pipette leads to a rapid loss of responsiveness to receptor-directed stimuli like compound $48 / 80$ [111] or IgE/antigen $[212,213]$. In the case of stimulation by compound 48/80 (a polycationic condensation product of $N$-methyl-p-methoxy phenylethylamine with iormaldehyde $[33,200]$ ), the period of responsiveness can be extended up to about 2 min when the pipette saline contains GTP [286]. However, even under these conditions the amplitude of the exocytotic response decreases progressively during the time of dialysis and this makes quantitative experiments very difficult. Furthermore, under these conditions the time-course of $48 / 80$ induced degranulation is much slower than in undisturbed cells as can be seen by following the morphological changes under the light microscope. The cytoplasmic composition of the cell can, however, be retained for long periods of time if instead of rupturing the patch of membrane between the cells and the pipette, it is merely permeabilised.

This approach was originally devised in order to investigâte the possible involvement of ion channels in the response of rat peritoneal mast cells to IgE/antigen and in these experiments the patch was permeabilised by a solution containing ATP (see section III-C) and very low free calcium [213]. The permeabilisation by $\mathrm{ATP}^{4-}$ generated a patch permeability having an access resistance of $100-2000 \mathrm{M} \Omega$ (compared with $2-20 \mathrm{M} \Omega 2$ when the patch is disrupted: see section IV-B). Besides retaining all molecules inside the cell which are larger than the pore size, the approx. 100-fold higher access resistance $\left(R_{\mathrm{A}}\right)$ ninakes the loss of small molecules also about 100 -fold slower than in the conventional whole-cell configuration (see Eqns. 5-8). For this reason the permeabilised-patch recording is called the slow-whole-cell configuration [213]. Other pore forming agents such as $\alpha$-toxin and nystatin have been used for cells which cannot be permeabilised with ATP $^{4-}[165,214]$.

With this method the time-course of degranulation in response to receptor directed stimuli can be recorded in (nearly) undisturbed cells. For masi cells it was found that the degranulation in response to IgE/antigen occurs on the time scale of minutes, whereas the capacitance change associated with exocytosis in re- 
sponse to compound $48 / 80$ occurs within seconds $[110,213,215]$, as occurs with cells normally stimulated in suspension [141]. The slow-whole-cell configuration thus enables us to compare the response of an intact cell to receptor directed ligands with the direct intracellular activation of exocytosis which is achieved using the conventional fast-whole-cell recording set-up.

\section{Regulating cytosol composition}

\section{$V$-A. Electrolyte composition}

Having selected the method of cell permeabilisation, there remain a number of other important considerations. Most importantly these relate to the composition of the suspending medium which will equilibrate rapidly with the cytosol of the permeabilised cells.

\section{$V-A-1$. Patch pipette}

With the use of a patch-pipette the composition of the extracellular and intracellular medium can be set independently of each other. A well defined physiological saline is generally lised as the extracellular medium (although this solution may be modified for certain experiments). In most experiments on exccytosis the pipette (intracellular) solutions have been based on potassium glutamate. In mast cells, problems arising from the presence of $\mathrm{KCl}$ in the pipette solution were first described by Almers and Neher [10]. They observed marked morphological changes within a few minutes. The cells took on a grainy appearance and became very sensitive to hydrostatic pressure. Suction collapsed the cell into a tight ball while slight pressure led to swelling and bleb extrusion. Both phenomena were associated with significant capacitance changes. When glutamate was used as the main intracellular anion the integrity of the cells was retained for at least $15 \mathrm{~min}$ [10]. It was concluded that high concentrations of intracellular $\mathrm{Cl}^{-}$leau to a rapid disintegration of the cytoskeleton. Furthermore, degranulation in response to GTP- $\gamma-S$ was less reproducible with $\mathrm{KCl}$ in the piperie. The differences of GTP- $\gamma$-S induced exocytosis in cells dialysed with glutamate and $\mathrm{Cl}^{-}$based solutions will be discussed below in some more detail with respect to the kinetics of degranulation (see section VI-C-2).

\section{V-A-2. Permeabilised cells}

Most investigations of the exocytotic mechanism in permeabilised cell suspensions have involved procedures using glutamate as the main electrolyte anion. The substitution of $\mathrm{Na}^{+}$for $\mathrm{K}^{+}$generally has little effect $[80,190]$. There are a number of reports (particularly relating to pituitary cells) in which acetate [381] propionate [303] and gluconate [228] have been used.
The reason why the $\mathrm{Cl}^{-}$ion has customarily been eschewed in permeabilised cells derives from the initial work on bovine adrenal medullary (chromaffin) cells $[28,190]$ in which it was shown that in comparison with glutamate, $\mathrm{Cl}^{-}$inhibits $\mathrm{Ca}^{2+}$-induced catecholamine release. Physiological justification for this lies in the fact that for most cell types the $\mathrm{Cl}^{-}$anion is a relatively minor component of the cytosol. This may not be the case for myeloid cells [172] and for these cells investigators have commonly used simple electrolytes based on the $\mathrm{Cl}^{-}$ion (e.g., our work on mast cells and neutrophils $[37,38,168]$ and that of others on neutrophils [330,331] and HL60 cells [343]). However, if variation in the composition of the electrolyte alters the characteristics of the regulatory process (as indeed it does in mast cells: see section VI-C) then this should be regarded as another opportunity to gain some insights into the mechanism.

\section{V-B. Regulation of $\mathrm{Ca}^{2+}$}

An important consideration for permeabilised cells concerns the regulation of $\mathrm{Ca}^{2+}$. Under most normal laboratory conditions, the concentration of free $\mathrm{Ca}^{2+}$ in a simple salt solution containing protein (e.g., albumin at $1 \mathrm{mg} \mathrm{ml}^{-1}$ ) and other supplements will be in excess of $10 \mu \mathrm{M}$ [68]. This is 100-rimes the concentration of the free ion in the cytosol of resting cells. In order to control $\mathrm{Ca}^{2+}$ in the physiological micromolar and nanomolar range of concentrations it is necessary to use buffer systems. These are generally based on the use of EGTA and methods for the preparation of such buffers are widely available [355].

In whole-cell patch-clamp experiments the intracellular $\mathrm{Ca}^{2+}$ is normally kept low by including an EGTA buffer in the pipette solution. Electrically excitable cells are usually voltage clamped at around $-70 \mathrm{mV}$ and under these conditions the voltage dependent calcium channels are closed. Upon depolarisation to a value above $-10 \mathrm{mV}$ these channels open so that $\mathrm{Ca}^{2+}$ flows rapidly into the cell and may overwhelm the capacity of the intracellular EGTA to maintain a low concintration of $\mathrm{Ca}^{2+}$. This has been found to lead, transiently, to a high concentration which is sufficient to induce exocytotir, activity in chromaffin cells [253], endocrine pituitary cells $[359,360]$ and in nerve terminals from the rat posterior pituitary [114,217].

In non-excitable cells, the release of calcium from intracellular stores is generally understood to be an important event in stimulus-exocytosis coupling. Although under patch-clamp, the intracellular calcium is assumed to be buffered, when the EGTA concentration is kept low (e.g., $100 \mu \mathrm{M}$ ) the calcium concentration has been found to be under the control of the cell and not the pipette solution $[251,254]$. 
By including the calcium indicator fura-2 in the pipette filling solution, it is possible to investigate changes in cellular calcium in response to stimulation. Such measurements are not possible and indeed are irrelevant when applying other techniques of cell permeabilisation since the intracellular and extracellular solutions are necessarily at equilibrium with each other.

\section{V-C. Regulation of nucleotide composition}

Much of our owa work has concerned the role of nucleotides in the regulation of exocytosis from streptolysin-O permeabilised cells [134]. In order to be able to impose precise concentrations and to ensure an effective zero baseline condition we routinely expose cells, prior to permeabilisation, to metabolic inhibitors (a combination of deoxyglucose and antimycin-A to suppress glycolysis and electron transport) $[167,178]$. After $5 \mathrm{~min}$ ireatment with inhibitors at $37^{\circ} \mathrm{C}$ the concentration of intra-cellular ATP in intact mast cells declines to a few percent of its initial level [178] and the system becomes refractory to stimulation by receptor directed agonists and $\mathrm{Ca}^{2+}$-ionophores. However, they remain fully responsive, following permeabilisation, to intracellularly applied activating effectors stich as the combination $\mathrm{Ca}^{2+}$-plus-GTP- $\gamma$-S [167] (see below: section VI-A).

As described above, mast cells dialysed with a paich pipette become insensitive to receptor-directed stimulation within about 2 min even in the presence of intracellular GTP (see section IV-C-5). This suggests that other components, essential for stimulus-exocytosis coupling, may be lost by dilution into the effectively infinite volume of the pipette. On the other hand, mast cells as well as neutrophils and eosinophils degranulate spontaneously when the non-hydrolysable GTP analogue GTP- $\gamma-\mathrm{S}$ is included in the intracellular solution $[111,259,261]$.

\section{V-D. Modulatory role of cytosol proteins}

\section{V-D-1. Permeabilised cells}

\section{Leakage of cytosol proteins}

According to the criterion of the $\mathrm{Ca}^{2+}$ dependence of exocytosis (maximal at pCa 6), the responsiveness of mast cells permeabilised by SL-O (in the presence of GTP- $\boldsymbol{y}$-S and ATP in a simple $\mathrm{NaCl}$ based electrolyte system) closely resembles the situation of IgE stimulation illustrated in Fig. 3. Much higier concentrations of both $\mathrm{Ca}^{2+}$ (Fig. 8a) and GTP- $\gamma$-S (Fig. 8b) are needed when the cells are permeabilised by ATP ${ }^{4-}$, which generates considerably smaller lesions (see section III-C) [198]. When the stimulus ( $\mathrm{Ca}^{2+}$-plus-GTP- $\boldsymbol{\gamma}$ $S)$ is applied after a protracted period of permeabilisation by $\mathrm{ATP}^{4-}$, (at a 10-fold higher concentration,
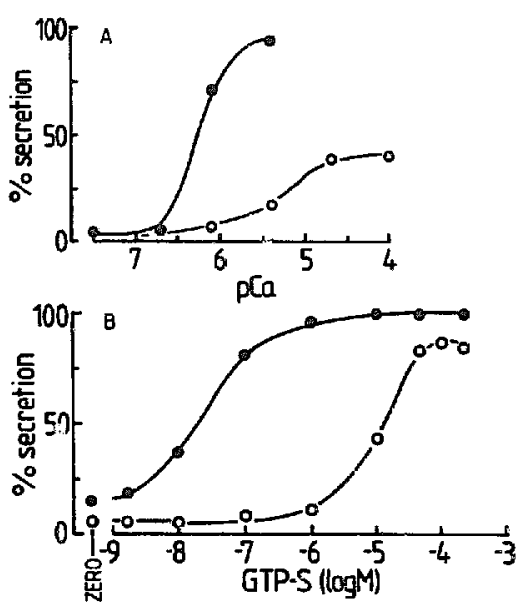

Fig. 8. Dependence on $\mathrm{Ca}^{2+}$ and GTP- $\gamma$-S for exocytosis from mast cells permeabilised with SL-O and $\mathrm{ATP}^{4-}$. (a\&b) Mast cells were permeabilised by $\mathrm{ATP}^{4-}(30 \mu \mathrm{M}$, open symbols) or by the combination SL-O-plus-ATP ${ }^{4-}$ and stimulated with (a) $15 \mu \mathrm{M}$ GTP- $\gamma-S$ and a range of $\mathrm{pCa}$ and (b) a range of GTP- $\gamma-\mathrm{S}$ ai fixed $\mathrm{pCa} 5$. From [198].

allowing leakage of actin), the sensitivity increases progressively (Fig. 9). After about $2 \mathrm{~h}$ of treatment with ATP $^{4-}$, a high affinity situation comparable with SL-O permeabilisation is achieved. We conclude that the cytosol contains an endogenous inhibitor, which leaks promptly following permeabilisation by SL-O, allowing the cells to respond to low concentrations of effectors, but only very slowly from cells permeabilised by ATP $^{4-}$. This inhibitory factor must be a component of the cytosol of intact cells and this probably explains why such high concentrations of $\mathrm{Ca}^{2+}$ must be achieved in order for exocytosis to occur in response to a $\mathrm{Ca}^{2+}$-only stimulus (Fig. 3). For stimulation in response to receptor activation, which enabies exocytosis to occur at low concentrations of $\mathrm{Ca}^{2+}$, a further signal (i.e., in addition to those provided by $\mathrm{IP}_{3}$ and diglyceride) is required [39]. This relieves the suppression of effector sensitivity so that exocytosis can proceed in response to $\mathrm{Ca}^{2+}$ at concentrations less than $10^{-6} \mathrm{M}$.

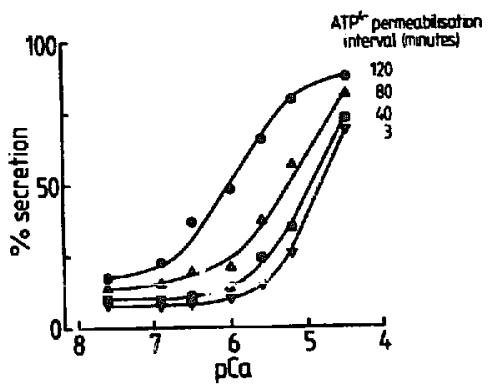

Fig. 9. Effect of the permeabilisation interval on the calcium dependence of secretion following permeabilisation by $\mathrm{ATP}^{4-}$. Mast cells were treateci with $\mathrm{ATP}^{4-}(50 \mu \mathrm{M})$ under non-stimulating conditions for proionged periods, sufficient to allow the efflux of soluble protein (measured as actin). They were then stimulated by addition of GTP- $\gamma-\mathrm{S}(15 \mu \mathrm{M})$ and a range of $\mathrm{Ca}^{2+}$ (as indicated) and incubated for a further $25 \mathrm{~min}$. From [198]. 
In contrast to the enhancement due to prolonged permeabilisation with $\mathrm{ATP}^{4-}$, cells permeabilised with SL-O become refractory to stimulation within minutes, though the period during which they remain responsive can be extended if their phosphorylation state is maintained by provision of ATP $[169,198]$ (see section VIIC). A similar time related loss of reactivity of digitonin permeabilised adrenal chromaffin cells has been reported [310].

\section{Introduction of exogenous proteins}

Permeabilisation by SL-O or the plant glycosides provides the opportunity to introduce antibodies [287,314], toxins $[2,5,35,339,340]$ and other foreign peptides and proteins into the cytosol and in this way to modulate the exocytotic process. Most such experiments have so far been confined to adrenal chromaffin cells. In an attempt to define the $\mathrm{Ca}^{2+}$-binding protein which regulates exocytosis, it was shown that calpactin (annexin 2, p36) could restore secretory competence to cells rendered refractory by exhaustive permeabilisation [7].

A requirement for the presence of inositol lipids in exocytosis from chromaffin cells is indicated by the observation that the ATP-dependent component of exocytosis is inhibited by introduction of a phospholipase $\mathrm{C}$ derived from Bacillus thuringensis [106]. Although this enzyme is specific for PI there is a consequent loss of the higher polyphosphoinositides probably due to a failure to maintain their synthesis. Some reversal of the inhibition could be obtained by provision of ATP which acts to maintain the level of the higher inositol lipids indicating that these, rather than the parent PI might be involved, possibly as an anchor for actin or one of the actin binding proteins [176,384], or possibly calpactin [129].

\section{Dual effectors for exocytosis}

VI-A. $\mathrm{Ca}^{2+}$ and a guanine nucleotide, together, are necessary and sufficient

\section{VI-A-1. SL-O permeabilised cells}

Fig. 10 illustrates the dependence on $\mathrm{Ca}^{2+}$ and GTP- $\gamma$-S for exocytosis from mast cells permeabilised by SL-O in buffered $\mathrm{NaCl}$ [142]. Routinely, before permeabilisation, the cells were pretreated with metabolic inhibitors for $5 \mathrm{~min}$. At this point they are resistant to stimulation by receptor-directed agonists such as compound $48 / 80$, or $\mathrm{Ca}^{2+}$-ionophores.

A number of important points can be made:

1. Exocytosis requires the presence of both $\mathrm{Ca}^{2+}$ and a guanine nucleotide (the 'essential effectors') $[167,201]$. Together, these suffice to induce almost total release of secretory products (measured as histamine or hexosaminidase). Any ligand which can bind and activate GTP-binding proteins (e.g., GTP, ITP. XTP, GTP- $\gamma-S$, GTP- $\alpha-S$ (both RP- and SF-isomers), $\mathrm{GppNHp}, \mathrm{GppCH}_{2} \mathrm{p}$ and the retrafluoroaluminate anion) can elicit secretion $[79,167,335]$ ).

2. Neither ATP $[167,201]$ nor $\mathrm{Mg}^{2+}$ [208] are required for exocytosis from the permeabilised cells and therefore a reaction involving phosphorylation is not an essential or integral step in the late stages of the exocytotic pathway.

3. When ATP is provided then the sensitivity for both of the essential effectors is considerably enhanced $[167,201]$. The sensitivity for $\mathrm{Ca}^{2+}$ increases approx. 3-fold and approaches a high affinity situation similar to that achieved following stimulation of RBL cells by IgE-directed crosslinking ligands (in Fig. 3) [167]; in some experiments the sensitivity for the guanine nucleotide increases by more than 50-fold. ATP must be regarded as a modulator, not an effector of exocytosis. The enhancement due to ATP and other phosphorylating nucleotides is probably mediated by protein kinase C $[87,169,201]$.

4. Exocytosis can be trisggered by guantine nucleotides (together with $\mathrm{Ca}^{2+}$ ) under conditions in which the phospholipase- $\mathrm{C}$ reaction is inhibited by neomycin (Fig. 11) [17,87]. The guanine nucleotide thus activates exocytosis at a late stage subsequent in the pathway through interaction with a GTP-binding protein which we have called $G_{\mathrm{E}}$ [136]. This is distinct from $G_{p}$, the activator of phospholipase-C [85].

5 . There have been many proposals for an involvement of phospholipase $A_{2}$ activation in the exocytotic pathway of mast cells $[288,315]$ and other celis (neutrophils [372]; eosinophils [323]; platelets [329]; monocytes; adrenal chromaffin cells [121]; pancreatic $\beta$-cells [363]). The phospholipase $A_{2}$ reaction causes the hydro:ysis of phospholipids releasing unsaturated fatty acids which can, in principle be metabolised by the lipoxygenase and cyclooxygenase pathways, generating leukotrienes and prostaglandins. The parent unsaturated fatty acids and several of their products can have potent paracrine effects, both as stimulators and inhibitors of cell function. In the case of intact mast cells [76] and eosinophils [154] it has been shown that application of exogenous phospholipase $\mathrm{A}_{2}$ can stimulate secretion. Mainly, these proposals have been based on pharmacological experiments using so-called $\mathrm{PLA}_{2}$ inhibitors including mepacrine (actually an alias of quinacrine, commonly used as a fluorescent indicator of exocytosis: see section IV-C-3) or bromphenacyl bromide. Certainly, in permeabilised cells, the combined stimulus for exocytosis, $\mathrm{Ca}^{2+}$-plus-guanine nuclestice, should also activate phospholipase $\mathbf{A}_{2}$ $[23,67,50]$. However, in jermeabilised platelets [92] and rabbit neutrophils [37] GTP- $\gamma$-S-induced secretion still proceeds at pCa 9 and under these conditions there is unlikely to be any activation of PLA $A_{2}$. hin permeabilised 


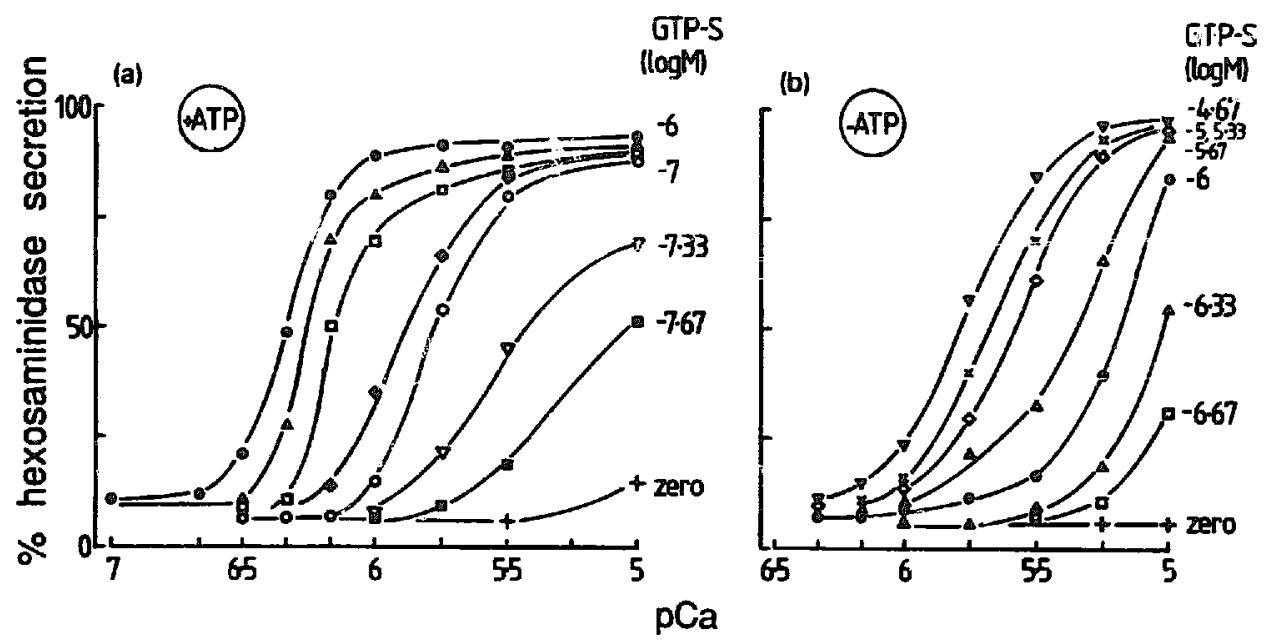

Fig. 10. Dependence on $\mathrm{Ca}^{2+}$ and GTP- $\gamma$-S for exocytosis from mast cells permeabilised by SL-O in buffered NaCl. Mast cells suspended in a simple $\mathrm{NaCl} /$ Pipes buffer containing $2 \mathrm{mM} \mathrm{Mg}^{2+}(\mathrm{pH} 6.8)$ were treated with metabolic inhibitors and then permeabilised with SL-O and stimulated to secrete by the presence of a range of $\mathrm{Ca}^{2+}$ and GTP- $\gamma$-S in the presence (a) or absence (b) of Mg.ATP (1 mM). After 10 min incubation the reactions were quenched in ice-cold saline, the cells were sedimented and secretory response measured as released hexosaminidase in the supernatant. From [142].

mast cells the two G-protein mediateư functions have proved hard to separate, but considerably higher concentrations of both effectors are needed to activate PLA $_{2}$ [79]. Exocytosis can proceed without discernible release of arachidonate in permeabilised chromaffin cells [240,241] and in intact RBL-2H3 cells after treatment with dexamethasone [91].

6. The soluble proteins of the cytosol leak rapidly following permeabilisation by SL-O $[139,168]$ and these therefore play no essential role in the mechanism of exocytosis (obviously, in the experiment illustrated (Fig. 10 ), the leakage of proteins is occurring concurrently

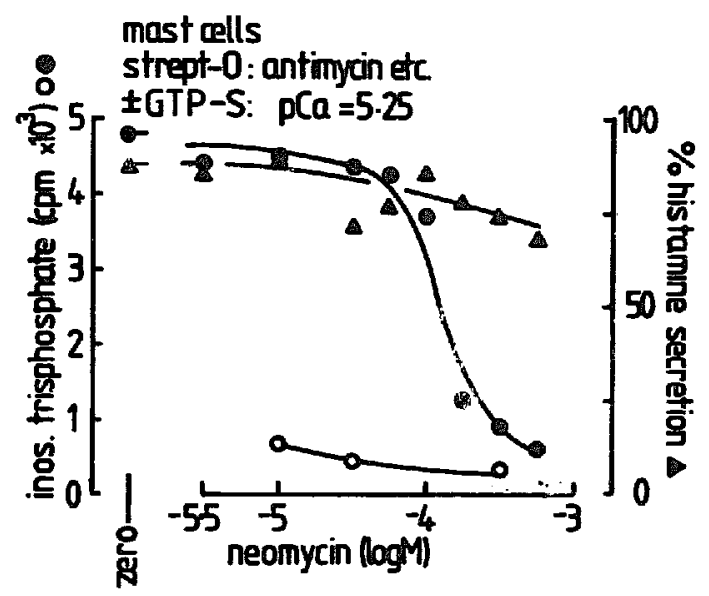

Fig. 11. GTP- $\gamma$-S-induced secretion can occur under conditions in whici phospholipase $\mathrm{C}$ is inhibited by neomycin. Mast ceil inositol lipids were labelled by overnight incu sation with [ $\left.{ }^{3} \mathrm{H}\right]$ inositol. Folfowing permeabilisation with SL-O thay were stimulated with $\mathrm{Ca}^{3+}$ (pCa 5) and GTP- $\gamma$-S (10 $\mu \mathrm{M})$ and samples taken for measurement of secretion (as released histamine) and inositide hydrolysis (as released inositol phosphates). The figure illustrates the selective inhibition of inositide hydrolysis as the concentration of neomycin is raised above $10^{-4} \mathrm{M}$. with exocytosis; this conclusion is well supported by other experiments already discussed: see above, section V-D and below, section VII-B).

Aithough most other secretory cells do not readily lend themselves to such detailed examination as the mast cells, it is evident that there is a considerable diversity in the control pathways operating in the different systems. However, the control pathway of other myeloid cells appears to resemble that of the mast cells rather closely. Thus, the combination stimulus, $\mathrm{Ca}^{2+}$ plus-guanine nucleotide, can induce secretion from permeabilised neutrophils [82], eosinophils $[93,261]$ and HL60 cells [343]. For all of these, exocytosis can proceed in the absence of ATP, which when provided, has the effect of enhancing the sensitivity for the two obligatory effectors. This stands in obvious contrast to many of the other well known secretory systems, as briefly outlined in section $\mathrm{I}$ and reviewed elsewhere $[132,133]$. The secretory cells have to serve many functions and to be able to respond to an array of very different external signals: there is a wide repertoire of intracellular control processes to match this (see Table II).

\section{VI-A-2. Microinjected cells}

The dependence of exocytosis on the concentration of microinjected GTP- $\gamma-\mathrm{S}$, assessed by counting the proportion of degranulated cells, is remarkably similar to that which induces secretion from SL-O permeabilised cells (Fig. 12) [356]. Furthermore, as with the permeabilised cells, the degranulation response displays a requirement for $\mathrm{Ca}^{2+}$, though here it must be present in the extracellular medium at millimolar concentrations at the time of the injection. In our hands 
(and in agreement with others: [351]), injection of $\mathrm{Ca}^{2+}$ alone was without effect though there is one report of a positive outcome, following iontophoresis of $\mathrm{Ca}^{2+}$ [183]. Significantly, the cells r:main responsive to microinjection of GTP- $\gamma-S$ even when extensively depleted of ATP (to about 1\% of normal levels) following prolonged incubation with metabolic inhibitors, to the point of becoming absolutely insensitive to stimulation by polybasic agonists (compound $48 / 80$ ). As with SL-O permeabilised cells, after metabolic depletion, the requirement for the guanine nucleotide merely shifts to about 10-fold higher concentration though this could be misleading because of the uncontrolled and transient entry of $\mathrm{Ca}^{2+}$ at the site of impalement.

\section{VI-A-3. Patch pipette}

The dependence on GTP- $\gamma$-S concentration in who'e-cell fratch-clamp experiments has been investigated [110]. In the range $20-500 \mu \mathrm{M}$ the increase of membrane area is independent of concentration and is about 4-fold (i.e., degranulation is complete). However, the time-course is markedly dependent on the GTP- $\gamma$-S concentration as described below (see section VI-D-1). If the cells are loaded with 20-40 $\mu \mathrm{M}$ GTP- $\gamma-S$, then a reduction of intracellular calcium to less than $60 \mathrm{nM}$ still allows about half of the cells to degranulate. Under these conditions, in those cells that do initiate secretion, exacytosis goes all the way despite the low $\mathrm{Ca}^{2+}$ concentration. However, the onset delay and

\section{TABLE II}

Secretory cells that have been investigated by the technique of membrane permeabilisation

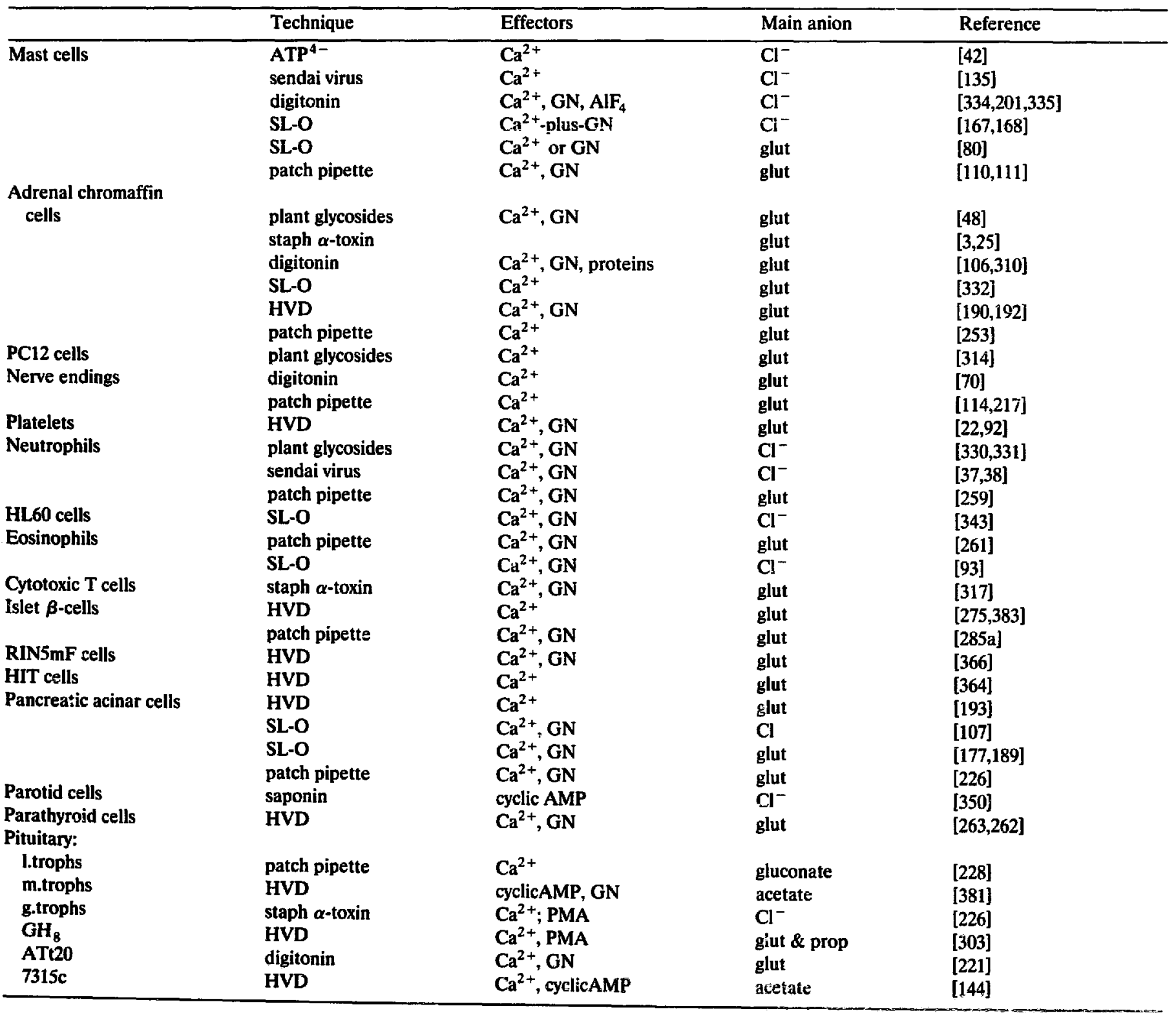


subsequent rate of exocytosis are dependent on the $\mathrm{Ca}^{2+}$ concentration $[215,251]$.

\section{VI-B. The meaning of effector concentration-response relationships}

Central to all discussion concerning the dependence of secretion on the concentration of effectors must be the question of whether the measured extent of release represeris a completed process, or whether it is rate and time related. All the measurements cited in the above paragraphs represent completed processes, the extent of secretion depending on the concentration (more sirictly, activity) of the effector substances. We need to understand why and how the integrated cellular process of secretion differs from a conventional enzyme-catalysed reaction in which the rate, but not the final extent of reaction is related to the concentrations of substrates and other modulatory effectors. Basic to this difference is the fact that secretion comprises a sequence of unit events (for further detail, see below: section VIII-A) in which the individual secretory grarules react in an all-or-none manner, independently of each other, with the plasma membrane. A partial extent of secretion thus indicates that only a fraction of the secretory granules (about 1000 in each mast cell: a few thousand cells in a test tube) has undergone exocytosis. This is made explicit in the experiment illustrated in Fig. 13 in which the progress of secretion in response to GTP- $\gamma-\mathrm{S}$ and a range of $\mathrm{Ca}^{2+}$ concentrations, was measured. The piogress curves indicate that for all concentrations of $\mathrm{Ca}^{2+}$, the

$$
\text { GTP- } \boldsymbol{\gamma}-\mathbf{S} \text { injection }
$$

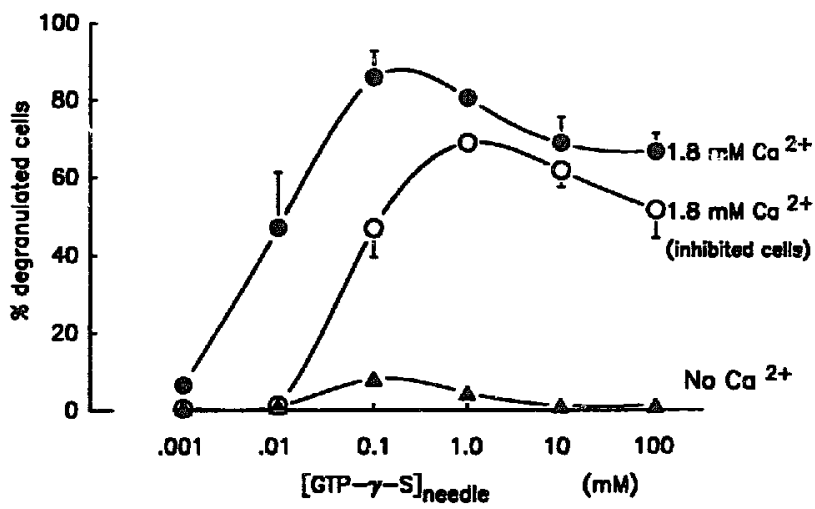

Fig. 12. Concentration dependence for degranulation of mast cells following injection of GTP-y-S, Effect of $\mathrm{Ca}^{2+}$-deprivation and metabolic inhibition. The abcissa indicates the concentration of GTP- $\gamma-S$ in the injection needle, this is diluted about 100-times on entry into the cytosol. 60 cells were injected for each measurement and the fraction of degranulated cells was counted. The data represent mean and S.E.M. of three experiments. 'No $\mathrm{Ca}^{2+}$ ' indicates substitution of $1.8 \mathrm{mM} \mathrm{CaCl}_{2}$ by $1 \mathrm{mM}$ EGTA. 'Inhibited cells' indicates pretreatment (for more than 45 min) with antimycin A (10 $\mu \mathrm{M})$ and 2-deoxyglucose $(5 \mathrm{mM})$, these cells were refractory to stimulation by compound $48 / 80$ at the time of injection. From [356].

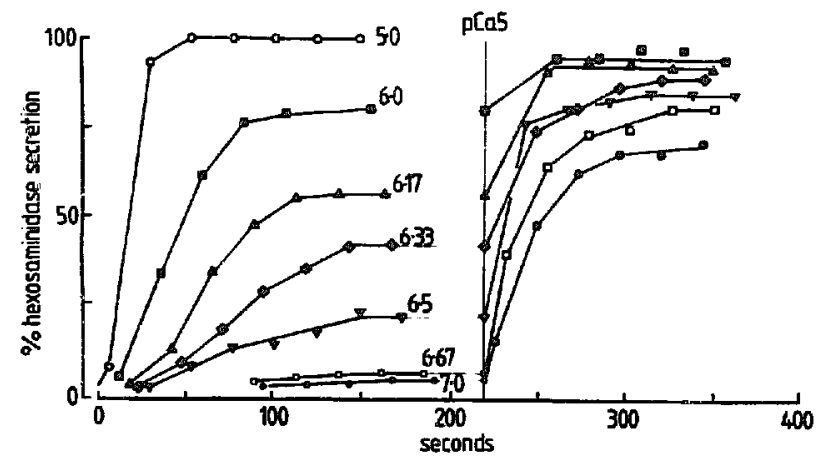

Fig. 13. Progress of secretion in response to GTP- $\gamma-S$ and a range of $\mathrm{Ca}^{2+}$ concentrations. Mast cells were permeabilised by SL-0 in the presence of GTP- $\gamma$-S $(10 \mu \mathrm{M}), \mathrm{Mg} . \mathrm{ATP}(1 \mathrm{mM})$ and a range of $\mathrm{Ca}^{2+}$ buffers ( $1 \mathrm{mM}$ EGTA) to fix pCa as indicated Samples were withdrawn and quenched at the times indicated. After allowing time for the secretion to terminate (about $3 \mathrm{~min}$ ), a high concentration of $\mathrm{Ca}^{2+}$ buffer, pCa 5 (5 mM EGTA) was added and further timed samples were removed. Secretion was measured as released hexosaminidase.

secretory reaction terminates within approx. $3 \mathrm{~min}$. In this experiment a $50 \%$ reaction was achizved at about pCa $6.17(0.676 \mu \mathrm{M})$ indicating that about $50 \%$ of the total granules contained in the cell suspension had fused and released their contents. A full stimulus ( $\mathrm{pCa}$ 5) applied at a later time, reinitiated secretion from the partially reacted cells. Similar results have been obtained by reacting cells with a range of GTP- $\gamma$-S (at pCa 5) and then restimulating with a high concentration of GTP- $\gamma$-S (unpublished observations). An analagous result demonstrating that $\mathrm{Ca}^{2+}$ primarily regulates the extent, but not the rate of exocytosis, has also been obtained from measurements of catecholamine secretion using HVD permeabilised adrenal chromaffin cells [190].

Partial secretion due to a sub-optimal stimulus couid reflect variable sensitivity of individual cells reacting in an all or none fashion, or it could be due to a partial response across the cell population. Voltammetric (section IV-C-2) [353] and capacitance (slow-whole-cell mode: see section IV-C-5) measurements following stimulation with a sub-optimal cuncentration of compound $48 / 80$ indicate a reduced extent of release in single cells. These observations, together with visual examination of a mast cell populat on under the light microscope indicate a wide spread of sensitivity to the partial stimulus so that some are totally degranulated, others have the smooth appearance of resting cells and most are partially degranulated. Furthermore, upon subsequent application of a higher concentration of $48 / 80$, the individual cells undergo further degranulation (Ref. 353 and Lindau, unpublished observations).

These experiments can therefore be interpreted in terms of the responses of individual exocytotic units. Such a unit could be either an individual granule or an individual cell. The data relate the effector concentra- 
tions to unit responses which are conventionally discussed in terms of binding affinity (in the present case, of $\mathrm{Ca}^{2+}$ or a guanine nucleotide). There is a spectrum of effector sensitivity such that a partial reaction indicates that the threshold concentration for release has been exceeded for some, but not all of the exocytotic units contained in the cell population, be these the granules or the cells. By elevating the effector concentration further, more units can then undergo release.

\section{VI.C. Exocytosis in zwitterionic electrolyte solutions}

\section{VI-C-1. SL-O permeabilised cells}

A different view of the exocytotic pathway can be perreived if, instead of permeabilising the cells in $\mathrm{NaCl}$ (or other simple salts) a zwitterionic electrolyte is used (e.g., glutamate, aspartate [80] or glycine (our unpublished results)). As previously (section I), when no ATP is supplied, exocytosis requires both $\mathrm{Ca}^{2+}$ and guanine nucleotide. In the presence of ATP nowever, a substantial degree of secretion $(60 \%)$ by $\mathrm{Ca}^{2+}$ alone and a modest (around 30\%) amount of secretion can be induced by GTP- $\gamma$-S at very low calcium (pCa 8.5). Such single-effector induced secretion is possibly mediated through a phosphorylation pathway involving protein kinase $C$ [169] since it is sensitive to inhibition by the diglyceride analogue stearyl-methyl-glycerol (AMG.C ${ }_{16}$ ) [202,367] and a PK-C pseudosubstrate peptide $[6,166]$ (which can gain entry to the permeabilised cells). It is unlikely that the guanine nucleotide (ie. $\mathrm{Ca}^{2+}$-independent) regulated pathway contributes significantly to the normal response of intact cells since this is strongly inhibited at the levels of $\mathrm{Cl}^{-}$which are normally present in mast cells [80]. By contrast, the extent of $\mathrm{Ca}^{2+}$-induced (guanine nucleotide independent) secretion merely requires the presence of the zwitterion, the extent increasing progressively as the fractional concentration of $\mathrm{Cl}^{-}$is reduced and so it is possible that this pathway could operate in the physiological situation. Against this however, a rather high concentration of $\mathrm{Ca}^{2+}$ (in the range $\mathrm{pCa} 6$ to $\mathrm{pCa} 5$ ) is required (cf. Fig. 3).

A number of specific effects of anions on G-protein functions have been described [159]. Thus, both $\mathrm{Cl}^{-}$ and $\mathrm{Br}^{-}$increase the affinity of $G_{0} \alpha$ for GTP- $\gamma-S$ and GTP, while $\mathrm{SO}_{4}{ }^{2-}$ decreases affinity and $\mathrm{F}^{-}, \mathrm{I}^{-}$and $\mathrm{NO}_{3}{ }^{-}$have little effect. The enhancing effect of $\mathrm{Cl}^{-}$is expressed at concentrations in the range $3-20 \mathrm{mM}$ (i.e., probably below the normal range of intracellular $\mathrm{Cl}^{-}$concentrations in myeloid cells [172]) and a specific binding site on the G-protein has been inferred. These phenomena are not confined to $G_{\mathrm{o}}$ and may well explain the enhancing effect of chloride and azide on the stimulation of adenylyl cyclase by hormones, fluoride and GTP-analogues [180,346]. How this relates to our observations is far from clcar, especially since
$\mathrm{Cl}^{-}$inhibits GTP- $\gamma$-S-induced $\left(\mathrm{Ca}^{2+}\right.$-independent) secretion, but bearing in mind the strong sequence nomologies that exist between all G-protein $\alpha$-subunits and also the monomeric GTP-binding proteins, a direct anion effect at the level of $G_{\mathrm{E}}$ remains a possibility.

Regardless of whether or not these pathways operate to regulate secretion under conditions of physiclogical stimulation, these experiments have revealed that two quite separate mechanisms, the one involving protein phosphorylation, the other which is phosphorylation independent (and may even be enabled by a dephosphorylation reaction: see below, section VII) coexist in the mast cell. Some support for the idea of two regulatory pathways comes from the finding that whereas secretion stimulated by crosslinking of IgE-receptors occurs independently of a late acting G-protein $\left(G_{\mathrm{E}}\right)[173,307]$, the receptors for ligands such as compound $48 / 80$ and the wasp venom peptide mastoparan appear to act late in the exocytotic pathway, directly with $G_{E}$ [18]. Only the latter pathway of activation is subject to inhibition by pretreating the cells with pertussis toxin. This is discussed in greater detail below (section VII-F-2).

\section{VI-C-2. Patch pipette}

Almost universally, glutamate has been used as the main intracellular anion in patch-clamp experiments, with $\mathrm{Cl}^{-}$not more than $25 \mathrm{mM}$. When the intracellular medium is also supplemented with EGTA (to suppress the level of $\mathrm{Ca}^{2+}$ ) and ATP, GTP- $\gamma$-S alone can induce degranulation in mast cells $[215,251]$ and neutrophils [259]. Although in most experiments the extracellular solution has generally been supplemented with extraceilular $\mathrm{Ca}^{2+}(2 \mathrm{mM})$ it has been found (using the intracellular $\mathrm{Ca}^{2+}$-indicator, fura-2), that degranulation can occur at intracellular pCa 8 (or even below this) $[254,260]$. It should be noticed, however, that in these experiments only the spatially averaged $\mathrm{Ca}^{2+}$ concentration in the individual cells has been recorded and so a somewhat higher level of $\mathrm{Ca}^{2+}$ directly under the plasma membrane (i.e., the site of fusion) might have escaped detection. Patch-clamp experiments with GTP- $\gamma$-S have also been carried out using EG YA outside as well as inside the cell and even then many celis were still able to degranulate. It thus appears that there is no requirement for an elevation of intracellular calcium above the resting level under whole-cell conditions.

When $\mathrm{Ca}^{2+}$ is allowed to fluctuate (i.e., it is only weakly buffered) and is measured by introducing fura- 2 into the cell, then large and rapid $\mathrm{Ca}^{2+}$ transients occur in response to external stimulation with antigens and compound $48 / 80$ or introduction of GTP- $\gamma-S$ $[9,250]$. Although the $\mathrm{Ca}^{2+}$ transients are clearly not necessary $[251,252]$, there is a striking coincidence of the calcium transient and the onset of exocytosis. This 


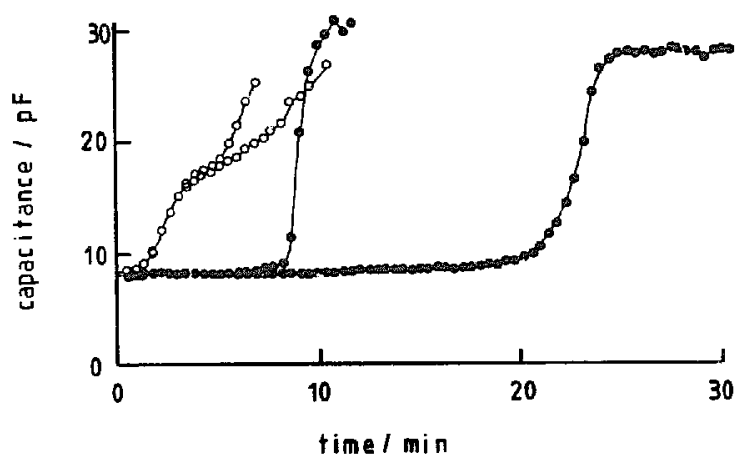

Fig. 14. Time-course of degranulation followed by measurement of membrane capacitance. The pipette solution contained $20 \mu \mathrm{M}$ GTP- $\gamma-S$ and $50 \mathrm{nM}$ free $\mathrm{Ca}^{2+}$. The traces compare the effects of varying the major anion, open symbols indicate glutamate, closed symbols $\mathrm{Cl}^{-}$).

will be discussed in more detail below (see VI-D-1). In the absence of GTP- $\gamma-\mathrm{S}, \mathrm{Ca}^{2+}$ must be elevated to several micromolar for sustained periods of time to induce mast cell degranulation [285], conditions which are never attained in intact cells stimulated under physiological conditions.

As mentioned above (see section $\mathrm{V}-\mathrm{A}-1$ ), replacement of glutamate by chlorivie was found to induce rapid disintegration of the cellular structure and to be inhibitory to degranulation [10]. This is particularly evident when the cells are stimulated with $20 \mu \mathrm{M}$ GTP- $\gamma$-S alone (i.e., maintaining intracellular calcium at about $50 \mathrm{nM}$ ). Under these circumstances, degranulation is markedly delayed, taking $\mathbf{8 - 2 0} \mathrm{min}$ before it commences. However, after this, the degranulation is very rapid (Fig. 14). Using a glutamate based electrolyte, degranulation in response to GTP- $\gamma$-S under otherwise identical conditions (i.e., at low $\mathrm{Ca}^{2+}$ ) commences after a delay of only $60-90 \mathrm{~s}$, but then the ensuing capacitance increase is much slower and occurs in phases of variable steepness as shown in Fig. 14. In agreement with the SL-O permeabilisation experiments very little difference was found between the degranulations with high and low $\mathrm{Cl}^{-}$when $\mathrm{Ca}^{2+}$ was in the micromolar range (Lindau, unpublished data).

It is unlikely that the modulation of exocytosis by $\mathrm{Cl}^{-}$results from $\mathrm{Cl}^{-}$-dependent changes of the granule membrane potential. Measurements of individual mast cell granules at the time of fusion indicate a widely scattered range of potentials (between 11 and $160 \mathrm{mV}$ ) [56] and this is therefore unlikely to be a determinant of a granule's ability to undergo exocytosis. The observations on single cells suggest that $\mathrm{Cl}^{-}$inhibition may be a consequence of the disintegration of the cytoskeleton by high intracellular $\mathrm{Cl}^{-}$.

\section{VI-D. Kinetics of the exocytotic reaction}

As an alternative to measuring completed events, a very different view of the secretnry process can be gleaned by measuring kinetics $[111,140,354]$.

\section{VI-D-1. Delayed onset of exocytosis: patch-clamp}

In patch-clamp experiments, using weakly buffered intracellular $\mathrm{Ca}^{2+}$, there is a characteristic delay before GTP- $\gamma$-S-stimulated exocytosis commences. This delay has been found to have an inverse linear relationship with the concentration of GTP- $\gamma$-S in the range $20-500$ $\mu \mathrm{M}$ (Fig. 15) [110]. At high concentrations of GTP- $\gamma-S$ the delay appears to approach a minimal value of approx. $20 \mathrm{~s}$ and it has been speculated that this might reflect the off-rate of GDP from its binding site on a guanine nucleotide binding protein. At $20 \mu \mathrm{M}$ GTP- $\gamma$-S the delay is about $70 \mathrm{~s}$ and the same delay is observed when GTP- $y-S$ is introduced in the presence of micromolar concentrations of $\mathrm{Ca}^{2+}[215,251,254]$. However, if $\mathrm{Ca}^{2+}$ is suppressed by including higher concentrations of EGTA $(>500 \mu \mathrm{M})$ then the time-course of degranulation becomes more variable and the delay can be markedly prolonged $[215,251,254]$.

The influence of $\mathrm{Ca}^{2+}$ on the time-course has been investigated in greater detail by m.aking simultaneous measurements of membrane capacitance and $\mathrm{Ca}^{2+}$ concentration [251,254]. When $\mathrm{Ca}^{2+}$ is weakly buffered, the onset of exocytosis is usually coincident with a large but brief $\mathrm{Ca}^{2+}$ transient which attains concentrations in the micromolar range (Fig. 16). However, after the calcium concentration has returned to the resting level the degranulation continues as indicated by the continued increase of membrane capacitance, albeit at a lower rate. In some cells there is a second calcium transient which is usually somewhat smaller as exemplified in the experiment shown in Fig. 16. During this second period of elevated calcium concentration the capacitance increases more steeply indicating an increased rate of exocytotic granule fusion. These experiments directly confirm and extend the previous observations using calcium buffers and suggest a modulatory role for calcium in the regulation of granule fusion once the exocytotic machinery has been turned on by GTP- $\gamma-S$.

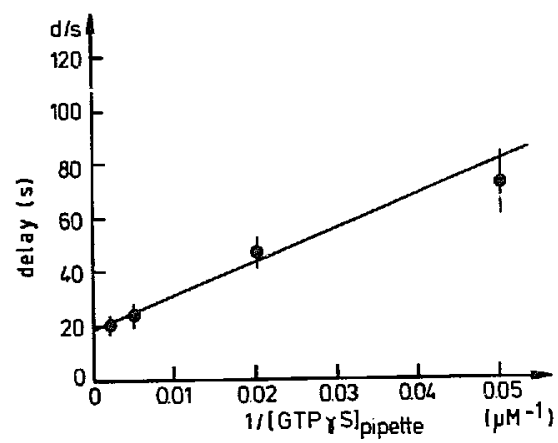

Fig. 15. Concentration dependence of the delay between beginning of intracellular dialysis and start of degratiulation. The pipette contained $100 \mu \mathrm{M}$ BAPTA and the indicated concentrations of GTP- $\gamma-\mathrm{S}$. Under these conditions $\mathrm{Ca}^{2+}$ is controlled by the cell as shown in Fig. 16. The extracellular saline contained $2 \mathrm{mM} \mathrm{CaCl}_{2}$. The delay is not strongly affected by the diffusion time required for GTP- $\gamma-S$ to enter the cell. From [110]. 

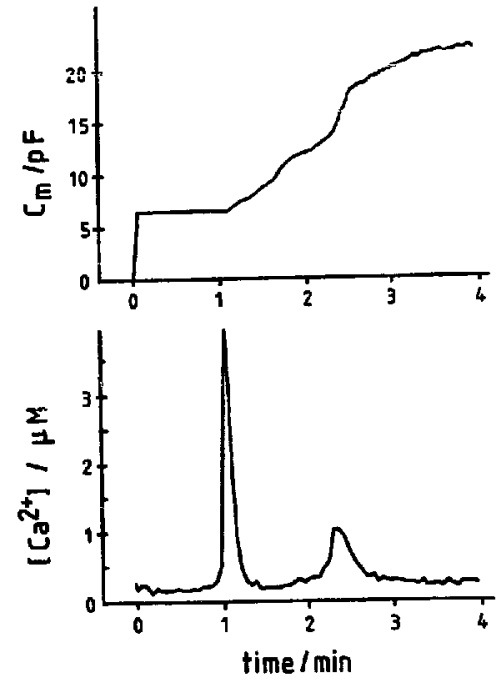

Fig. 16. Simultaneous measurement of membrane capacitance and intracellular free $\mathrm{Ca}^{2+}$ concentration in a single cell. $\mathrm{Ca}^{2+}$ was measured by including $100 \mu \mathrm{M}$ fura-2 in the pipette solution and the fluorescence at 390 and $358 \mathrm{~nm}$ as well as capacitance conductance and access resistance were determined every $2 \mathrm{~s}$. The peak of the first $\mathrm{Ca}^{2+}$ transient coincides with the onset of exocytosis (1 min), but the capacitance continues to increase after $\mathrm{Ca}^{2+}$ has returned to the resting level (1.5-2 $\mathrm{min})$. The second smaller calcium transient is correlated with an increased slope of the capacitance trace corresponding to a higher rate of granule fusion (approx. $2.5 \mathrm{~min}$ ).

In mast cells the calcium transient does not depend on extracellular calcium and can be elicited without a delay by including inositol trisphosphate $\left(\mathrm{IP}_{3}\right)$ (i.e., no GTP- $\gamma-\mathrm{S})$ in the pipette solution [254]. The $\mathrm{Ca}^{2+}$ is thus released from an $\mathrm{IP}_{3}$ sensitive intracellular pool. In neutrophils, GTP- $\gamma$-S also induces calcium release and this is also inhibited by the simultaneous presence of $\mathrm{IP}_{3}$. However, $\mathrm{Ca}^{2+}$ release due to injection of $\mathrm{IP}_{3}$ was not detectable [260].
VI-E. Delayed onset of exocytosis: SL-O permeabilised cells

\section{VI-E-1. ATP induces onset delays}

A delay in onset is also a feature of exocytosis from permeabilised mast cells but the characteristics of the delay, in terms of effector concentrations and other conditions, are rather different [142,354]. Fig. 17 illustrates the time-course of hexosaminidase release following addition of $\mathrm{Ca}^{2+}$ (pCa 5) to cells permeabilised 2 min previously in the presence of ATP $\left(\mathrm{Mg}^{2+}\right.$ salt) and a range of concentrations of GTP- $\gamma-\mathrm{S}$. Following completion of the pair of essential effectors there is a delay before secretion commences, the duration of which is related, in an inverse fashion, to the concentration of the guanine nucleotide. The inset graph in Fig. 17 reveals that the time-lag (plotted inversely, to imply progress of a reaction through the silent period) is proportional to the square-root of the concentration of GTP- $\gamma$-S. Similar experiments in which the cells were loaded with a fixed concentration of GTP- $\gamma$-S (10 $\mu M$ ) and then triggered by transfer to a range of $\mathrm{Ca}^{2+}$ concentrations reveal a similar relationship of the delay to the concentration of the varied effector. It would appear that the lag represents the time taken to achieve a new steady-state condition which is conducive to exocytosis. The reciprocal of this time lag could express a rate given by

rate $=k \cdot\left\{\left[\mathrm{Ca}^{2+}\right][\mathrm{GTP}-\gamma-\mathrm{S}]\right\}^{1 / 2}$

Note that the reaction rate constant, $k$, has the dimensions of that describing the kinetics of a first order reaction.

Unlike the patch-clamp experiments discussed in the previous paragraph, there is no tendency to satura-
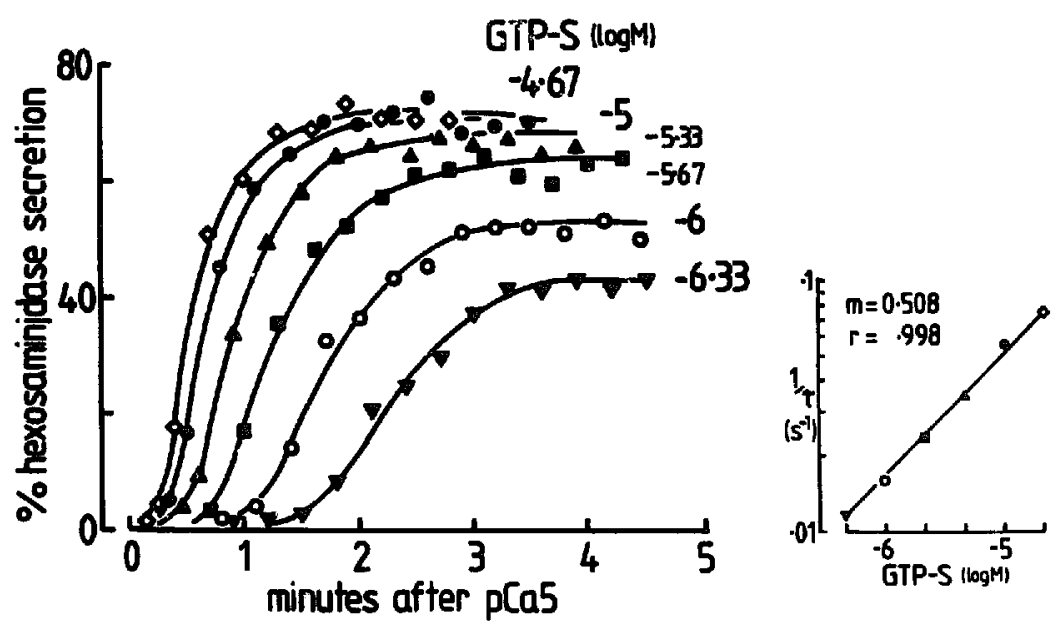

Fig. 17. Time-course of secretion from mast cells permeabilised in the presence of ATP. Mast cells, pretreated with metabolic inhibitors, were permeabilised by SL-O in the presence of dilute $(0.2 \mathrm{mM}) \mathrm{Ca}^{2+}$ buffer (pCa 7), Mg.ATP (1 mM) and a range of GTP- $\gamma$-S as indicated. At time zero, $3 \mathrm{mM}$ CaEGTA buffer, pCa 5, was added and samples removed and quenched as indicated. From [354]. 
tion at high effector concentrations and the inverse square-root dependence holds as either effector is elevated in the concentration ranges tested (i.e., up to 20 $\mu \mathrm{M} \mathrm{GTP}-\gamma-\mathrm{S}$ and pCa 5). In order to shorten the delay by a factor of 10 it is necessary to increase the concentration of $\mathrm{Ca}^{2+}$ or GTP- $y-\mathrm{S}$ by 100 . If we stimulate the cells with concentrations of the two effectors sufficient to induce maximal exocytosis (10 $\mu \mathrm{M} \mathrm{GTP}-\gamma-\mathrm{S}$, then $\mathrm{pCa} 5$ ) a delay of $15 \mathrm{~s}$ before exocytosis commences is typical; at concentrations above this the delay becomes progressively shorter; if we trigger at $\mathrm{pCa} 6$, then secretion is delayed for over a minute, but when it does start it occurs at about the same rate and reaches the same final extent. This resembles the outcome of patch-pipette experiments which have been carried out under similar conditions (see Fig. 13) [110].

\section{VI-E-2. Parallel or sequential effector systems}

We have not been able to reach any definite conclusion about the scquence of the $\mathrm{Ca}^{2+}$ and GTP- $\gamma-\mathrm{S}$ mediated steps. Delays such as we have observed are a characteristic feature of coupled enzyme reactions [43]. In a simple linear or sequential pathway of homogeneous reactions, the delay $\tau$ is determined by the time taken to establish steady state conditions and its reciprocal gives an apparent first order rate constant, $k_{\text {app }}$, for the process [105]. This form of analysis has also been applied to the more complex situation of cellular reactions such as in the activation of NADPH-oxidase and production of $\mathrm{H}_{2} \mathrm{O}_{2}$ by human neutrophils. This process exhibits a $k_{\text {app }}$ which is invariant to alterations in agonist concentration [379] and clearly contrasts with our observations concerning the onset of exocytosis in mast cells in which there is a clear dependence of the delay on the concentrations of two effectors. Since these appear to act synergisticaily and symmetrically, a parallel pathway of activation is suggested [142]. Dr Tobias Meyer has proposed the following formulation which could account for the unusual square-root dependence (Eqn. 9) which we have observed.

$g$ and $c$ represent a G-protein and $\mathrm{a} \mathrm{Ca}^{2+}$ binding protein, respectively; it is assumed that these are so abundant that the concentrations [g] and [c] can be treated as being constant:

GTP- $\gamma-S+g \rightarrow G$

$\mathrm{Ca}^{2+}+\mathrm{c} \rightarrow \mathrm{C}$

The nucleotide- and the $\mathrm{Ca}^{2+}$-bound forms, $\mathrm{G}$ and $C$, can act together (possibly involving a third protein) to catalyse the conversion of $e$, a nascent fusion factor, to its activated form $E$ :

$\mathbf{G}+\mathbf{C} \rightarrow \mathbf{G C}$

$\mathrm{GC}+e \rightarrow E$.
The rate of formation of $\mathrm{GC}$ is then given by the proportionality

$\mathrm{d}[\mathrm{GC}] / \mathrm{dt} \alpha[\mathrm{G}][\mathrm{C}]$.

Since $[G]$ and $[C]$ depend on $\left[\mathrm{Ca}^{2+}\right]$ and $[\mathrm{GTP}-\gamma-\mathrm{S}]$ respeztively,

$\mathrm{d}[\mathrm{GC}] / \mathrm{dt} \alpha[\mathrm{GTP} \cdot \gamma \cdot \mathrm{S}]\left[\mathrm{Ca}^{2+}\right]$.

The time-dependent concentration of [GC] can be obtained by integrating this expression to yield

$\mathrm{GC}(\mathrm{t}) \alpha[\mathrm{GTP}-\gamma-\mathrm{S}]\left[\mathrm{Ca}^{2+}\right] \cdot \mathrm{t}$.

Since $\mathrm{d}[E] / \mathrm{dt} \alpha[e][\mathrm{GC}]$ and since $[e]$ is initially constant,

$E(\mathrm{t}) \alpha[\mathrm{GTP}-\gamma-\mathrm{S}] \cdot\left[\mathrm{Ca}^{2+}\right] \cdot \mathrm{t}^{2}$.

Fusion commences when $[E]$ reaches a threshold level, $E_{\mathrm{thr}}$, after a (delay) time $\tau$;

$E_{\mathrm{thr}} \alpha[\mathrm{GTP}-\gamma-\mathrm{S}]\left[\mathrm{Ca}^{2+}\right] \cdot(\tau)^{2}$.

Thus, $1 / \tau \alpha\left\{\left[\mathrm{Ca}^{2+}\right] \cdot[\mathrm{GTP}-\gamma-\mathrm{S}]\right\}^{1 / 2}$

While providing a plausible basis for the square-root dependence on effector concentrations, neither this scheme nor the sequential argument provide any indications concerning the identity of the intermediates and the nature of the steady state condition which appears to be a sine qua non for exocytosis.

\section{VI-E-3. Abrupt onset in the absence of ATP}

All the above results refer to experiments in which the permeabilised cells were supplemented with ATP or ATP- $y$-S. A very different result is achieved if otherwise identical experiments are carried out in its absence (Fig. 18). In this case exocytosis commences without any detectable delay and secretion ensues at its maximum rate within $3 \mathrm{~s}$ of completing the pair of essential effectors [354]. Since exocytosis is also instantaneous when the cells are provided with (nonphosphorylating) AppNHp [142], we were led to conclude that ATP delays the onset of exocytosis by tend-
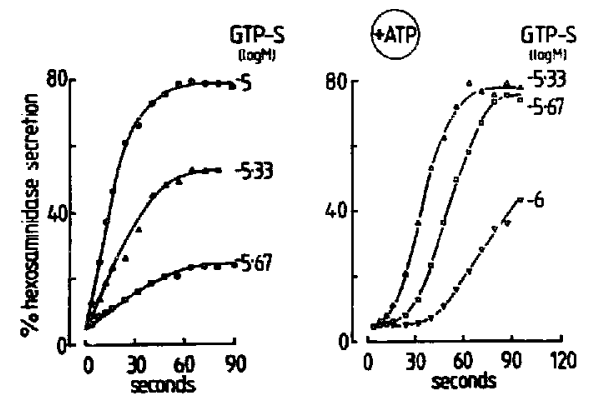

Fig. 18. Time-course of secretion from SL-O permeabilised cells in the absence and presence of ATP. The experimental details are similar to those described in the legend to Fig. 17. From [354]. 

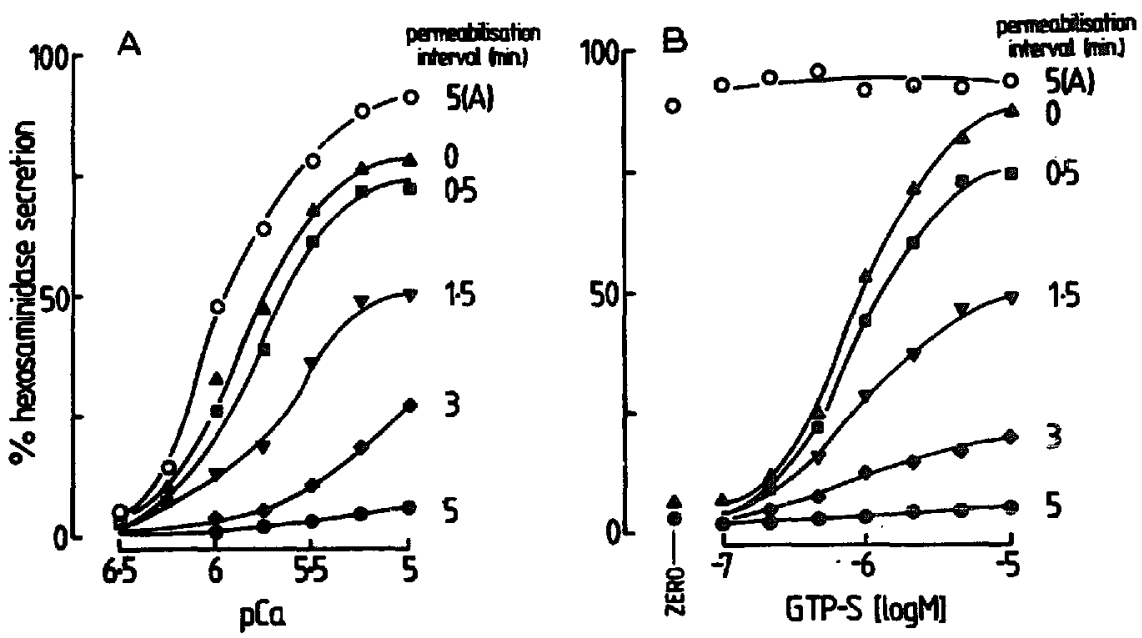

Fig. 19. Dependence on $\mathrm{Ca}^{2+}$ and GTP- $\gamma-\mathrm{S}$ of exocytosis from mast cells stimulated after different permeabilisation intervals. Mast cells, pretreated for $5 \mathrm{~min}$ with metabolic inhibitors and suspended in buffered salt solution containing $0.2 \mathrm{mM}$ calcium buffer (pCa 7) were permeabilised by addition of SL-O $\left(0.4 \mathrm{iu} \mathrm{ml}^{-1}\right)$ and then triggered by transfer at the times indicated (the permeabilisation interval) to tubes containing either (A) GTP- $\gamma-S(10 \mu M)$ and calcium buffers $(3 \mathrm{mM})$ to give a range of $\mathrm{Ca}^{2+}$ or (B) a range of GTP- $\gamma-S$ and calcium buffer $(3$ $\mathrm{mM}$ ) to regulate pCa 5.25. At $5 \mathrm{~min}$, ceils (open symbols) were also transferred to solutions of the two effectors supplemented with $\mathrm{Mg}$.ATP (100 $\mu \mathrm{M})$. The incubations were terminated after a further $10 \mathrm{~min}$ and the hexosaminidase released into the supernatant was determined. From [81].

ing to maintain a phosphorylation state. From this it follows that the enabling reaction might involve dephosphorylation. Since both essential effectors have the effect of shortening the ATP-induced delay the possibility exists that, in combination with their binding proteins, they cause the activation of a phosphatase that might be the target of $G_{\mathrm{E}}$.

In a recent re-examination of onset kinetics we have found [208] that ATP is able to induce delays equally well when the system is depleted of $\mathrm{Mg}^{2+}$ (by buffering $\mathrm{Ca}^{2+}$ with HEDTA instead of the normal EGTA we can suppress $\mathrm{Mg}^{2+}$ to $<10^{-8} \mathrm{M}$ ). So far as we are aware there are no examples of reactions in which ATP acts as a donor in phosphorylation reactions under these conditions and so other reasons must be sought to explain why ATP causes a delay in the onset of exocytosis. As is well known, anionic species of ATP act as allosteric regulators of a number of intracellular activities including the inhibition of $\mathrm{K}^{+}$channels in islet cells [20] and some forms of phosphofructokinase (e.g., in red blood cells [272] and malarial parasites $[64,65])$. Thus, there exists the possibility that ATP inhibits the onset of exocytosis by acting as an allosteric regulator of an enabling enzyme for exocytosis. However, the idea of a protein dephosphorylation as an enabling stage in the process of guanine nucleotide induced exocytosis has instead found some support in experiments involving the use of an inhibitor of protein phosphatases (see section VII-C).

VII. Evidence for a G-protein mediated dephosphorylation as an enabling reaction for exocytosis

\section{VII-A. Okadaic acid, a protein phosphatase inhibitor}

Among other possible mechanisms that might explain the retardation in the onset of exocytosis (Fig. 17) would be a receptor niediated process having specificity for ATP and ATP- $\gamma-\mathrm{S}$, but this would have to be one which did not involve a role for soluble second messengers since these would leak from the permeabilised cells. Another would involve the release of pyrophosphate and transfer of the aden: iyl group to some fixed structure within the cells. A demonstration that exocytosis could be blocked by a defined inhibitor of protein phosphatases would certainly strengthen the dephosphorylation argument. Okadaic acid is one such inhibitor ${ }^{2}$. Okadaic acid inhibits myosin phosphatase [349] and more generally those phosphatases (of the classes 1 and 2A) which catalyse the dephosphorylation of those substrates phosphorylated by protein kinase $\mathrm{C}$ $[46,88,152])$.

On the premise that the enabling reaction for exocytosis requires protein dephosphorylation, one might have expected that treatment of mast cells with an inhibitor of protein phosphatases would be inhibitory.

\footnotetext{
${ }^{2}$ Okadaic acid is a polyether present in marine dinoflagellates $[245,348]$ which accumulates in sponges, mussels and scallops and is the toxic principle associated with diarrhetic illness derived from eating contaminated Eutropean mussels [203]. Initial observations revealed that it has potent tumour promoting activity [123] and induces ornithine decarboxylase activity [344] in mouse skin. Although the tumour promoting activity of okadaic acid (and other related toxins) is as strcng as phorbol esters, the mechanism is clearly different $[122,345]$. The first hints that okadaic acid might exert its effects, not by phosphorylation, but through the maintenance of a phosphorylated state due to the inhibition of a protein phosphatase came from the demonstration that it could induce long lasting contractions of smooth muscle in the absence of $\mathrm{Ca}^{2+}$ [325] by a direct effect on the contractile elements [273]. Smooth muscle centracion depends on the degree of myosin phosphorylation and hence in a dynamic situation, on the relative activities of myosin light chain kinase and phosphatase.
} 

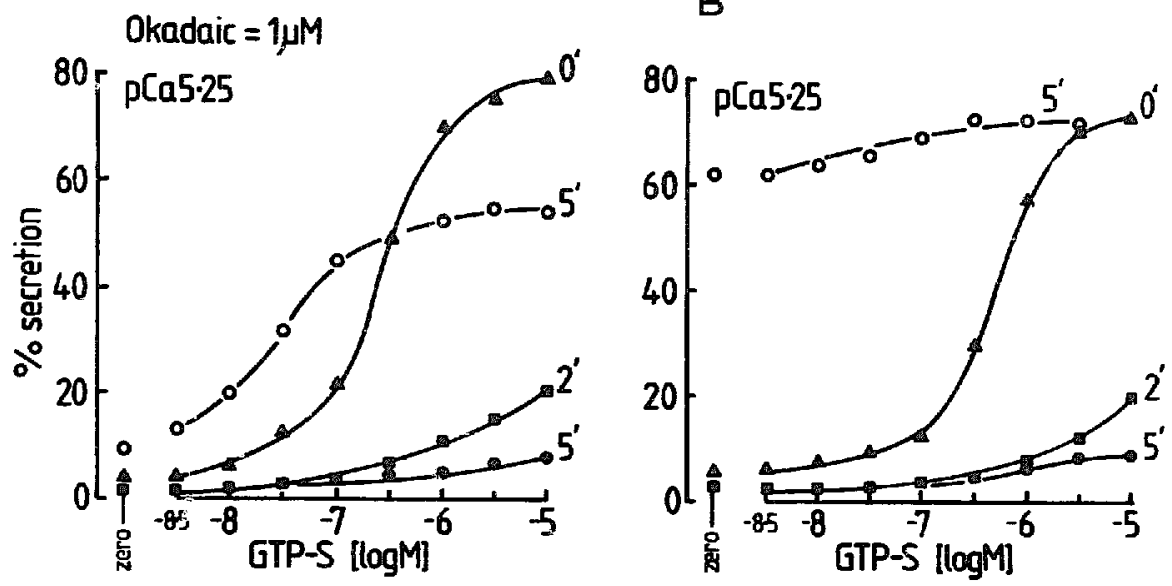

Fig. 20. Dependence on $\mathrm{Ca}^{2+}$ and GTP- $\gamma$-S of exocytosis from mast cells stimulated after different permeabilisation intervals: Okadaic acid ensures retention of GTP-dependence for secretion frum cells rendered refractory by prepermeabilisation and restored by ATP. Mast cells were treatcd with DMSO (A) or $1 \mu \mathrm{M}$ okadaic acid (B) for $5 \mathrm{~min}$, followed by metabolic inhibitors and $0.2 \mathrm{mM}$ calcium buffer ( $\mathrm{pCa} 7$ ) for a further 2 $\min$ and then permeabilised by addition of SL-0. At set times (the permeabilisation interval) the cells were stimulated to secrete by transfer to solutions containing $3 \mathrm{mM}$ calcium buffer (pCa 5.25) and GTP- $\gamma$-S as indicated. At 5 min (open symbols), cells were also transferred to solutions supplemented with $100 \mu \mathrm{M}$ ATP. The incubations were terminated after a further 10 min and secretion determined as release of hexosaminidase. From [81].

However, not only dnes okadaic acid fail to inhibit secretion [81], but it has no discemible effects on the onset kinetics either (unpublished observation). On the other hand, when the cells are conditioned so that exocytosis can be induced by $\mathrm{Ca}^{2+}$ alone, okadaic acid can then restore guanine nucleotide dependence (see section VII-C).

VII-B. SL-O permeabilised cells lose responsiveness to $\mathrm{Ca}^{2+}$ and GTP- $\gamma-S$

Following permeabilisation by streptolysin $O$, the ability of mast cells to undergo exocytosis in response to provision of $\mathrm{Ca}^{2+}$-plus-GTP- $\gamma-\mathrm{S}$ (in the absence of ATP) decays over a period of about $5 \mathrm{~min}$ [169]. As shown in Fig. 19, there is a progressive (rightwards) shift in the dependence of secretion on the concentration of $\mathrm{Ca}^{2+}$ so that after about $5 \mathrm{~min}$ the cells are unable to respond to $10 \mu \mathrm{M} \mathrm{Ca}^{2+}$. This decay occurs very much more slowly in cells permeabilised in the presence of ATP [169], or which have been pretreated with PMA, indicating that maintained phosphorylation, or initial hyperphosphorylation might serve to retain high sensitivity for $\mathrm{Ca}^{2+}$ and hence an ability to respond to the essential effectors. A phosphorylation state, maintained by protein kinase $C$ is almost certainly implicated.

Exocytotic responsiveness can be restored to refractory cells permeabilised in the absence of ATP. For example, when ATP $(100 \mu \mathrm{M})$ is provided together with the stimulus after a permeabilisation interval of 5 min, the sensitivity for $\mathrm{Ca}^{2+}$ returns to its initial level and exocytosis can once again be elicited. Based on experiments with inhibitors AMG.C ${ }_{16}$ (stearylmethyl glycerol, a diether analogue of diglyceride [202,367]) and PKC-I peptide [81] (a peptide based on the pseu- dosubstrate sequence, amino acids $19-31$ of protein kinase $C[6,166])$ we believe that the restoration of responsiveness is yet another reaction mediated through a phosphorylation catalysed by protein kinase C [169].

When the cells have been conditioned by permeabilisation for $5 \mathrm{~min}$, followed by restoration of responsiveness by late addition of ATP, $\mathrm{Ca}^{2+}$ alone becomes sufficient to stimulate exocytosis. It appears that the step normally controlled by $G_{\mathrm{E}}$ has either occurred spontaneously, or has been obviated ${ }^{3}$. Since rephosphorylation (i.e., addition of ATP) restores responsiveness it is plausible that one or more dephosphorylation reactions could figure among the changes occurring during the interval following permeabilisation. This again suggests that the requirement for a guanine nucleotide in immediately stimulated cells reflects the conditions needed for a specific protein dephosphorylation. The catalytic target of $G_{\mathrm{E}}$ may be a protein phosphatase.

\section{VII-C. Okadaic acid ensures dependence on guanine nucleotide}

Evidence to support this conclusion was obtained by testing the guanine nucleotide-dependence for exocyto-

\footnotetext{
3 Note: We obtained results similar to those illustrated in Fig. 19 on at least 25 occasions over a period of a year; however it must be said that in other experitricits, following add-back of ATP, a complete independence of guanine nucleotide was not achieved and instead the secretion was characterised by a considerable enhancement in the apparent affinity for GTP- $\gamma$-S (i.e., commencing at concentrations as low as $10^{-9} \mathrm{M}$, see Fig. $3 \mathrm{C}$ in [169]). The observed guanine nucleotide-independence and the increased sensitivity towards GTP- $\gamma$-S are likely to be manifestations of the same phenomenon but the reason underlying this variability is not clear.
} 
sis following restoration of responsiveness to pre-permeabilised cells treated with okadaic acid (with the intention of retaining a phosphorylated state after permeabilisation: see Fig. 20) or with PMA (with the aim of generating a hyperphosphorylated state prior to permeabilisation). After such preconditioning and after taking the cells through the cycle of permeabilisation and restoration with ATP, dependence on the guanine nucleotide is fully restored. Although one could imagine other possibilities, these experiments certainly suggest that the G-protein which mediates exocytosis $\left(G_{E}\right)$ may have a protein phosphatase as its target. When the cells are permeabilised in the absence of ATP, phosphorylation is not maintained and dephosphorylation may even be accelerated due to the leakage of soluble endogenous phosphatase inhibitors. Among other things this reduces the sensitivity for $\mathrm{Ca}^{2+}$, which then recovers following readdition of ATP; meanwhile another dephosphorylation event, sensitive to okadaic acid and which comprises a normal step of the exocytotic pathway, occurs spontaneously. Following this, $\mathrm{Ca}^{2+}$ alone is a sufficient stimulus to exocytosi3. A problem remains however, since exocytosis (in immediately permeabilised cells) can be elicited in the absence of $\mathrm{Mg}^{2+}$ [208], a component which is considered to be essential for the activation of the okadaic acid sensitive protein phosphatases.

VII-D. Evidence for protein dephosphorylation as an enabling sten in other secietory cells

Only in lower eukaryotic organisms (Paramecium tetraurelia) has a dephosphorylation reaction been positively identified as a necessary precursor of regulated exocytosis $[237,311,386]$. In sea urchin eggs (the cortical granule discharge reaction [374]) and in mammalian neurosecretory cells (bovine adrenal chromaffin cells [57,58]) a dephosphorylation reaction is suggested by the finding that ATP- $\gamma$-S blocks exocytosis, possibly by forming stable thiophosphorylated proteins. However, in permeabilised PC12 ells [371] (a phaeochromacytoma line derived from aurenal chrom fin cells) and in mast cells as already stated (see section VI-E-3), ATP$\gamma$-S (like ATP) modulates, but certainly does not block the exocytotic mechanism. A recent account [177] demonstrating an enhancement in both the extent of amylase secretion and in the sensitivity for $\mathrm{Ca}^{2+}$ in this process by introduction of a cloned tyrosyl phosphatase into SL-O permeabilised pancreatic acini, is further grounds for a dephosphorylation mechanism of exocytosis.

VII-E. Evidence for a late-acting GTP-binding protein $\left(G_{E}\right)$ mediating secretion in other cells

Mast cells and rat basophilic leukaemia cells cultured in the presence of ribavirin [224] or mycopheno- lic acid [376] become refractory to stimulation by IgEdirected antigens and to $\mathrm{Ca}^{2+}$ ionophores. These compounds are inhibitors of IMP (inosine monophosphate) dehydrogenase and prevent the conversion of inosine to hypoxanthine $[69,219,347,380]$. The consequence is the suppression of the purine nucleoside salvage pathway and the selective depletion of guanine nucleotides: ATP levels are maintained. The effects of the IMP dehydrogenase inhibitors can thus be taken as evidence for a role for GTP at a stage in the stimulus-response pathway which is later than the elevation of cytosol $\mathrm{Ca}^{2+}$. A requirement for guanine nacleotides in the activation of adenylate cyclase in intact cells was similarly demonstrated by the use of inhibitors of this class [179].

All other evidence implicating GTF and a GTP-binding protein mediating exocytosis $\left(G_{E}\right)$ in regulated secretory processes comes from experiments with permeabilised cells. Apart from the myeloid cells already mentioned (see section VI-A-1), there are many other systems in which GTP is either sufficient on its own as a mediator of exocytosis, or it modulates the exocytotic reaction (positively or negatively) through interaction with a GTP-binding protein at a late stage in the pathway.

\section{VII-E-1. Neutrophils and HL60 cells}

The initial definition of $G_{E}$, a GTP-binding protein which mediates exocytosis, came from experiments on rabbit neutrophils permeabilised with Sendai virus $[37,136]$. Secretion of $\boldsymbol{\beta}$-glucuronidase (a marker of azurophilic granules) could be elicited either by $\mathrm{Ca}^{2+}$ at concentrations buffered in the micromolar range or by guanine nucleotides such as GTP- $\gamma$-S and GppNHp. Pretreatment of the cells with phorbol ester was found to inhibit the $\mathrm{Ca}^{2+}$-induced secretion and so the activation due to the guanine nucleotides is unlikely to be due to an interaction with $G_{\mathrm{p}}$, the activator of phospholipase C. Further evidence in favour of a second site for GTP in the stimulus-secretion sequence of these cells came from the finding that GDP and GDP$\beta-S$ are inhibitory to secretion induced by $\mathrm{Ca}^{2+}$. This suggests that the GTP-binding protein $G_{E}$ plays an active role in $\mathrm{Ca}^{2+}$-induced lysosomal enzyme secretion even when exogenous GTP is not provided. On the other hand, the extent of GTP- $\gamma$-S-induced secretion increased as the concentration of $\mathrm{Ca}^{2+}$ is suppressed towards and even below pCa 10. In the related HL60 cells, permeabilised with SL-O, the nucleotides which synergise with $\mathrm{Ca}^{2+}$ to induce $\beta$-glucuronidase secretion include XTP and ITP, neither of which cause activation of phospholipase $C$ [343]. This again demonstrates that the GTP-binding protein which activates phospholipase $\mathrm{C}\left(G_{\mathrm{P}}\right)$ is quite distinct from that which mediates exocytosis. There is also evidence for a late acting GTP-binding protein in the regulation of the 
respiratory burst [220], which unlike secretion, may be considered to be a real as opposed to an artificial (i.e., cytochalasin-dependent) function of these cells.

\section{VII-E-2. Platelets}

The most evident effect of the guanine nucleotides on serotonin secretion from HVD-permeabilised platelets is to shift the dependence of secretion on $\mathrm{Ca}^{2+}$ to lower concentrations $[149,197,151]$. Since provision of thrombin or agonistic phorbo! ester [150,194] produces a very similar effect on the $\mathrm{Ca}^{2+}$-dependence of amine secretion, it was initially suggested that the effect of the GTP analogues in this system is cxerted through $G_{\mathrm{P}}$ with consequent generation of diglyceride and an enhancement in the sensitivity for $\mathrm{Ca}^{2+}$ [197]. However, a case for the involvement of $G_{E}$ can be made, since, if sufficiently high concentrations of guanine nucleotide are used ( $100 \mu \mathrm{M} \mathrm{GTP}-\gamma$-S), then it is possible to induce exocytosis from all three types of secretory granule under conditions in which the concentration of $\mathrm{Ca}^{2+}$ is suppressed to the point at which there is no activation of phospholipase $C[22,92,151]$.

\section{VII-E-3. Adrenal chromaffin cells}

Contrary to earlit. observations obtained using HVD-permeabilised bovine chromaffin cells which indicated a negative influence of GppNHp [192] or GTP$\gamma$-S [48] on $\mathrm{Ca}^{2+}$-induced exocytosis, it now appears that GppNHp, ITP, XTP and GTP (all activating ligands for GTP binding proteins [47]) [241] can induce $\mathrm{Ca}^{2+}$-independent secretion, albeit at a rather low level (3-5\%), from digitonin permeabilised cells. In this system, GTP- $\gamma-S$ has only a rather marginal effect.

The rank order of nucleotides stimulating $\mathrm{Ca}^{2+}$-independent exocytosis (for maximal stimulation, XTP > ITP $>$ GppNHp $>$ GTP- $\gamma-\mathrm{S}$ ) is quite distinct from the order for activation of PLA ${ }_{2}$. Whether the conditions of stimulation by guanine nucleotides also rule out a role for phospholipase $\mathrm{C}$ activation (i.e., a $G_{\mathrm{P}}$ mediated reaction) is not quite so sure. According to our calculations based on the conditions used and assuming the presence of contaminating calcium at about 25 $\mu \mathrm{M}$ the 'zero- $\mathrm{Ca}^{2+}$, condition is likely to have been at about pCa 8 , which might have been insufficiently low to ensure full suppression of the ( $G_{\mathrm{p}}$-mediated ? $\mathrm{PI}$ - $\mathrm{C}$ reaction. However, as phorbol esters do not elicit secretion, the effect of the guanine nucleotides is unlikely to involve activation of protein kinase $C$ (which could be expected to enhance the sensitivity for $\mathrm{Ca}^{2+}$ [191]). A further indication of G-protein involvement in the late stages of the pathway is offered by the finding that pretreatment with pertussis toxin enhances the effective affinity for $\mathrm{Ca}^{2+}$ for exocytosis from digitonin permeabilised chromaffin cells $[264,333]$. These experiments make a good, if not quite overwhelming case for thinking that in chromaffin cells, activation of $G_{E}$ offers an aiternative pathway to exocytosis. Moreover, GTP-binding proteins of both major classes, $r a b 3 A$ and pertussis toxin substrates, are present as curnonients of the chromaffin granule membrane [96,361].

\section{VII-E-4. Parathyroid}

Unlike most secretory systems, secretion from the parathyroid [60,61,324], renal juxtaglomerular cells (renin release) $[120,279]$ and the release of human placental lactogen $[78,147]$ is associated with a reduction in the concel tration of extracelluiar $\mathrm{Ca}^{2+}$. For parathyroid cells, hormone secretion occurs as this is reduced to less than $1.25 \mathrm{mM}$ [117], with a corresponding decline in the level of intracellular $\mathrm{Ca}^{2+}$ [244]. However, it is unlikeiy that the secretory response is elicited simply as a consequence of reducing $\mathrm{Ca}^{2+}{ }_{i}$ since dopamine, noradrenaline and $\mathrm{Li}^{+}$are all capable of inducing secretion and do so without any alteration in the concentration of cytosol $\mathrm{Ca}^{2+}[256]$.

There is evidence for the involvement of GTP-binding proteins at two distinct stages in the stimulus-secretion sequence of these cells. In parathyroid cells treated with pertussis toxin, exocytosis becomes insensitive to the inhibitory effects of high extracellular $\mathrm{Ca}^{2+}$ and appears to proceed constitutively. Since the application of $\mathrm{Ca}^{2+}$-ionophore inhibits release regardless of whether cells have been treated with the toxin, the pertussis substrate is probably mediating events at the receptor level [117], possibily associated with production of inositol phosphates [59]. On the other hand, the finding that PT treatment also renders the $\mathbf{m}$ insensitive to the inhibitory effects of $\mathrm{Ca}^{2+}$-inannel agonists argues in favour of a downstream location of a regulatory G-protein [118].

Surprisingly it was found that exocytosis from permeabilised cells correlates not with depletion, but with an ation of cytosol $\mathrm{Ca}^{2+}$ (see Fig. 21), although the exter of $\mathrm{Ca}^{2+}$ induced secretion is rather small [263]. $\rightarrow$ curs in the same range of concentrations $\left(10^{-7}\right.$

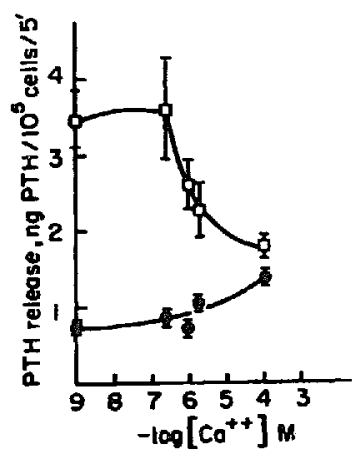

Fig. 21. Dependence on $\mathrm{Ca}^{2+}$ and guanine nucleotide for hormone secretion from permeabilised parathyroid cells. Secretion was measured from HVD-permeabilised parathyroid cells incubated for 5 min in a glutamate system containing Mg.ATP $(5 \mathrm{mM})$, GppNHp and Ca.EGTA buffers to regulate pCa as indicated. $\bullet$, control; $\square$, GpplNHp (10 $\left.{ }^{-5} \mathrm{M}\right)$. From [262] 
$10^{-5} \mathrm{M}$ ) which causes activation of most other secretory systems and from this viewpoint the control mechanism for exocytosis appeared initially to be perfectly conventional. Non-metabolisable analogues of GTP (i.e., GTP- $\gamma$-S and GppNHp) are also capable of inducing exocytosis in the permeabilised cells and this occurs to an extent that is much greater than that due to elevation of $\mathrm{Ca}^{2+}$ (Fig. 21). This effect can be regarded as $\mathrm{Ca}^{2+}$-independent since it is fully expressed at $\mathrm{pCa}$ 9. When loaded with GppNHp $\left(10^{-5} \mathrm{M}\right)$ exocytosis remains maximal as the level of $\mathrm{Ca}^{2+}$ is raised up to $200 \mathrm{nM}$ but above this it declines steeply approaching a baseline response at pCa 6 [262] nicely in line with the physiological response of intact cells.

\section{VII-E-5. Pituitary melanotrophs}

Secretion of $\alpha$-MSH from cells of rat pituitary gland intermediate lobe is dependent on the presence of extracellular $\mathrm{Ca}^{2+}$. Following depolarisation, $\mathrm{Ca}^{2+}$ enters the cell inducing exocytosis as demonstrated by simultaneous fura-2 and capacitance measurements with the patch pipette. The rate of secretion grows with the 4th or 5th power of the intracellular calcium concentration [360]. In intact cells the secretion can be enhanced by agonists for $\beta$-adrenergic receptors acting conventionally to elevate cyclicAMP [362]. However, in permeabilised cells (high voltage discharge) cyclicAMP is without effect on $\mathrm{Ca}^{2+}$-induced secretion unless GTP (or one of its analogues) is also provided [382]. $\mathrm{Mg}^{2+}$ is also a requirement for the potentiation, but not for the exocytotic reaction. The finding that neomycin, an inhibitor of inositide-specific phospholipase $\mathrm{C}$, is without effect on the enhancement due to GTP suggests that this is another example of involvement of a G-protein at a late stage in the control pathway for exocytosis. Confirmation of this latter point will require a formal demonstration of maintained $\alpha$-MSH secretion in the face of full suppression of $\mathrm{IP}_{3}$ release.

\section{VI-E-6. Pituitary lactotrophs}

A capacitance increase of $20-50 \%$, commencing after a delay of 3-10 min has been found to occur in bovine lactotrophs (anterior pituitary) dialysed with high $\mathrm{Ca}^{2+}$ using a patch pipette $[229,389]$. When GTP$\gamma-\mathrm{S}$ is included in addition to $1 \mu \mathrm{M} \mathrm{Ca}^{2+}$ in the pipette the amplitude of the exocytotic response is decreased but the rate is increased [327]. These results could be explained by a stimulatory role of G-proteins in the translocation of granules to the plasma membrane and an inhibitory role of $\mathrm{G}$-proteins at the fusion site.

\section{VII-E-7. Pituitary gonadotrophs}

Secretion of lutenizing hormone (LH) from $\alpha$-toxin permeabilised pituitary cells can be stimulated by elevation of $\mathrm{Ca}^{2+}$ and at resting levels of $\mathrm{Ca}^{2+}(\mathrm{pCa}$ 7) by introduction of cyclicAMP, GTP- $\gamma-\mathrm{S}$ or GppNHp. This stimulatory effect of the guanıne nucleotides is probably mediated through $G_{\mathrm{S}}$ and the generation of cyclicAMP. However, by pretreating the cells with GTP- $\gamma-S$ (GppNHp is without effect), subsequent responses due to elevation of $\mathrm{Ca}^{2+}$, introduction of cyclicAMP, treatment with PMA or the combination cyclicAMP plus PMA, are all inhibited suggesting the presence of an inhibitory GTP-binding protein operating late in the pathway $[97,370]$.

\section{VII-E-8. Exocrine pancreatic acinar cells}

Patch clamp experiments have shown that acetylcholine induces capacitance changes indicative of exocytotic activity in pancreatic acinar cells. These capacitance changes were absent when 1-2 mM EGTA was included in the pipette solution. The capacitance changes were inhibited by GDP- $\beta-S$ and potentiated by GTP- $\gamma$-S which indicates the involvement of a G-protein in the elevation of intracellular calcium or exocytosis [226]. While the capacitance increase is only transient in the presence of extracellular calcium, it is smaller but sustained in the absence of extracellular calcium which indicates a role for extracellular calcium for the re-uptake (endocytosis) of the granule membranes [227].

In SL-O permeabilised pancreatic acinar cells, GTP$\gamma$-S increases the effective affinity for $\mathrm{Ca}^{2+}$ in the secretion of amylase in a manner which requires the presence of ATP $[107,189,276]$, while GDP and 2 '-deoxyGDP both suppress the maximum extent of $\mathrm{Ca}^{2+}$ induced secretion [276]. Treatment of the cells with phorbol ester also enhances secretion implying a role for protein kinase $C$ and activation by $G_{\mathrm{P}}$ of phospholipase $\mathrm{C}$. However, the finding that the combined application of phorbol ester and GTP- $\gamma-S$, both at their maximally effective concentration (and also at lower concentrations) causes an even greater enhancement of secretion suggests that the guanine nucleotide also interacts at another point in the exocytotic pathway [107]. Using a cell-free system, Edwardson [247] and his colleagues have shown that fusion of isolated pancreatic plasma membranes and zymogen granules (measured by the technique of fluorescence dequenching of the membrane probe octadecylrhodamine B-chloride) with concomitent release of amylase can be induced by GTP and its non-hydrolysable analogues or $\left[\mathrm{ALF}_{4}\right]^{-}$. Such fusion requires neither $\mathrm{Ca}^{2+}$, cytosol proteins, nor ATP. These results make a strong case for thinking that in pancreatic acinar cells, fusion of secretory granules with the plasma membrane is mediated by a G-protein acting at a stage subsequent to the action of $\mathrm{Ca}^{2+}$. There are several low molecular weight (21.5-29 $\mathrm{kDa}$ ) GTP-binding proteins integrally associated with the cytosolic face of the zymogen granule membranes, though whether these constitute a component of the exocytotic mechanism is not known [277]. Equally well 
they could represent vestigial species related to the formation, maturation and maintenance of the secretory vesicles.

\section{VII-E-9. Inhibitory mechanisms}

\section{Insulin and ACTH secreting cells}

In insulin secreting cells and in ACTH secreting cells there is evidence for GTP-binding proteins acting both to promote and to inhibit exocytosis. In permeabilised islets [378], RINm5F and HIT-T15 (insulinoma) cells [364,366] and in ATt20 (pituitary) cells $[221,222]$, secretion can be induced either by $\mathrm{Ca}^{2+}$, or by non-hydrolysable analogues of GTP at low $\mathrm{Ca}^{2+}$. In RIN5mF cells, GTF- $\gamma-S$ remains effective as $\mathrm{Ca}^{2+}$ is suppressed to pCa 9 , under which conditions the $G_{\mathrm{p}}$ mediated release of $\mathbf{I P}_{3}$ does not occur. Stimulation of receptors, for $\alpha_{2}$-adrenergic agonists or somatostatin can inhibit exocytosis induced by $\mathrm{Ca}^{2+}$ in a manner requiring the presence of GTP and which is reversed by pretreatment with pertussis toxin. This suggests that there is a GTP-binding protein, $G_{E_{i}}$ which inhibits exocytosis. Since such inhibition is determined by the normal inhibitory receptors, it would appear likely that this G-protein is located at the plasma membrane. Although these receptors remain coupled to adenylate cyclase in permeabilised pancreatic islets [182] and RINm5F cells [365] (conventionally by suppression of cyclicAMP production, through $G_{i}$ ) there is no correlation between the amount of cyclicAMP and the rate of secretion. When GTP is provided to permeabilised RINm5F cells, adrenaline and clonidine ( $\alpha_{2}$-agonists) inhibit both $\mathrm{Ca}^{2+}$ - and diglyceride-induced secretion, an effect which is abolished by pretreatment with pertussis toxin [365]. The non-hydrolysable analogues of GTP do not support inhibition, presumeably because they support the activation response so strongly.

\section{VI-F. Classification of $G_{E}$, the GTP-binding protein mediating exocytosis in myeloid cells}

In order to understand how GTP and the GTP-binding protein $G_{\mathrm{E}}$ regulates secretion, it will be helpful to compare what we know of its functional characteristics with other GTP-binding proteins having well defined structures, but which in some cases lack a defined function. It must be stressed that $G_{\mathrm{E}}$ exists so far only as a concept, not as a reality: it is a conclusion born of experiments in cell physiology, not biochemistry.

In attempting to classify $G_{\mathrm{E}}$ as a GTP-binding protein we need to consider the signal transducing G-proteins (heterotrimeric structures linked upstream to cell surface receptors and downstream to catalytic effectors such as adenylyl cyclase, phospholipase $C$ and a number of ion channels) and also the monomeric GTP-binding proteins, of which the ras proteins and elongation factor are widely regarded as structural and mechanistic archetypes.

Ras-related GTP-binding proteins have been implicated as mediators of vesicle fusion at a number of stages in the pathway leading to both constitutive and regulated secretion (for an overview see reference [53]). When injected into mast cells, the oncogenic form of ras (H-ras p21 $1^{\mathrm{val}_{12}}$ which is persistently activated) induces degranulation [36]. This occurs after a prolonged lag period of about $3 \mathrm{~h}$ and although the proto-oncogene product is without effect, the meaning of this result in termis of G-protein regulation of exocytosis remains far from clear. In reconstitution experiments, GTP is required to enable trafficking to occur between the endoplasmic reticulum and the Golgi stacks [24,40] and then through the Golgi [232,321] and again in the terminal stages of the constitutive secretory pathway, in cells as diverse as yeast [309] and mammalian liver [232]. In general, the non-hydrolysable analogues of GTP inhibit vesicle traffic [232] and from this it is understood that the GTP-binding proteins must cycle repeatedly between the GTP- and GDP-bound states $[24,52,53,257]$. However, an alternative view, based on reconstitution of endosome fusion, does allow for a supportive role for GTP- $\gamma-S$ so long as the system is depleted of cytosol factors [230].

A role for small GTP-binding proteins in the terminal stages of the regulated exocytotic process has also been discerned in several mammalian cells [32]. A ras-related protein, $r a b 3 A$, which in neural tissues associates exclusively with secretory vesicles $[96,115,236]$, has been shown to undergo a cycle of dissociation and reassociation during and after the release of glutamate induced by $\mathrm{K}^{+}$-depolarisation or $\mathrm{Ca}^{2+}$-ionophore [116] which may indicate a role at some stage in the trafficking process. In most other systems [132,133] it appears that the sensitivity of the non-hydrolysable analogues of GTP (GTP- $\gamma$-S S $_{9}$ GpivHp and $\mathrm{GppCH}_{2}$ ) in support of the secretory process can be as much as $10^{3}$ times higher than that of the parent nucleotide [167]. These findings are based on investigations of permeabilised cells and in mast cells the effect of cytosol proteins is to suppress the sensitivity for both essential effectors (see section V-D) [198].

Although the argument is far from being settled, we take the view that the role and characteristics of $G_{E}$ are distinct from those of the GTPases which ensure accuracy and directionality of membrane interaction in the constitutive pathway [52,138]. A more appropriate paradigm for $G_{E}$ function is possibly provided by the familiar G-proteins such as $G_{\mathrm{S}}, G_{i}$ and transducin. Persistent binding of GTP (or analogues) results in dissociation and release of $\alpha$-subunits from such heterotrimeric G-proteins with consequent activation of downstream effectors. Some support for this proposal may come from the finding [209] that when mast cells 
are deprived of $\mathrm{Mg}^{2+}$ (using HEDTA buffers (see section VI-E-3) to chelate $\mathbf{M g}^{2+}$ and to buffer the $\mathrm{Ca}^{2+}$ ) GTP becomes almost equipotent with GTP- $\gamma-S$. Under these conditions the GTPase activity of the heterotrimeric signal transducing G-proteins is not supported $[54,128,161]$.

\section{VII-F-1. $G_{E}$ : an argument for a heterotrimeric signal transducing G-proiein}

The clostridial ADP-ribosylating toxins have been widely used in attempts to establish the role and classidentity of GTP-binding proteins in cellular processes. Pretreatment of mast cells with pertussis toxin, which catalyses ADP-ribosylation of $G_{i}$ and related G-proteins, inhibits exocytosis in response to polycationic stimulation, but not the response due to IgE receptordirected stimulation [308]. Although it is well established that ADP ribosylation by PT treatment does not prevent activation of $G_{\mathrm{i}}$ by GTP-y-S, it does retard the onset of the $G_{\mathrm{i}}$-associated cyclase inhibition about 5fold [174]. This offers the possibility that by measuring the kinetic characteristics (particularly the onset delays) of exocytosis in PT-treated cells, we might get some insight into the class of the $G_{\mathrm{E}}$ protein. However, the delay in the onset of exocytosis in PT-treated mast cells, whether measured in SL-O permeabilised cells (Lillie \& Gomperts, unpublished experiments), or in patch-clamp experiments was found to be completely unchanged [215]. In the slow-whole-cell configuration of the patch-clamp set-up (see section IV-C-5), GTP- $y$-S caused degranulation with an unchanged time-course and amplitude even on a cell which had first been shown to be insensitive to stimulation by compound $48 / 80$.

Using the patch-pipette, we have introduced into neutrophils a number of different GTP-binding proteins isolated from neutrophils and pre-activated with low concentrations of GTP- $\gamma-S$. So far, none of these preparations (including $G_{n \alpha}$, (the main neutrophil pertussis toxin substrate) $[49,127,265]$, brain $G_{i}$, brain $\beta \gamma$ [249,342], or mixtures containing $G_{22}, G_{24}$ and $G_{26}$ [51]) stimulated exocytosis (Nüsse, Bokoch and Lindau, unpublished). These experiments indicate that either $G_{E}$ is a different protein or that the proteins failed to bind in an effective manner. In contrast, at $10 \mathrm{nM}$ or higher concentration, all of these preparations except for $\beta \gamma$ inhibited exocytosis when applied simultaneously with GTP- $\gamma-S$. Since the pipette contains $20 \mu \mathrm{M}$ GTP- $\gamma-S$ and only approx. $20 \mathrm{nM}$ G-protein, the depletion of the nucleotide should not be significant. The experiments might indicate the ability of a variety of G-proteins to bind to the exocytotic effector system without activating it, thereby preventing its stimulation by the endogenous GTP- $\gamma$-S-activated $G_{\mathrm{E}}$.

\section{$V I I-\vec{F}-2$. Receptor control of $G_{E}$ function}

Support for the idea that the $G_{E}$ function is ex- pressed by a member of the class of signal transducing G-proteins now comes from a complex set of experiments in which it has been shown that the group of polybasic agonists which elicit mast cell degranulation do so, probably by interacting directly with a GTP-binding protein quite distinct from $G_{\mathrm{P}}[18]$. The polybasic agonists comprise a very diverse group of compounds, including compound 48/80 [283] (a condensation product of $N$-methyl-p-methoxy phenylethylamine with formaldehyde $[33,200])$, the bee venom peptide mastoparan [162], substance $P$ [113], polylysine [108] and possibly the complement derived peptide $\mathrm{C} 3 \mathrm{a}$ [124]. There is no evidence that any of these interact with a formal cell surface receptor [297] though unlike the stimulation pathway involving the receptor for $\operatorname{IgE}$ [308], stimulation of exocytosis is prevented in cells which have been treated with pertussis toxin $[242,248,308]$.

In these experiments [18] the technique of $\mathrm{ATP}^{4-}$ permeabilisation (see section III-C) has been used to load and trap GTP- $\gamma-S$ [130]. Internalisation of GTP- $\gamma$ $S$ renders the cells spontaneously responsive to application of extracellular $\mathrm{Ca}^{2+}$ [130] but when loaded at very high concentrations (around $1 \mathrm{mM}$ ) this becomes self inhibitory (see Fig. 5). However, under these conditions exocytosis can still be elicited following stimulation of the resealed cells with mastoparan or compound $48 / 80$. Such agonist-induced secretion proceeds without any involvement of $\mathrm{Ca}^{2+}$ : it occurs in the absence of external $\mathrm{Ca}^{2+}$ anö it cannot be mimicked by application of $\mathrm{Ca}^{2+}$-ionophores, nor by activators of protein kinase $\mathrm{C}$. Moreover, under these conditions, phospholipase $\mathrm{C}$ activity is inhibited (possibly due to the presence of an inhibitory G-protein, $G_{\mathrm{Pi}}$ ) so that any secretory activity which is dependent on the guanine nucleotide is likely to involve a GTP-binding protein late in the exocytotic pathway, by definition $G_{\mathrm{E}}$.

As an alternative to loading the cells with overwhelming concentrations of GTP- $\gamma-\mathrm{S}$, direct masking of polyphosphoinositides by loading with neomycin also prevents phospholipase $C$ activation $[85,313]$, yet under these conditions again, the polycationic agonists remain effective so long as the cells are simultaneously loaded with GTP [17]. Furthermore, and in contrast to direct stimulation of $G_{\mathrm{E}}$ with non-hydrolysable analogues of GTP, secretion due to the polybasic agonists from cells loaded with neomycin and GTP is inhibited by treatment with pertussis toxin [17]. For these reasons it is likely that $G_{\mathrm{E}}$ is one of the heterotrimeric $(\alpha \beta \gamma)$ signal-transducing G-proteins, having some resemblance to the group exemplified by $G_{i}$.

Some clues to the possible mechanism of activation come from the finding that a number of these polybasic agonists, including mastoparan [158,160], compound $48 / 80$ and substance $P$ [242] are able to interact with 
the carboxy terminus of the $\alpha$ subunit of the G-protein $G_{i}$, causing direct activation of its GTPase function $[66,243,373]$. Neomycin is another direct activator of GTPase activity (of the membrane associated G-proteins in platelet plasma membranes) $[156,157]$ and it also activates secretion when applied externally to mast cells (and even internally when provided at exceedingly high concentrations which certainly suppress phospholipase $C$ activity) [17]. All these activating polycations can be regarded as structural amphipaths expressing non-polar surfaces which could conceivably insert into, and indeed across membranes. In the case of compound $48 / 80$, spectroscopic studies using a spinlabelled derivative indicate penetration into a non-polar environment [270]. Mastoparan also, is understood to penetrate the plasma membrane and in so doing, to interact directly with the receptor interface of the $\alpha$-subunits of $\mathrm{G}$-proteins such as $G_{\mathrm{o}}$ and $G_{\mathrm{i}}$ $[158,160,373]$.

The mechanism of activation clearly involves more than just the penetration of the plasma membrane followed by interaction with a G-protein at the cytoplasmic surface. If it were as simple as this, then one would expect that all susceptible G-protein functions would be activated regardless of cell type. However, the mast cells derived from other tissues and/or species as well as the closely reiated rat basophilic leukaemia cells are resistant or much less sensitive to these polycationic activators $[19,21]$. There are a number of other problems: thus polylysines of molecular weights 3000 and 70000 are reported to be equally active on a weight (but not on a mole) basis [108], implying that it is the total number of charged residues which determines the extent of secretion. Also, when subfractionated, high molecular weight polymers of compound $48 / 80$ are reported to be much less potent in stimulating secretion than the hexamer $[271,296]$ (but see [200]), which could hardly be expected to be sble to traverse the thickness of a membrane.

Despite these reservations, the polybasic agonists are probably best regarded as pseudo-receptors which interact directly with G-proteins, consequentiy activating the downstream function of $G_{\mathrm{E}}$ in susceptible cells. The varying susceptibility of the different mast cell types may be due to variable expression of specific membrane components required for proper membrane insertion. This conclusion is supported by the finding that mastoparan, which is a very poor agonist for secretion of serotonin from intact platelets (maximum about $3 \%$ ) can induce over $80 \%$ release when provided to digitonin-permeabilised cells [274]. As with the RBL cells it is likely that in platelets, activation by mastoparan (which induces $\mathrm{Ca}^{2+}$-independent secretion) is due to interaction with a pertussis scnsitive GTP-binding protein, late in the exocytotic pathway [274].
VIII. The exocytotic event

\section{V'I!'A. Exocytris of single granules}

The quantal concept of exocytosis is due to the experiments of Katz and his collaborators [100,184,185]. The phenomenon of the miniature end-plate potential at the neuromuscular junction derives from the boluslike release of acetylcholine and the consequent opening of acetylcholine receptor channels in the post-synaptic membrane. Their measurements thus recorded a secondary response to the exocytosis in which the movement of $\mathrm{Na}^{+}$ions registered a current flow which reported on an earlier process. The quantal nature of the exocytutic event can now be directly demonstrated by high resolution measurements of the capacitance of the plasma membrane of a cell while it is undergoing exocytotic secretion.

When a secretory granule fuses, the area of the plasma membrane increases by an amount equal to the area of the granule membrane and the capacitance increases as a discrete step, each granule contributing approx. $10 \mathrm{fF} \mu \mathrm{m}^{-2}$ of membrane. The stepwise nature of the fusion process was first demonstrated in the pioneering work of Neher and Marty [253] on chromaffin cells. Capacitance steps corresponding to the sequential fusion of individual granules have subsequently been observed in rat mast cells [111], mast cells from normal [13] and beige mice [55,56,388], human neutrophils [259], guinea-pig peritoneal eosinophils $[216,261]$ and horse blood eosinophils [312]. In all three cell types the magnitude of the capacitance steps is in excellent agreement with morphometric data on the exocytotic granules obtained by electron microscopy of thin sections $[26,153,154,216,336]$. The mean step sizes vary from $3 \mathrm{fF}$ in human neutrophils to several hundred $\mathrm{fF}$ in beige mouse mast cells and horse eosinophils, corresponding to granule diameters ranging from 300 $\mathrm{nm}$ to more than $1 \mu \mathrm{m}$.

Fig. 22 shows typical sequences of capacitance steps measuzed during degranulation of (a) a human neutrophil (b) a guinea-pig eosinophil and (c) a horse eosinophil. By measuring the step height of a large number of individual steps, one may construct frequency-distribution diagrams as shown for the neutrophils in Fig. 22d. If the granules are assumed to have a simple spherical geometry, then upon fusion, a granule having diameter $\mathbf{d}_{\mathbf{G}}$ (measured in microns), should generate a capacitance change of $\Delta C_{M}$ fF according to

$\Delta C_{\mathrm{M}}=\pi \mathrm{d}_{\mathrm{G}}^{2}$

For neutrophils, the step size distribution corresponds to a Gaussian distribution of granule diameters having a mean of $d_{0}=280 \mathrm{~nm}$ and variance $\sigma=40 \mathrm{~nm}$ 
(smooth line in Fig. 22d) [259]. The capacitance steps of the guinea-pig eosinophils have been transformed into a granule size distribution also assuming a spherical geometry (Fig. 22e) and this can be fitted approx. by the sum of two Gaussian distributions $d_{1}=520 \pm 10$ $\mathrm{nm}$ and $d_{2}=590 \pm 260 \mathrm{~nm}$ reflecting a relatively wide distribution with a rather sharp peak (smooth line) [216]. These distributions are in good agreement with the morphometric data for human neutrophil azurophilic granules [26,336] and guinea-pig eosinophil crystalloid granules [216], respectively. The agreement between the granule dimensions and the capacitance step sizes for each cell type so far tested, clearly demonstrates that during exocytosis the granules mainly fuse sequentially, one by one, with the plasma membrane.

\section{VII-B. Compound exocytosis}

While the large majority of capacitance steps fall within a limited range, indicative of a single population of granules having rather uniform dimensions, in murine mast cells a significant number of capacitance steps were recorded which are of a size much larger than expected for the fusion of individual granules [14]. These large steps most likely arise from the phenomenon known as 'compound exocytosis', meaning that two or more granules may fuse among each other and then fuse with the plasma membrane. It has generally been assumed that such granule to granule fusions occur at the time of exocytosis as a consequence of the stimulus to secrete. From this assumption one would predict that the incidence of large capacitance steps (caused by exocytosis of pre-fused granules) would tend to become more frequent as secretion progresses, since this would give time for such compound granules to form. However, the incidence of the large steps is mainly concentrated in the early stages of GTP- $y$-S-induced degranulation and so this observation must be taken as evidence that the large granules are present in the resting cells and that they are primarily located close to the periphery [14]. Such fusions must therefore occur at some point in the time before, and unrelated to, the stimulus and final release to the exterior.

\section{VIII-C. Granulogenesis: the formation of secretory gran- ules}

A detailed examination of the capacitance step size distribution in rat mast cells reveals a series of regularly spaced peaks which correspond to a periodicity in granule size [13] (see Fig. 23) which is in rather good agreement with the multimodel distribution of granule volumes derived from morphometric analysis of electron micrographs of thin sections [146]. This periodicity indicates that the larger granules may be formed by the
A

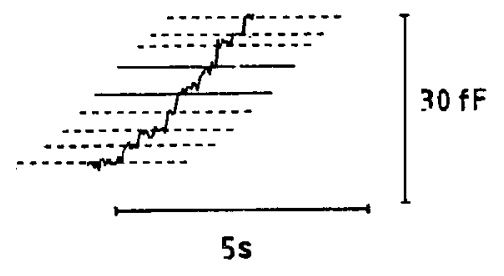

D

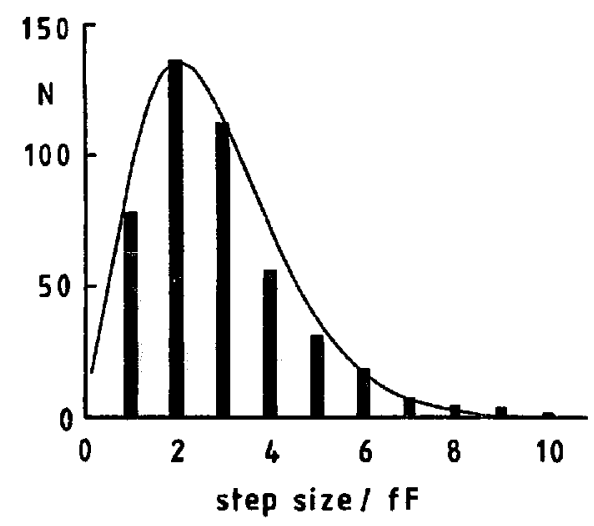

B

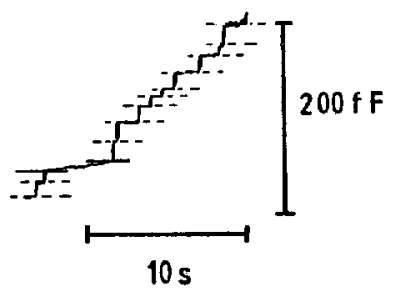

C

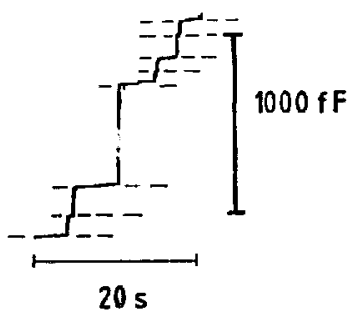

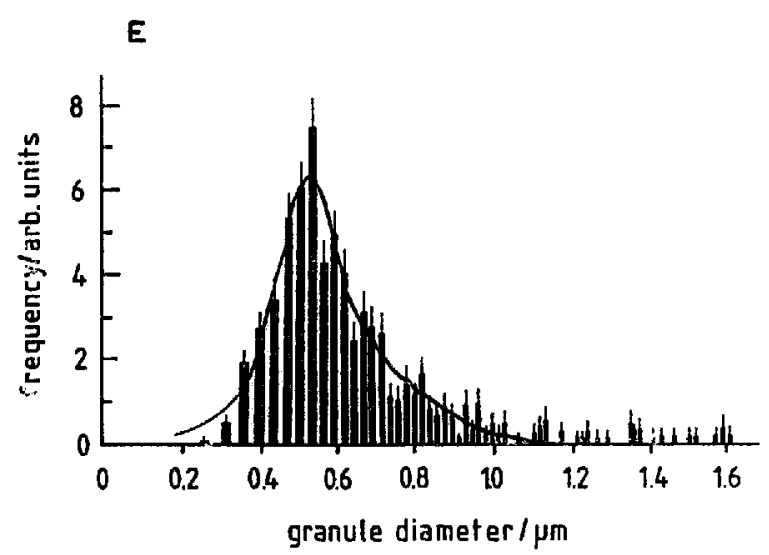

Fig. 22. High resolution capacitance measurements with a lock-in amplifier reveal the stepwise nature of the membrane capacitance increase reflecting the sequential fusion of individual granules. Note the markedly different step sizes in human neutrophils (A), guinea-pig eosinophils (B) and horse eosinophils (C). (D) and (E) illustrate the frequency distributions of step sizes for human neutrophils and the derived granule size distribution for guinea-pig eosinophils. 
A

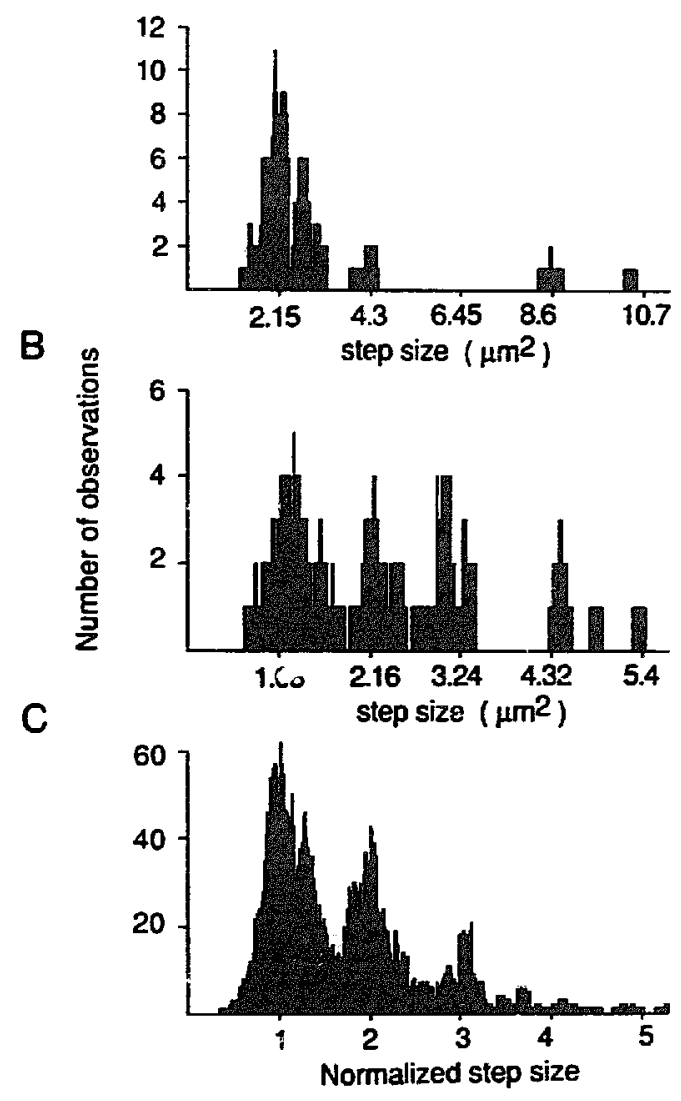

Fig. 23. Quantal distribution of granule size. The granule size distribution shows several regularly spaced peaks. The position and spacing of the individual peaks varies between individual cells (e.g., A and B). After normalization to multiples of unit granule surface area the peaks are also seen in pooled data from many cells (C). From [13].

fusion of smaller 'unit' granules with each other. In response to intracellular stimulation with GTP- $y-S$, the membrane capacitance of mast cells from adult rats increases approx. 4-fold, whereas the increase is only 2-fold in mast cells from 3-week-old animals [13]. This again closely parallels the nearly 2 -fold increase of granule volume per cell as well as the total histamine per cell [146]. The distribution of step sizes is identical for cells from both the new-born and the adult animals indicating that while the number of granules per cell increases during maturation, their size distribution re-

A
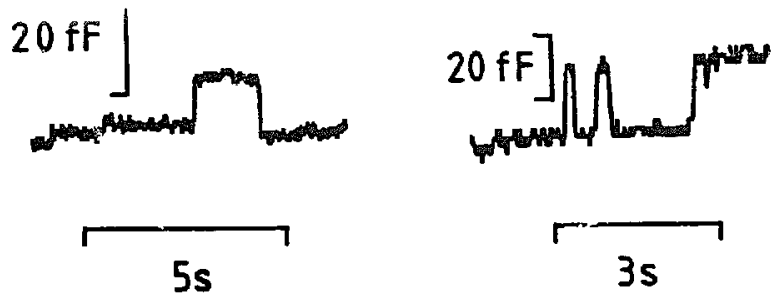

mains essentially unaltered. This observation is in contrast to the morphometric analysis where the number of granules per cell was reported to be constant whereas the mean size of the granules appeared to increase by more than 50\% [146]. However, in beige mice the giant granules which typify this phenutype are not present in the mast cells of new born animals and sppear to be formed by a process of continued intergranule fusion during the maturation of the cells [12].

\section{VIII-D. The fusion pore}

\section{VIII-D-I. Capacitance flicker}

High resolution measurements on rat mast cells reveal that 'on-steps' may be followed by 'off-steps' of similar amplitude (Fig. 24). This is due to the closure or annealing of a fusion pore shortly after it has opened and indicates that in the early stages at least, membrane fusion is a reversible process [111]. Such transient changes have been called 'flickers' by analogy with the openings and closings of ion channels, also referred to as flickers. While capacitance flickers are rather frequently observed in the mast cell only very few such events are seen during degranulation of guinea-pig eosinophils [216] and have not yet been detected during degranulation of horse eosinophils ( 25 cells). In human neutrophils the steps are very small and so it is not possible to make a reasonable estimate of the frequency of flicker events. Capacitance flickers, presumably reflecting reversible fusion events have, however, been observed in nerve terminals derived from the posterior pituitary (Lindau \& Nordmann unpublished) (see Fig. 24) and also during fusion of red blood cells with fibroblasts mediated by a viral fusion protein [338]. The capacitance flicker phenomenon has been investigated in detail in the mast cells of beige mice. Having only a few (typically less than 10) granules of enormous size, these mutant cells give rise to particularly large capacitance steps $[12,55,56,388]$.

\section{VIII-D-2. The opening of the fusion pore}

When a cell is held at a fixed membrane potential under voltage clamp conditions, the fragment of mem-

B
C

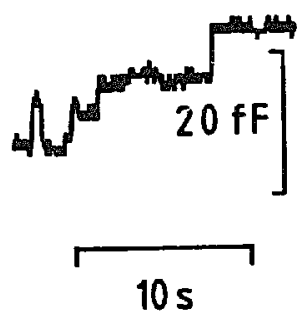

Fig. 24. Capacitance 'on-steps' and 'off-steps'. Off steps have occasionally been observed. This figure shows examples from a rat mast cell (A), guinea-pig eosinophil (B) and a nerve terminal (C). 

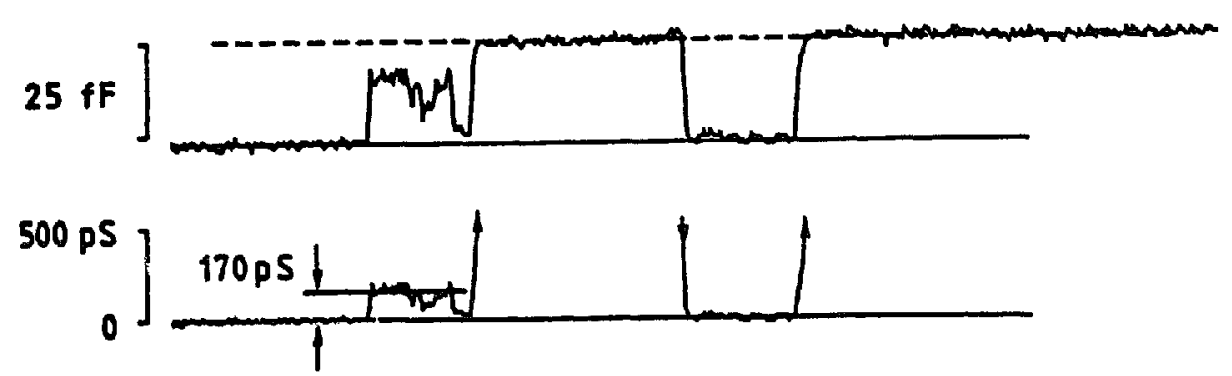

Fig. 25. Relationship between fusion pore conductance and capacitance change for a single granule fusion. The time-course of the capacitance Irace (top) and the corresponding opening of the fusion pore as indicated by the fusion pore conductance (bottom) was measured in a degranulating guinea-pig eosinophil.The arrows indicate that between them the pore conductance was greater than I nanosiemens which is the detectable threshold for a granule of this size and an $800 \mathrm{~Hz}$ sine wave command voltage.

brane added upon fusion has to be charged to the given holding potential and the current which does this is carried through the fusion pore. If the areas of the granule membranes are sufficiently large, as they are in beige mouse mast cells, the charging current becomes considerable. It is then possible to measure the charging current and the time-course of the early fusion pore conductance can be determined $[56,338]$. The initial conductance of these pores is scattered widely with a median value of $280 \mathrm{pS}$ (quite comparable to that of a gap junction [338]) and within a few milliseconds of its initial formation it rapidly dilates $[56,338,388]$. The reclosing of the fusion pore leading to the capacitance flickers (see Fig. 24) occurs not only when the fusion pore is in its initial low conductance state but also after the pore conductance has increased to several nanosiemens [338].

In guinea-pig eosinophils, the fusion events are occasionally preceded by a relatively long-lived state having a pore conductance of 70-250 pS [216], which is very similar to the initial fusion pore conductance of beige mouse mast cells. Fig. 25 shows the time-course of the developing pore conductance measured in a degranulating guinea-pig eosinophil. It can be seen that the pore maintains a relatively constant conductance of $170 \mathrm{pS}$ for a while, then closes, then opens again and rapidly attains a much higher conductance. As with the mast cell, complete reclosure of a pore can occur even after its conductance has exceeded $1 \mathrm{nS}$ [216].

When the granules are loaded with the fluorescent dye quinacrine, release of the dye into the exterior medium (i.e., secretion, see section IV-C-3) occurs only after the capacitance on-step has been irreversibly established. During periods of sustained capacitance flicker there is no measurable loss of dye, indicating that the fusion pore is too narrow to allow rapid exchange between the granule matrix and the extracellular phase [55]. Similarly, the increase in the volume of the granules, which is due to the hydration of the heparin matrix and which is such a blatant feature of exocytosing mast cells (Fig. 6) [55,95,387], only occurs after the increase in membrane capacitance is irre- versibly established [387,388]. The inward movement of water and the volum: increase are therefore consequences of exocytosis and cannot possibly drive the fusion process as has frequently been suggested $[16,77,302,316]$. Furthermore, it is possible to induce membrane fusion and the resultant release of secretory products under conditions in which the swelling of the granules has been prevented. This can be achieved by treating the cells with isotonic solutions of histamine under conditions of low $\mathrm{pH}$ which restricts the extensive hydration of the proteoglycan matrix so that there is no swelling on stimulation $[95,239]$. Even then, neither the duration of the flicker state nor the rate of expansion of the fusion pore are altered, which again confirms that the swelling of the granules does not determine the initiation or the expansion of the fusion pore [239].

While the ultimate detail of the membrane fusion mechanism remains obscure, it is now certain that for the mast cell at least, an osmotic mechanism, can be ruled out. In view of this very clear conclusion, and other criticisms $[29,163]$ it must be doubtful whether an osmotic mechanism of exocytotic membrane fusion in other cells, for which there have been frequent proposals (e.g., chromaffin cells: [204,289,290], platelets: [291,368], parathyroid: [62]) all based on the influx of water into the secretory granule to provide a driving force, can still be considered realistic.

Fig. 26 shows a hypothetical arrangement of the organisation of membrane proteins constituting a fusion pore. This is assumed to be a protein complex consisting of several subunits (A) as proposed by Wolf Almers $[8,11]$. The initial opening of the pore is assumed to be associated with a change in the arrangement of protein subunits leading to the formation of a channel which traverses both the plasma and the granule membrane (B). This generates a structure which could be similar to gap junctions, so far the only proteins known to span two membranes in series. For such a structure, one would predict a pore length of 15 nm (i.e., two membrane widths), so that the measured $280 \mathrm{pS}$ conductance corresponds to a pore diameter of 2-3 nm. The variability of the initial conductance may 
arise either from variability in the structure of the open pore or could alternatively reflect a variable number of subunits which may be preassembled and which then lead to pores of variable size. For the subsequent dilation of the pore two possibilities are suggested in Fig. 26. One possibility (C) involves the insertion of further protein subunits of the same or a different kind. Such a mechanism would be similar to the mechanism proposed for pore formation by streptolysin-O [45] which generates lesions in membranes by forming oligomeric ring structures after membrane insertion. Another possibility would be that pore expansion is mediated by flow of lipids into the spaces between the protein subunits (D) $[8,11]$. Any proposal based on a protein-lined pore has the advantage that the hydrophobic regions of the lipids never come into contact with the aqueous phase at any time during the fusion process, a problem which would be most difficult to solve if the pore is presumed to be composed of lipids.

If the initial approx. $280 \mathrm{pS}$ conductance reflects the formation of a protein lined pore similar to a gap junction $[8,337,338]$ (see also Fig. 25), then we can reasonably anticipate that it should be able to close again. However, as we have seen, reclosing of the fusion pore can occur even after its conductance has increased many times over, to several nanosiemens corresponding to a pore size of 7-20 nm [337] at which it approaches the dimensions which are visible in freeze-fracture micrographs (see Fig. 2). The fusion pore can thus be extensively dilated by incorporation of further proteins or lipids to form a much lerger open structure, without ever losing the ability to reclose. The mechanism underlying the reversible opening and clos- ing of these large structures is still far from being understood.

VIII-D-3. Individual (microscopic) steps in the exocytotic event

The recording of single fusions and the associated capacitance flicker extends the level of measurement to the microscopic events which comprise the terminal stage of the exocytotic process. This recalls the progression, about 10 years ago, from measuring membrane currents under voltage clamp to observing single channel events by the patch-clamp technique. It has now become possible to measure the conductance of single fusion pores and to determine their microscopic kinetic properties such as the rates of opening and their open-time distribution (see VIII-D-2). If those granules that are neither unfused (U) nor stably fused (S) are classified together as a transition or 'flicker' state (F), then the following scheme is immediately suggested [i2]

$\mathrm{U} \Leftrightarrow \mathrm{F} \rightarrow \mathrm{S}$

The time-course of mast celi degranulation, previously shown to be sensitive to the concentrations of GTP- $y$-S and $\mathrm{Ca}^{2+}$ (see VI-D-1) has recently been examined at the level of microscopic kinetics using this simple formulation. It was found that the time between irreversible fusion events (formation of the $S$ state) is inversely proportional to the GTP- $\gamma$-S concentration and is then curtailed still further by elevation of $\mathrm{Ca}^{2+}$; the duration of the flickers is unaffected. The kinetics could be explained only if the transition from $F$ to $S$ is

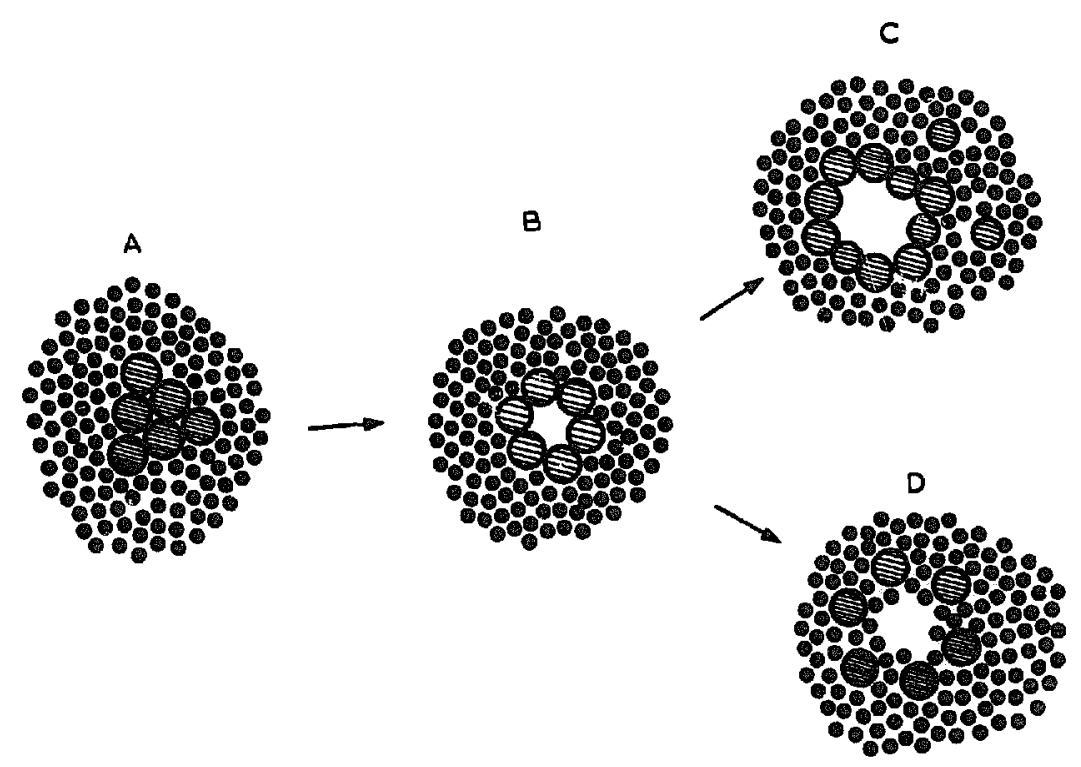

Fig. 26. Hypothetical scheme illustrating the organisation of the fusion pore. The fusion pore is an assembly of several protein subunits (A). The pore opens due to a structural rearrangement in response to an intracellular signal (B). The pore expands by insertion of further protein subunits (C) or by flow of lipid into the space between the protein subunits (D). 
sensitive to the concentration of GTP- $\gamma-S$ and $\mathrm{Ca}^{2+}$ whereas the $F$ to $U$ transition is assumed to be constant [15]. However, commonsense must dictate that the situation is more complicated than this since the transition rate srom $U$ to $F$ is virtually zero in the absence of GTP- $\gamma$-S and becomes quite high in its presence, as indicated by rapid degranulation. A more detailed analysis of the flickers now appears to require more than one F-state (J.M. Fernandez, personal communication) so the simple three state scheme given above should be considered as a minimal model which can account for the flicker phenomenon but not for the detailed properties of the reversible intermediate structures.

VII-D-4. Is non-osmotic membrane tension the driving force for fusion?

Some further clues about the structure and kinetics of the fusion pore and the more general interaction between the two fusing membranes are offered by the finding that after sustained periods of capacitance flicker, the plasma membrane capacitance declines [238] (Fig. 27). This is due to the transfer of surface area away from the plasma membrane into the granule membrane during the time the two are linked by the fusion pore and it occurs at a rate of $0.16 \mu \mathrm{m}^{2} \mathrm{~s}^{-1}$ of flicker duration. Thus, for a typical rat peritoneal mast cell having a surface area of $500-1000 \mu \mathrm{m}^{2}$, approx. $0.02 \%$ of its surface area is transferred per second, adding approx. $10 \%$ to the area of a typical granule having a surface area of $1.6 \mu \mathrm{m}^{2}$. Flicker episodes extending for upwards of $1 \mathrm{~s}$ are not infrequent and so the scale of transfer away from the plasma membrane though smail, is significant. From the point of view of the recipient granule membrane, the transfer is quite considerable. The observation has been interpreted to reflect a difference in the tension between the two fusing membranes, though whether or not this plays a role in initiating or expanding the fusion pore remains to be determined.

Whatever the role of this lipid flow turns out to be, the observation strongly suggests that the fusion pore rapidly takes on a lipidic character. This favours the idea of a pore expansion model as is illustrated in Fig. $26 \mathrm{~d}$, the 'dispersing subunit model' [1i]. We confidently anticipate that the wider importance of these individual phenomena, revealed by high resolution capacitance measurements, will become clearer when similar experiments are performed on other cell types in which the control mechanisms for exocytosis, or more simply, in which the contents of the secretory granules are different.
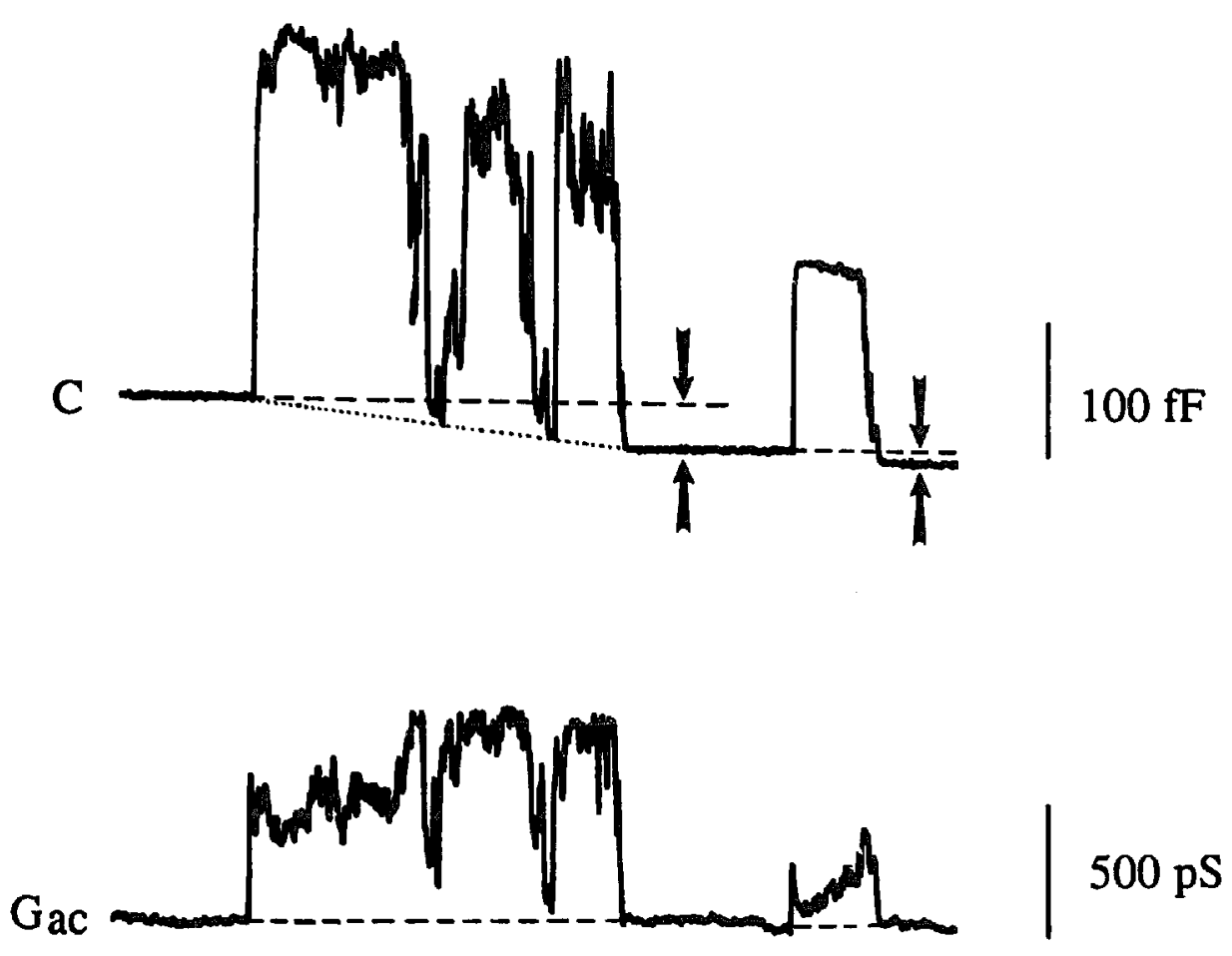

$10 \mathrm{~s}$

Fig. 27. Lipid flow in the fusion pore. When the fusion pore recloses after an episode of flicker the capacitance is slightly smaller than the initial capacitance (top trace). The decrease reflects a true decrease in capacitance since no change is observed in the conductance trace (bottom trace). From [238]. 
In this latter respect, the eosinophils which are currently being investigated in our laboratories should be particularly appropriate. In these cells, the phenomena related to exocytosis can be investigated with very high resolution (i.e., approaching that which can be achieved with the mutant beige mouse mast celis) but the composition of the granule matrix is quite different from that of the mast cell, being hydrophilic and thus rapidly dissipated following exocytosis and exposure to the extracellular saline $[216,261,312]$.

\section{Envoi}

'Unlike the Pope, I believe my opinions to be very fallible, and therefore I may be mistaken that the enemy's fleet has gone to Europe; but I cannot think myself otherwise, notwithstanding the variety of opinions which a number of good people have formed'

The Right Hon Lord Viscount Nelson, K.B., Commander in Chief, on board HMS Victory standing off Antigua, 12 June 1805.

We have presented a great deal of data and a number of complex arguments concerning the mechanism of regulated exocytosis, especially as it is manifested in myeloid cells. A number of events which occur in response to stimulation have been identified or suggested sach as activation of phospholipases $C$ and $A_{2}$, protein kinase $C$, phosphorylation, dephosphorylation and $\mathrm{Ca}^{2+}$ release. However, the direct involvement of any of these pathways in the activation of exocytotic granule fusion is still completely obscure. One feature stands out and that is that guanine nucleotides and hence a GTP binding protein (possibly more than one) are key players in this process. They are certainly equal in importance to $\mathrm{Ca}^{2+}$ which has heen continuously recognised as an effector for secretiun for almost a century $[103,148,218,298,299]$.

As our work and that of others has proceeded, we have from time to time presented schematic figures to illustrate how we believe the various intracellular effectors and modulators interact with events lying up and downstream and between themselves [132]. On occasion, especially at times when matters appear to be approaching a firm conclusion, such pictorial summaries, however facile, can certainly be helpful. It is our opinion that as of now, the field is moving as never before and that any update of previous schematics that we might present here will become fossilised well before the ink on these pages is dry. Our opinion remains simply that; we have presented the data and the arguments as they appear to us now and we hope that our colleagues will find much to enjoy and much to argue about. But a scheme represents some kind of conclusion and this is not the time to present schemes.

\section{Acknowledgements}

It is a pleasure to acknowledge generous support over a period of many years from the Wellcome Trust. Additional important financial help has been provided by the Medical Research Council, The Vandervell Foundation and the Gower Street Secretory Mechanisms Group. The continued support by the Deutsche Forschungsgemeinschaft is also gratefully acknowledged.

We are indebted to Dr Douglas Chandler, University of Arizona, who provided the photomontage and wrote the legends of Fig. 2 and to Dr. Julio Fernandez who provided Figs. and 23 and 27.

Technical note. The script for this paper was jointly written using the SPRINT (Borland) word processor on a PC in London and 1ST WORD PLUS on an Atari ST in Berlin. SPRINT presents many useful facilities for the scientific author such as automatic cross referencing for sections, figures and equations. Also, because many buffers can be open simulianeously, it enables immediate access to subsidiary files such as tables, author bibliographies etc. The references were compiled using the DMS4CITE database (Sidereal Technologies, Inc. 263 Center Avenue, Westwood NJ 07675 USA). The text was communicated between the authors using electronic mail and a home made conversion program for the different word processor codes. No hard copy of the text was transmitted at anytime.

\section{References}

1 Afzelius, B. (1956) Exp. Cell Res. 10, 257-285.

2 Ahnert-Hilger, G., Bader, M-F., Bhakdi, S. and Gratzl, M. (1989) J. Neurochem. 52, 1751-i 758.

3 Ahnert-Hilger, G., Bhakdi, S. and Gratzl, M. (1985) J. Biol. Chem. 260, 12730-12734.

4 Ahnert-Hilger, G., Mach, -..., Fohr, K.J. and Gratzl, M. (1989) Meth. Cell Biol. 31. 63-90.

5 Ahnert-Hilger, G., Weller, U., Dauzenroth, M-E., Habermann, E. and Gratzl, M. (1989) FEBS Lett. 242, 245-248.

6 Alexander, D.R., Hexham, J.M., Lucas, S.C., Graves, J.D., Cantrell, D.A. and Crumpton, M.J. (1989) Biochem. J. 260, 893-901.

7 Ali, S.M., Geisow, M.J. and Burgoyne, R.D. (1989) Nature 340, 313-315.

8 Almers, W. (1990) Annu. Rev. Physiol. 52, 607-624.

9 Almers, W. and Neher, E. (1985) FEBS Lett. 192, 13-18.

10 Almers, W. and Neher, E. (1987) J. Physiol. (Lond) 386, 205-218.

11 Almers, W. and Tse, F.W. (1990) Neuron 4, 813-818.

12 Alvarez De Toledo, G. and Fernandez, J.M. (1988) in Cell Physiology Of Blood (Gunn, R.B. and Parker, J.C., eds.), Vol. 43, 333-344, Society of General Physiologisis series, Rockefeller University Press, New York.

13 Alvarez De Toledo, G. and Fernandez, J.M. (1990) J. Cell Biol. $110,1033-1039$.

14 Alvarez De Toledo, G. and Fernandez, J.M. (1990) J. Gen. Physiol. 95, 397-409.

15 Alvarez De Toledo, G. and Fernandez, J.M. (1990) Biophys. J. $57,495 a$. 
16 Anderson, P., Rohlich, P. and Uvnas, B. (1979) Acta Physiol. Scand. 105, 350-358.

17 Aridor, M. and Sagi-Eisenberg, R. (1991) J. Cell Biol. 111, 2885-2891.

18 Aridor, M., Traub, L.M. and Sagi-Eisenberg, R. (1990) J. Cell Biol. 111, 909-917.

19 Arock, M., Deveilier, P., Luffau, G., Guillosson, J. and Renoux, M. (1989) Int. Archs. Allergy appl. Immunol. 89, 229-235.

20 Ashcroft, F.M. and Kakei, M. (1989) J. Physiol. (Lond) 416, 349-367.

21 Assem, E.S.K., Ghanem, N.S., Abdullah, N.A., Repke, H., Foreman, J. and Hayes, N. (1989) Immunopharmacology 17, 119-128.

22 Athayde, C.M. and Scrutton, M.C. (1990) Eur. J. Biociem. 189, 647-655.

23 Axelrod, J., Burch, R.M. and Jelsema, C.L. (1988) Trends in Neurosci. 11, 117-123.

24 Bacon, R.A., Salminen, A., Ruohola, H., Novick, P. and Ferro-Novick, S. (1989) J. Cell Biol. 109, 1015-1022.

25 Bader, M.-F., Thierse, D., Aunis, D., Ahnert-Hilger, G. and Gratzl, M. (1986) J. Biol. Chem. 261, 5777-5783.

26 Bainton, D.F., Ullyot, J.L. and Farquhar, M.G. (1971) J. Exp. Med. 134, 907-934.

27 Baker, P.F. and Knight, D.E. (1978) Nature 276, 620-622.

28 Baker, P.F. and Knight, D.E. (1981) Phil. Trans. R. Soc. Lond. B. 296, 83-104.

29 Baker, P.F. and Knight, D.E. (1984) Bioscience reports 4, 285-298.

30 Baker, P.F., Knight, D.E. and Umbach, J.A. (1985) Cell Calcium 6, 5-14.

31 Baker, P.F., Knight, D.E. and Whitaker, M.J. (1980) Proc. R. Soc. Lond. B. 207, 149-161.

32 Balch, W.E. (1990) Trends in Biochem. Sci. 15, 473-477.

33 Baltzly, R., Buck, J.S., De Beer, E.J. and Webb, F.J. (1949) J. Am. Chem. Soc. 71, 1301-1305.

34 Bangham, A.D. (1968) Prog. Biophys. Mol. Biol. 18, 29-95 Pergamon Press, Oxford.

35 Bansal, M.K., Phillips, J.H. and Van Heyningen, S. (1990) FEBS Lett. 276, 165-168.

36 Bar-Sagi, D. and Gomperts, B.D. (1988) Oncogene 3, 463-469.

37 Barrowman, M.M., Cockcroft, S. and Gomperts, B.D. (1986) Nature 319, 504-507.

38 Barrowman, M.M., Cockcroft, S. and Gomperts, B.D. (1987) J. Physiol. (Lond) 383, 115-124.

39 Beaven, M.A., Rogers, J., Moore, J.P., Hesketh, T.R., Smith, G.A. and Metcalfe, J.C. (1984) J. Biol. Chem. 259, 7129-7136.

40 Beckers, C.J.M. and Balch, W.E. (1989) J. Cell Biol. 108, 1245-1256.

41 Bennett, J.P., Cockcroft, S. and Gomperts, B.D. (1980) Nature 282, 851-853.

42 Bennett, J.P., Cockcroft, S. and Gomperts, B.D. (1981) J. Physiol. (Lond) 317, 335-345.

43 Bergmeyer, H. -U. (1963) Methods of Enzymatic Analysis. 3-13 Academic Press.

44 Beyer, E.C. and Steinberg, T.H. (1991) J. Biol. Chem. 266, 7971-7974.

45 Bhakdi, S., Tranum-Jensen, J. and Sziegoleit, A. (1985) Infect. Immun. 47, 52-60.

46 Bialojan, C. and Takai, A. (1988) Biochem. J. 256, 283-290.

47 Bilezikian, I.P. and Aurbach, G.D. (1974) J. Biol. Chem. 249, 157-161.

48 Bittner, M.A., Holz, R.W. and Neubig, R.R. (1986) J. Biol. Chem. 261, 10182-10188.

49 Bokoch, G.M., Bickford, K. and Bohl, B.P. (1988) J. Cell Biol. 106, 1927-1936.

50 Bokoch, G.M. and Gilman, A.G. (1984) Cell 39, 301-308.

51 Bokoch. G.M. and Parkos, C.A. (1988) FEBS Lett. 227, 66-70.

52 Buume, H.R. (1988) Cell 53, 669-671.
53 Bourne, H.R., Sanders, D.A. and McCormick, F. (1990) Nature $348,125-132$.

54 Brandt, D.R. and Ross, E.M. (1986) J. Biol. Chem. 261, 16561664.

55 Breckenridge, L.J. and Almers, W. (1987) Proc. Natl. Acad. Sci. USA 84, 1945-1949.

56 Breckenridge, L. and Almers, W. (1987) Nature 328, 814-817.

57 Brooks, J.C. and Brooks, M. (1985) Life Sciences 37, 1869-1876.

58 Brooks, J.C., Treml, S. and Brooks, M. (1984) Life Sci. 35, $569-574$.

59 Brown, E.. Enyedi, P., LeBoff, M., Rotberg, J., Preston, J. and Chen, C. (1987) FEBS Lett. 218, 113-118.

60 Brown, E.M. (1991) Physiol Revs. 71, 371-411.

61 Brown, E.M., LeBoff, M.S., Oetting, M., Posillico, J.T. and Chen, C. (1987) Recent Prog. Hormone Res. 43, 337-382.

62 Brown, E.M., Pazoles, C.J., Creutz, C.E., Aurbach, G.D. and Pollard, H.B. (1978) Proc. Natl. Acad. Sci. USA 75, 876-880.

63 Buckingham, L. and Duncan, J.L. (1983) Biochim. Biophys. Acta 729, 115-122.

64 Buckwitz, D., Jacobasch, G. and Gerth, C. (1990) Mol. Biochem. Parasitol. 40, 225-232.

65 Buckwitz, D., Jacobasch, G. and Gerth, C. (1990) Biochem. J. 267, 353-357.

66 Bueb, J.-L., Mousli, M., Bronner, C., Rouot, B. and Landry, Y. (1990) Mol. Pharmacol. 38, 816-822.

67 Burch, R.M., Luini, A. and Axelrod, J. (1986) Proc. Natl. Acad. Sci. USA 83, 7201-7205.

68 Campbell, A.K. (1983) Wiley, Chichester, UK 556.

69 Cass, C.E., Lowe, J.K., Manchak, J.M. and Henderson, J. F. (1977) Cancer Res. 37, 3314-3320.

70 Cazalis, M., Dayanithi, G. and Nordmann, J.J. (1987) J. Physiol. (Lond) 390, 71-91.

71 Chandler, D.E. (1988) Curr. Top. Membr. Transp. 32, 169-292.

72 Chandler, D.E., Bennett, J.P. and Gomperts, B.D. (1983) J. Ultrastructure Res. 82, 221-232.

73 Chandler, D.E. and Heuser, J.E. (1979) J. Cell Biol. 83, 91-108.

74 Chandler, D.E. and Heuser, J.E. (1980) J. Cell Biol. 86, 666674.

75 Cheek, T.R., Jackson, T.R., O'Sullivan, A.J., Moreton, R.B., Berridge, M.J. and Burgoyne, R.D. (1989) J. Cell Biol. 109, 1219-1227.

76 Chi, E.Y., Henderson, W.R. and Klebanoff, S.J. (1982) Lab. Invest. 47, 579-585.

77 Chock, S.P. and Schmauder-Chock, E.A. (1990) BioFactors 2, 133-146.

78 Choy, V.J. and Watkins, W.B. (1976) J. Endocrinonol. 69, 349-358.

79 Churcher, Y., Allan, D. and Gomperts, B.D. (1990) Biochem. J. 266, 157-163.

80 Churcher, Y. and Gomperts, B.D. (1990) Cell Regul 1, 337-346.

81 Churcher, Y., Kramer, I.M. and Gomperts, B.D. (1990) Cell Regul 1, 523-530.

82 Cockcroft, S. (1991) Biochem. J. 275, 127-131.

83 Cockcroft, S. and Gomperts, B.D. (1979) Nature 279, 541-542.

84 Cockcroft, S. and Gomperts, B.D. (1980) Biochem. J. 188, 789-798.

85 Cockcroft, S. and Gomperts, B.D. (1985) Nature 314, 534-5.36.

86 Cockcroft, S. and Gomperts, B.D. (1988) in Calcium and Drug Action, 305-338, Springer-Verlag, Heidelberg.

87 Cockcroft, S., Howell, T.W. and Gomperts, B.D. (1987) J. Cell Biol. 105, 2745-2750.

88 Cohen, P., Holmes, C.F.B. and Tsukitani, Y. (1990) Trends in Biochem. Sci. 15, 98-102.

89 Cole, K.S. (1935) J. Gen. Physiol. 18, 877-887.

90 Cole, K.S. (1968) University of California Press, Berkeley.

91 Collado-Escobar, D., Cunha-Melo, J.R. and Beaven, M.A. (1989) J. Immunol. 
92 Coorssen, J.R., Davidson, M.M.I .. and Haslam, R.J. (1990) Cell Regul. I, 1027-1041.

93 Cromwell, O., Bennett, J.P., Kay, A.B., Hide, I. and Gomperts, B.D. (1991) J. Immunol. 147, 1905-1911.

94 Cunha-Melo, J.R., Gonzaga, H.M.S., Ali, H., Huang, F.L., Huang, K. and Beaven, M.A. (1989) J. Immunol. 143, 26172625 .

95 Curran, M. and Brodu ick, M.S. (1985) Biophys. J. 47, 172a.

96 Darchen, F., Zahraoui, A., Hammel, F., Monteils, M.-P., Tavitian, A. and Scherman, D. (1990) Proc. Natl. Acad. Sci. USA 87. 5692-5696.

97 Davidson, J., Van Der Merwe, P.A., Wakefield, I. and Millar, R.P. (1991) Mol. Cell. Endocrinol. 76, C33-C38.

98 DeCoursey, T.E., Chandy, K.G., Gupta, S. and Cahalan, M. D. (1985) J Neuroirnmunol. 10, 71-95.

99 De Duve, C. (1963) in Lysosomes (de Reuck, A.S.V. and Cameron, M.P., eds.), p. 163, Churchill, London.

100 Del Castillo, J. and Katz, B. (1956) Prog. Biophys. 6, 121-170.

101 De Young, M.B., Nemeth, E.F. and Scarpa, A. (1987) Arch. Biochem. Biophys. 254, 222-233.

102 Di Virgilio, F., Lew, D.P. and Pozzan, T. (1984) Nature 310, 691-693.

103 Douglas, W.W. (1968) Brit. J. Pharmacol. 34, 451-474.

104 Duchen, M.R., Millar, J. and Biscoe, T.J. (1990) J. Physiol. (Lond) 426, 5P.

105 Easterby, J.S. (1981) Biochem. J. 199, 155-101.

106 Eberhard, D.A., Low, M.G. and Holz, R.W. (1990) Biochem. J. $268,15-25$.

107 Edwardson, J.M., Vickery, C. and Christy, L.J. (1990) Biochim. Biophys. Acta 1053, 32-36.

108 Ennis, M., Pearce. F.L. and Weston, P.M. (1980) Brit. J. Pharmacol. 70, 329-334.

109 Füssle, R., Bhakdi, S., Sziegoleit, A., Tranum-Jensen, J., Kranz, T. and Wellensiek, H.J. (1981) J. Biol. Chem. 91, 83-94.

110 Fernandez, J.M., Lindau, M. and Eckstein, F. (1987) FEBS Lett. 216, 89-93.

111 Fernandez, J.M., Neher, E. and Gomperts, B.D. (1984) Nature 312, 453-455.

112 Fewtrell, C.. Lagunoff, D. and Metzger, H. (1981) Biochim. Biophys. Acta 644,363-368.

113 Fewtrell, C.M.S., Foreman, J.C., Jordan, C.C., Oehme, P., Renver, H. and Stewart, J.M. (1982) J. Physiol. (Lond) 330, 393-411.

114 Fidler-Lim. N., Nowycky, M.C. and Bookman, R.J. (1990) Nature 344, 449-451.

115 Fischer Von Mollard, O., Mignery, G.A., Baumert, M., Perrin, M.S., Hanson, T.J., Burger, P.M., Jahn, R. and Sudhof, T.C. (1990) Proc. Natl. Acad. Sci. USA 87, 1988-1992.

116 Fischer Von Mloliard, G., Sudhof, T.C. and Jahn, R. (1991) Nature 349, 79-81.

117 Fitzpatrick, L.A., Brandi, M. -L. and Aurbacii, G.D. (1986) Endocrinology 119, 2700-2703.

118 Fitzpatrick, L.A., Brandi, M.L. and Aurbach, G.D. (1986) Biochem. Biophys. Res. Commun. 138, 960-965.

119 Foreinan, J.C., Mongar, J.L. and Gomperts, B.D. (1973) Nature 245, 249-251.

120 Fray, J.C.S., Park, C.S. and Valentine, A.N.D. (1987) Endocrine Rev. 8, 53-93.

121 Frye, R.A. and Holz, R.W. (1984) J. Neurochem. 43, 146-150.

122 Fujiki, H., Suganuma, M., Suguri, H., Yoshizawa, S., Takagi, K., Sassa, T., Uda, N., Wakamatsu, K., Yamada, K., Yasumoto, T., Kato, Y., Fusetani, N., Hashimoto, K. and Sugimura, T. (1988) in Mycotoxins and Phycotoxins '88, 453-460, Elsevier, Amsterdam.

123 Fujiki, H. and Sugimura, T. (1987) Adv. Cancer Res. 49, 223-264.
124 Fukuoka, Y. and Hugli. T.E. (1990) J. Immunol. 145, 18511858.

125 Gallin F. K. (1984) Fed Proc. 43, 2385-2389.

126 Gallin, E.K. (1986) J. Leukocyte Biol. 39, 241-254.

127 Gierschik, P., Sidiropoulos, D., Spiegel, A. and Jakobs, K.H. (1987) Eur. J. Biocham. 165, 185-194.

128 Gierschik, P., Steisslinger, M.. Siridopoulos, D., Herrman, E. and Jakobs, K.H. (1989) Eur. J. Biochem. 183, 97-105.

129 Glenney, J.R., Tack, B. and Powell, M.A. (1987) J. Cell Biol. $104,503-511$.

130 Gomperts, B.D. (1983) Nature 306, 64-66.

131 Gomperts, B.D. (1984) in Biological Membranes, Vol 5. (Chapman, D., ed.), 284-340, Academic Press, New York.

132 Gomperts, B.D. (1990) Annu. Rev. Physiol. 52, 591-606.

133 Gomperts, B.D. (1990) in G Froteins (lyengar, R. and Birnbaumer, L., eds.), pp. 601-637, Academic Press, San Diego.

134 Gomperts, B.D. (1991) in Histamine (Uvnas, B., ed.), 119-144, Springer-Verlag, Berlin.

135 Gomperts, B.D., Baldwin, J.M. and Micklem, K.J. (1983) Biochem. J. 210, 737-745.

136 Gomperts, B.D., Barrowman, M.M. and Cockcroft, S. (1986) Fed. Proc. 45, 2156-2161.

137 Gomperts, B.D., Bennett, J.P. and Allan, D. (1981) Eur. J. Biochem. 117, 559-562.

138 Gomperts, B.D., Churcher, Y, Koffer, A., Kramer, I.M., Lillie, T.H.W. and Tatham, P.E.R. (1990) Biochem. Soc. Symp. 56, $85-101$.

139 Gomperts, B.D., Cockcroft, S., Howell, T.W., Nüsse, O. and Tatham, P.E.R. (1987) Biosci. Reports. 7, 369--381.

140 Gomperts, B.D., Cockcroft. S., Howell, T.W. and Tatham, P.E.R. (1988) in Molecular Mechanism In Secretion (Thorn, N.A., Treiman, M. and Petersen, O.H., eds.), pp. 248-258, Munksgaard, Copenhagen, Denmark.

141 Gomperis, B.D. and Fewtrell, C.M.S. (1985) in Molecular Mechanisms of Membrane Signalling, Chapter 12, in Vol. 4 of Molecular Aspects of Cellular Regulation (Cohen. P. and Houslay, M.D., eds), pp. 377-409, Elsevier, Amsterdam.

142 Gomperts, B.D. and Tatham, P.E.R. (1988) Cold Spring Harbor Symp. Quant. Biol. 53, 983-992.

143 Greenberg, S., Virgilio, F.D., Steinberg, T.H. and Silverstein, S.C. (1988) J. Biol. Chem. 263. 10337-10343.

144 Guild, S., Frey, E.A., Pocotte, S.L. and Kebabian, J.W. (1988) Brit. J. Pharmacol. 94, 737-744.

145 Hamill, O.P., Marty, A., Neher, E., Sakman, B. and Sigworth, F.J. (1981) Eur. J. Physiol. 391, 85-100.

146 Hammel, I., Lagunoff, D. and Kruger, P.G. (1988) Lab. Invest. 59; 549-554.

147 Handwerger, S., Conn, P.M., Barrett, J., Barry, S. and Golander, A. (1981) Am. J. Physiol. 240, E550-E555.

148 Harvey, A.M. and Maclntosh, F.C. (1940) J. Physiol. (Lond) 97, 408-416.

149 Haslam, R.J. and Davidson, M.M.L. (1984) FEBS Lett. 174, 90-95.

150 Haslam, R.J. and Davidson, M.M.L. (1984) Biochem. J. 222, 351-361.

151 Haslam, R.J., Williams, K.A., Davis, W., Sherwood, J. and Van der Meulen, J. (1990) Adv. Second Messenger and Phosphoprotein Res. 24, 364-369.

152 Haystead, T.A.J., Sim, A.T.R., Carling, D., Itonnor, R.C., Tsukitani, Y., Cohen, P. and Hardie, D.G. (1989) Nature 337, 78-81.

153 Helander, H.F. and Bloom, G.D. (1974) J. Microscopy. 100 , 315-321.

154 Henderson, W.R., Chi, E.Y., Jorg. A. and Klebanoff, S. J. (1983) Am. J. Pathol. 111, 341-349. 
155 Heppel, L.A., Weisman, G.A. and Friedberg, I. (1985) J. Mumbr. Biol. 86, 189-196.

156 Herrmann, E., Gierschik, P. and Jakobs, K.H. (1989) Eur. J. Biochem. 185, 677-683.

157 Herrmann, E. and Jakobs, K.H. (1988) FEBS Lett. 229, 49-53.

158 Higashijima, T., Burnier, J. and Ross, E.M. (1990) J. Biol. Chem. 265, 14176-14186.

159 Higashijima, T., Ferguson, K.M. and Sternweis, P.C. (1987) J. Biol. Chem. 262, 3597-3602.

160 Higeshijima, T., Uzu, S., Nakajima, T. and Ross, E.M. (1988) J. Biol. Chem. 263, 6491-6494.

161 Hilf, G. and Jakobs, K.H. (1989) Eur. J. Pharmacol. 177, 155-163.

162 Hirai, Y., Yasuhara, T., Yoshida, H., Nakajima, T., Fujino, M. and Kitada, C. (1979) Chem. Pharm. Bull. 27, 1942-1944.

163 Holz. R.W. (1986) Annu. Rev. Physiol, 48, 175-189.

164 Honda, K., Maeda, Y., Sasakawa, S., Ohno, H. and Tsuchida, E. (1981) Biochem. Biophys. Res. Commun. 101, 165-171.

165 Horn, R. and Marty, A. (1988) J. Gen. Physiol. 92, 145-159.

166 House, C. and Kemp, B.E. (1987) Science 238, 1726-1728.

167 Howell, T.W., Cockcroft, S. and Gomperts. R.D. (1987) J. Cell Biol. 105, 191-197.

168 Howell, T.W. and Gomperts, B.D. (1987) Biochim. Biophys. Acta 927, 177-183.

169 Howell, T.W., Kramer, I. and Gomperts, B.D. (1989) Cellular Signalling 1, 157-163.

170 Hughes, A.R., Takemura, H. and Putney, J.W. (1989) Cell Calcium 10, 519-525.

171 Impraim, C.C., Foster, K.A., Micklem, K.J. and Pasternak, C.A. (1980) Biochem. J. 186, 847-860.

172 Ince, C., Thio, B., Van Duijn, B., Van Dissel, J.T., Ypey, D.L. and Leijh, P.C.J. (1987) Biochim. Biophys. Acta 905, 195-204.

173 Ishizaka, T. (1989) Clin. Immunol. Immunopathol. 50, 20-29,

174 Jakobs, K.H., Aktories, K. and Schultz G. (1984) Eur. J. Biochem. 140, 177-181.

175 Jamieson, J.D. and Palade, G.E. (1967) J. Cell Biol. 34, 597-615.

176 Janmey, P.A., lida, K., Yin, H.L. and Stossel, T.P. (1987) J. Biol. Chem. 262, 12228-12236.

177 Jena, B.P., Padfield, P.J., Ingebritsen, T.S. and Jamieson, J.D. (1991) J. Biol. Chem. 266, 17744-17746.

178 Johansen, T. (1987) Pharmacol. Toxicol. 61, 1-20.

179 Johnson, G.S. and Mukku, V.R. (1979) J. Biol. Chem. 254, 95-100.

180 Johnson, R.A., Pilkis, S.J. and Hamet, P. (1975) J. Biol, Chem. 250, 6599-6607.

181 Johnson, R.G., Carty, S.E., Fingerhood, B.J. and Scarpa, A. (1980) FEBS Lett. 120, 75-79.

182 Jones, P.M., Fyles, J.M., Persaud, S.J. and Howell, S. L. (1987) FEBS Lett. 219, 139-144.

183 Kanno, T., Cochrane, D.E. and Douglas, W.W. (1973) Canad. J. Physiol. Pharmacol. 51, 1001-1004.

184 Katz, B. (1966) Nerve, Muscle and Synapse. McGraw-Hill, New York.

185 Katz, B. (1971) Science 173, 123-126.

186 Kawa, K. (1989) J. Physiol. (Lond) 415, 211-231.

$187 \mathrm{Kim}, \mathrm{K}$. and Westhead, E.W. (1989) Proc. Natl. Acad. Sci. USA 86, 9881-9885.

188 Kinoshita. K. and Tsong. T.Y. (1977) Nature 268, 438-441.

189 Kitagawa, M., Williams, J.A. and De Lisle, R.C. (1990) Am. J. Physiol. 259, G157-G164.

190 Knight, D.E. and Baker, P.F. (1982) J. Membr. Biol. 68, 107140.

191 Knight, D.E. and Baker, P.F. (1983) FEBS Lett. 160, 98-100.

192 Knight, D.E. and Baker, P.F. (1985) FEBS Lett. 189, 345-349.

193 Knight, D.E. and Koh, E. (1984) Cell Calcium 5, 401-418.

194 Knight, D.E., Niggli, V. and Scrutton, M.C. (1984) Eur. J. Biochem. 143, 437-446.
195 Knight, D.E. and Scrutton, M.C. (1980) Thrombosis. Res. 20, 437-446.

196 Knight, D.E. and Scrutton, M.C. (1986) Biochem. J. 234, 497506.

197 Knight, D.E. and Scruitton. M.C. (1986) Eur. J. Biochem. 160, 183-190.

198 Koffer, A. and Gomperts, B.D. (1989) J. Cell Sci. 94, 585-591.

199 Koffer, A., Tatham, P.E.R. and Gomperts, B.D. (1990) J. Cell Biol. 111, 919-927.

200 Koibuchi, Y., Ichikawa, A., Nakagawa, M. and Tomita, K. (1985) Eur. J. Pharmacol. 115, 163-170.

201 Koopmann, W.R. and Jackson, R.C. (1990) Biochem. J. 265, 365-373.

202 Kramer, I.M., Van Der Bend, R.L., Tool, A.T.J., Van Blitterswijk, W.J., Roos., D. and Verhoeven, A.J. (1989) J. Biol. Chem. 264, 5876-5884.

203 Kumagai, M., Yanagi, T., Murata, M., Yasumoto, T., Kat, M., Lassus, P. and Rodriguez-Vazquez, J.A. (1986) Agric. Biol. Chem. 50, 2853-2857.

204 Ladona, M.G., Bader, M.F, and Aunis, D. (1987) Biochin. Biophys. Acta 927, 18-25.

205 Lagunoff, D. and Rickard, A. (1983) Exp. Cell. Res. 144, 353-30́0.

206 Lawson, D., Raff, M.C., Fewtrell, C.M.S., Gonperts, B. D. and Gilula, N.B. (1977) J. Cell Biol. 72, 242-259.

207 LeNeveu, D.M., Rand, P.M. and Parsegian, V.A. (1976) Nature 259, 601-603.

208 Lillie, T.H.W., Whalley, T.D. and Gomperts, B.D. (1991) Biochim. Biophys. Acta 1094, 355-363.

209 Lillie., T.H.W. and Gomperts. B.D. (1991) Phil. Trans. Roy. Soc. (Lond.), in press.

210 Lind, I., Ahnert-Hilger, G., Fuchs, G. and Gratzl, M. (1987) Analyt. Biochem. 164, 84-89.

211 Lindau. M. (199i) Quart. Rev. Biophys.

212 Lindau, M. and Fernandez, J.M. (1986) J. Gen. Physiol. 88, 349-368.

213 Lindau, M. and Fernandez, J.M. (1986) Nature 319, 150-153.

214 Lindau, M., Fernandez, J.M. and Neher, E. (1985) Soc. Neurosci. Abstr. 11, 953.

215 Lindau, $M$. and Nüsse, O. (1987) FEBS Lett. 222, 317-321.

216 Lindau, M., Nüsse, O., Bennett, J., Cromwell, O., Kay, A.B. and Gomperts, B.D. (1991) submitted for publication.

217 Lindau, M., Stuenkel, E.L. and Nordmann, J.J. (1990) Biophys. $J_{.}$, in press.

218 Locke, F.S. (1894) Zentralblat. Physiol 8, 166-167.

219 Lowe, J.K., Brox, L. and Henderson, J.F. (1977) Cancer Res. 37, 736-743.

220 Lu, D.J. and Grinstein, S. (1990) J. Biol. Chem. 265, 1372113729.

221 Luini, A. and De Matteis, M.A. (1988) Cell. Mol. Neurobiol. 8, 129-138.

222 Luini, A. and De Matteis, M.A. (1990) J. Neurochem. 54, 30-38.

223 Mann, P.J.G., Tennenbaum, M. and Quastel, J.H. (1939) Biochem. J. 33, 451-474.

224 Marquardt, D.L., Gruber, H.E. and Walker, L.L. (1987) J. Pharmacol. Exp. Therap. 240, 145-149.

225 Marty, A. and Neher, E. (1983) in Single Channel Recording (Sakmann, B. and Neher, E., eds.), 107-121, Plenum Press, NY.

226 Maruyama, Y. (1988) J. Physiol. (Lond) 406, 299--313.

227 Maruyama, Y. (1989) Pflugers Arch. 413, 438-440.

228 Mason, W. T., Rawlings, S.R., Cobbett, P., Sikdar, S.K., Zorec, R., Akerman, S.N., Benham, C.D., Berridge, M.J., Cheek, T. and Moreton, R.B. (1988) J. Exp. Biol. 139, 287-316.

229 Mason, W., Sikdar, S.K. and Zorec, R. (1988) J. Physiol. (Lond) $407,88 \mathrm{p}$. 
230 Mayorga, L.S., Diaz, R., Colombo, M.l. and Stahl, P.D. (1989) Cell Regul 1, 113-124.

231 McMillian, M.K., Soltoff, S.P. and Talamo, B.R. (1988) Biochem. Pharmacol. 37, 3790-3793.

232 Melançon, P., Glick. B.S., Malhotra, V., Weidman, P.J., Serafini, T., Gleason, M.L.. Orci, L. and Rothman, J.E. (1987) Cell $51,1053-1062$.

233 Menestrina, G. (1986) J. Membr. Biol. 90, 177-190.

234 Metzger, H., Alcaraz, G., Hohman, R., Kinet, J.-P., Pribluda, V. and Quarto, R. (1986) Annu. Rev. Immunol. 4, 419-470.

235 Miller, M.R., Castellot, J.J. and Pardee, A.B. (1978) Biochemistry $17,1073-1080$.

236 Mizoguchi, A., Kim, S., Ueda, T., Kikuchi, A., Yorifuji, H., Hirokawa, N. and Takai, Y. (1991) J. Biol. Chem. 265, 1187211879.

237 Momayezi, M., Lumpert, C.J., Kersken, H., Gras, U., Plattner, H., Krinks, M.H. and Klee. C.B. (1987) J. Cell Biol. 105, 181-189.

238 Monck, J.R., Alvarez De Toledo, G. and Fernande?, J.M. (1990) Proc. Natl. Acad. Sci. USA 87, 7804-7808.

239 Monck, J.R.. Oherhauser, A.. Alvarez De Toledo, G. and Fernamdez, J.M. (1990) Bioplyys. J. 59, 39-47.

240 Morgan, A. and Burgoyne, R.D. (1990) Biochem. J. 271, 571$\$ 74$.

241 Morgan, A. and Burgoyne, R.D. (1990) Biochem. J. 26\%), 521526.

242 Mousli, M., Bronner, C., Bueb, J.-L., Tschirhart, E., Gies, J.-P. and Landry, Y. (1989) J. Pharm. Exp. Therap. 250, 329-335.

243 Mousli, M., Bronner, C., Landry, Y., Bockaert, J. and Rouot, B. (1990) FEBS Lett. 259, 260-262.

244 Muff, R. and Fischer, J.A. (1986) FEBS Lett. 194, 215-218.

245 Murakami, Y., Oshima, Y. and Yasumoto, T. (1982) Bull. Jpn. Soc. Sci. Fish 48, 69-72.

246 Mustelin, T.M., Poso, H. and Andersson, L.C. (1986) EMBO J. 5. 3287-3290.

247 Nadin, C.Y., Rogers, J., Tomlinson, S. and Edwardson, J. M. (1989) J. Cell Biol. 109, 2801-2808.

248 Nakamura, T. and Ui, M. (1985) J. Biol. Chem. 260, 3584-3593.

249 Neer, E.J., Lok, J.M. and Wolf, L.G. (1984) J. Biol. Chem. 25\%, $14222-14229$.

250 Neher, E. (1988) Neuroscience 26, 727-737.

251 Neher, E. (1988) J. Physin!, (Lond) 395, 193-214.

252 Neher, E. and Almers, W. (1986) EMBO J. 5, 51-53.

253 Neher, E. and Marty, A. (1982) Proc. Natl. Acad. Sci. USA 79, 6712-6716.

254 Neher, E. and Penner, R. (1988) in Molecular Mechanisms in Secretion (Thorn, N., Treiman, M. and Peterson, O.H., eds.), pp. 262-270, Munksgaard, Copenhagen.

255 Nemeth, E. F, and Scarpa, A. (1986) FEBS Lett. 203, 15-19.

256 Nemeth, E.F., Wallace, J. and Scarpa, A. (1986) J. Biol. Chem. 261, 2668-2674.

257 Novick, P.J., Goud, B., Salminen, A., Walworth, N.C., Nair, J. and Potenza, M. (1988) Cold Spring Harbor Symp. Quant. Biol. 53, 637-647.

258 Nüsse, O. (1988) Diplomarbeit, Freie Universität Berlin.

259 Nüsse, O. and Lindau, M. (1988) J. Cell Biol. 107, 2117-2123.

260 Nüsse, O. and Lindau, M. (1990) Bioscience Reports 10, 93103.

261 Nüsse, O., Lindau, M., Cromwell, O., Kay, A.B. and Gomperts, B.D. (1990) J. Exp. Med. 171, 775-786.

262 Oetting, M., LeBoff, M., Swiston, L., Preston, J. and Brown, E. (1986) FEBS Lett. 208, 99-104.

263 Oetting, M., Leboff, M.S., Levy, S., Swiston, L., Preston, J., Chen, C. and Brown, E.M. (1987) Endocrinology 121, 15711576.

264 Ohara-Imaizumi, M., Takeda, K., Kawae, N. and Kumakura, K. (1990) Neurosci. Lett. 110, 167-171.
265 Oinuma, M., Katada, T. and Ui, M. (1987) J. Biol. Chem. 262, 8347-8353.

266 Oliva, C.. Cohen, I.S. and Mathias, R.T. (1988) Biophys. J. 54, 791-799.

267 Orci, L. and Perrelet, A. (1978) Cell Surface Revs. 5, 629-656.

268 Orci, L., Perrelet, A. and Friend, D.S. (1977) J. Cell Biol. 75. 23-30.

269 Ornberg, R.L. and Reese, T.S. (1981) J. Cell Biol. 90, 40-54.

270 Ortner, M.J. and Chignell, C.F. (1981) Biochem. Pharmacol. 30, 283-288.

271 Ortner, M.I., Sik, R.H., Chignell, C.F. and Sokoloski, E.A. (1979) Mol. Pharmacol. 15, 179-188.

272 Otto, M., Heinrich, R., Kuhn, B. and Jacobasch, G. (1990) Eur. J. Biocilem. 49, $164-178$

273 Ozal:i, H., Kohama, K., Nonomura, Y., Shibata, S. and Karaki, H. (1987) Arch. Pharmacol. 335, 356-358.

274 Ozaki, Y., Matsumoto, Y., Yatomi, Y., Higashihara, N., Kariya, T. and Kume, S. (1990) Biochem. Biophys. Res. Commun. 170, 779- 795 .

275 Pace. C.S., Tarvin, J.T., Neighbors, A.S., Pirkle, J.A. and Greider, M.H. (198()) Diabetes 29, 911-918.

276 Padficld, P.J., Ding, T.-D. and Jamieson, J.D. (1991) Biochem. Bionpliys. Res. Commun. 174, 536-541.

277 Padfield, P.J. and Jamieson, J.D. (1991) Biochem. Bioplys Res. Commun. 174, 600)-605.

278 Palade, G. (1975) Science 189, 347-358.

279 Park, C.S., Honeyman, T.W., Chung, E.S., Lee, J.S., Sigmon, D.H. and Fray, J.C.S. (1986) Am. J. Physiol. 251, F1055-F1062.

280 Parsegian, V.A., Rand, R.P. and Gingell, D. (1984) Ciba Foundation Symposium 103, 9-27.

281 Parsegian, V.A. and Rau, D.C. (1984) J. Cel! Riol. 95, 196s200 s.

282 Pasternak, C.A., Alder, G.M., Bashford, C.L., Buckley, C.D., Micklem, K.J. and Patel, K. (1985) Biochem. Soc. Trans. 50, 247-264.

283 Paton. W.D.M. (1957) Pharmacol, Rev, 9, 269-321.

284 Penner, R., Matthews, G. and Neher, E. (1988) Nature 334. 499-504.

285 Penner, R. and Neher, E. (1988) FEBS Lett. 226, 307-31.3.

285a Penner, R. and Neher, E. (1988) J. Exp. Biol. 1.39, 329-345.

286 Penner, R., Pusch, M. and Neher, E. (1987) Biosci. Reports 7. 313-321.

287 Perrin, D., Langley, O.K. and Aunis, D. (1987) Nature 326, 498-501.

288 Peters, S.F., MacGlashan, D.W., Schleimer, R.P., Hayes, E.C., Adkinson, N.F. and Lichtenstein, L.M. (1985) Am. Rev. Respir. Dis. 132, 367-373.

289 Pollard, H.B., Pazoles, C.J., Creutz, C.E., Ramu, A., Strott, C.A., Ray, P., Brown, E.M., Aurbach, G.D., Tack-Goldmars, K.M. and Shulman, N.R. (1977) J. Supramolec. Struct. 7. 277-285.

290 Pollard, H.B., Pazoles, C.J., Creutz, C.E., Scott, J. H., Zinde", O. and Hotchkiss, A. (1984) J. Biol. Chem. 259, 1114-1121.

291 Pollard, H.B., Tack-Goldman, K., Pazoles, C.J., Creutz, C.E. and Shulman, N.R. (1977) Proc. Natl. Acad. Sci. USA 74. 5295-5299.

292 Pozzan, T., Lew, D.P., Wollheim, C.B. and Tsien, R.Y. (1983) Science 221, 1413-1415.

293 Prince, W.T., Rasmussen, H. and Berridge, M.J. (1973) Biochim. Biophys. Acta 329, 98-107.

294 Pusch, M. and Neher, E. (1988) Pfluegers Archiv, 411, 204-211. Putney, J.W. (1986) Annu. Rev. Physiol. 48, 75-88

297 Repke, H. and Bienert, M. (1987) FEBS Lett. 221, 230-240.

298 Ringer, S. (1883) J. Physiol. (Lond) 3, 195-202.

299 Ringer, S. (1894) J. Physiol. (Lond) 4, 29-42.

300 Rink, T.J. and Sanchez, A. (1984) Biochem. J. 222, 833-836. 
301 Rink, T.J., Sanchez, A. and Hallam, T.J. (1983) Nature 305, 317-319.

302 Rohlich. P., Anderson, P. and Uvnas, B. (1971) J. Cell Biol, 51, 465-483.

303 Ronning. S.A. and Martin. T.F.J. (1985) Biochem. Biophys. Res. Commun. 130, 524-532.

304 Rorive, G. and Kleinzeller, A. (1972) Biochim. Biophys. Acta 274, 226-239.

305 Rothschild, L. (1957) J. Biophys. Biochem. Cytol. 3, 103-110.

306 Ruggiero, M., Zimmerman, T.P. and Lapetina, E.G. (1985) Biochem. Biophys, Res. Commun. 131, 620-627.

307 Saito, H. Ishizaka, K. and Ishizaka, T. (1989) J. Immunol, 14,3, 250-258.

Mo Saito, H. Okajima, F., Molski, T.F.P. Sha'afi, R.I. Ui, M. and Ishiaka, T. (1987) J. Immund, 138, 3927-3934.

30 Sulminen, A. and Novick, P.J. (1987) Cell 49, 527-538.

310 Saralian, T. Aunis, D, and Bader, M.P. (1487) J. Biol, Chent. 262. $16671=16676$.

311 Satir, B.H., Busch, G., Vuoso, A. and Murtaugh. T.J. (19kk) J Cell. Blochem, 36, 429,443,

312 Secpek, S. Nïsse, O., Sachsse, G. and Lindaw, M. (1991) Eur. J. Cell Biol, 54, 23.

313 Schacht, J. (1976) J. Neurochem. 37, 1119-1124.

314 Schater, T., Karli, U.O., Gratwohl. E. K.M. Schweizer, F.E. and Burger, M.M. (1987) J. Neurochem. 49, 1697-1707.

315 Schleimer, R.P., MacGlashan, D.W., Peters, S.P., Pinckard. R.N. Adkinson, N.F. and Lichteustein, L.M. (1986) Am. Rev, Respir. Dis, 133, 614-617.

316 Schmauder-Chock. E.A. and Chock. S.P. (1990) Histochem. J. 22. 215-226.

317 Schrezenmeier, H. Ahnert-Hilger. G. and Fleischer. B. (1988) J. Immunol, 141, 3785-3790.

318 Schwarz, G. and Robert. C.H. (1990) Biophys. J, 58, 577-583,

319 Schweizer, F.E., Schafer, T, and Burger, M.M. (1991) Biochem. Pharmacol, $41,163-169$.

3.0 Segal, D.M. Tuurog, J,1), and Metzger, H, (1977) Proc. Natl. Acad, Sci, USA 74, 2493 $=2997$,

321 Seger. N. Mulholland, J, and Bulstsin, D. (1926) Coll 52. $913=934$.

32 Selinger, Z, Eimerl, S. and Schramm, M, (197d) Proc. Nall. Aend, Sei. USA 71, 128=131.

323 Shaw, R, J, Cromwell, O, and Kny, A.B, (1984) Clin. Exp. Immunol, 36, $716=722$.

324 Sherwood. L.M. Potts, J,T, Care, A.D. Mayer, G.P. and Aurbach, G.D. (1966) Nature 209, 52-55,

323 Shibata, S. Ishida, Y. Kitano, H, Ohizumi, Y., Habon. J, Tsukitani, Y, and Kikuchi, H, (1982) J. Pharm. Exp. Therap. 223, $133=143$,

32 Shoback. D.M. Thatcher, J.G. Leombruno, R, and Brown, E.M. (1983) Endocrinology 113, 424-426.

327 Sikdar, S. Zorec, R, Brown, D. and Mason, W, (1989) FEBS Lell. $253,88-92$.

328 Smith, C.L. Ahkong, Q.F, Fisher, D. and Lucy, J.A. (1982) Biochim. Biophys, Acta 682, 109m 114 .

329 Smith. J.B. Ingerman. C. Kocsis. J.J. and Silver, M. J, (1973) J. Clin. Invest. 52. 965-969.

130 Smolen. J.E. and Stoehr, S.J. (1985) J. Inmunol, 134, I859. $18 \%$.

$33 !$ Smolen, J.E. and Stoehr, S.J. (1986) Biochim. Biophys. Acta 889, 171-178.

332 Sontag. J.M. Aunis. D. and Bader, M.F. (1988) Eur. J, Cell Biol. 46, 316-326.

33 Sontag, J.M. Thierse, D., Rowot, B., Aunis. D. and Bader, M.F. (1991) Biochem. J. 274, 339-347)

334 Sorimachi, M. Nishimura, S. and Sadano. H. (1987) Biomed. Res. 8. 205-209,
335 Sorimachi, M., Nishimura, S., Yamagami, K. and Yada, T. (1988) Japan. J. Physiol, 38, 227-232.

336 Spitznagel, J., Dalldorf, F., Leffell, M.S., Folds, F. S., Welsh, I.R.H., H., C.M. and E., M.L. (1974) Lab. Invest. 30, 774-785.

337 Spruce, A.E., Breckenridge, L.J., Lee, A.K. and Almers, W, (1990)) Neuron 4, 643-654.

338 Spruce, A.E. Iwata. A.. White. J.M. and Almers, W, (1989) Nature 342, 555-558.

339 Stecher, B.. Gratzl, M. and Ahnert-Hilger, G. (1989) FEBS Lett. 248, 23-27.

340 Stecher, B., Weller, U., Hahermann, E., Gratal, M. and Ahnert-Hilger, G. (1989) FEBS Lett. 255, 391-394.

.41 Steinberg, T.H. Newman, A.S., Swanson, J.A. and Silverstein, S.C. (1987) J. Biol. Chem. 262.8884-8888.

342 Sternweis, P.C. and Robishaw, J.D. (1984) J. Biol. Chem. 259, $13816-13813$.

343 Stutchificld, J. and Cockerof, S. (1988) Biochem. J. 250, 375= 332.

344 Suganuma, M. Fujiki, H., Suguri, H. Yoshizawa, S., Ihrota. M. Nakayasu, M. Ojiku, M., Wakumatsu, K., Yamadı, K. and Suginura. T. (19N6) Proc. Natl. Acud. S6i. USA 85, 1768-17\%!.

34 Suganuma, M. Sutuji, M., Suguri, H., Ojika, M., Yamada, K. and Fujiki. H, (1989) FEBS Lell. 2\$0, $615=6,18$,

346 Svoboda. M. and Christophe, J. (1978) FEBS Lelt. 86. 230-234.

347 Sweeney. M.J. Hoffman. D.H. and Esterman, M.A. (1972) Cancer Res. 32, IN(1)3-Is(W).

348 Tachibana, T., Scheuer, P.J, Tsukituni, Y. Kikuchi, H Van Engen. D. Clardy, J., Gopichard, Y, and Schmitz, F.J. (1981) J. Am. Chem. Sox. 103, 2469-2471.

349 Takai, A. Bialojan. C. Troschka. M. and Ruegg. J.C. (1987) FEBS Latl. 217, 81- 14 ,

350 Tukuma, T. (I08s) Binchem. J. 256. 867-871.

331 Tasaka, K., Sugiyama, K., Konoto. S. and Yamasaki. H. (1970) Proc, Japan Acid. 46, 317-321.

15? Tatham, P.E.R. Cusack, N.J, and Gomperis, B.D. (1988) Eur. J. Pharnacol. 147, 1, - 21

853 Tutham, P.E.R., Duchen. M.R. and Millar, J. (1991) in press.

354 Tatham, P.E.R. and Gomperts, B.D. (1984) Biosci. Reports, 9. 99- 109 .

355 Tatham. P.E.R. and Gomperts, B.D. (196()) in Peptide Hormoneso A Practical Approach. Vol, 2. 257-260, IRL. Press, Oxford.

350 Tatham, P.E.R. and Gomperts, B.D. (I991) J. Cell Sci. 9K, $217-224$.

357 Tatham, P.E.R. and Lindau, M. (1990) J. Gen. Physiol. 95, 459-476.

358 Tedeschi, A., Miadonma. A.. Lorini, M.. Arquati, M. and Zanussì C. (1989) Int. Arshs, Allergy appl. Immunol. 90. $109-111$.

359 Thomas, P., Suprenant, A. and Almers, W. (1990) Bionhysical Journal 57,245 .

360 Thomas, P.. Suprenant. A. and Almers, W. (1991) Neuron 5 723-73.3.

361 Toutant. M., Aunis. D., Bockatert, J., Homburger, V. and Rowot. B. (1987) FEBS Lett. 215, 339-344.

362 Tsuruta, K., Grewe. C.W, Cote. T.E., Eskay, R.L. and Kebahian, J,W, (1982) Endocrinology 110, 1133-1140.

363 Turk, J.. Wolf. B.A., Lefkowith, J.B., Stump, W.T. and McDaniel. M.L. (1986) Biochim. Biophys. Acla 879, 399-409.

364 Ulirich, S., Prentki, M. and Wollheim, C.B. (1990) Biochem. J. 270, 273-276.

365 Ullrich. S. and Wollheim. C.B. (1988) J. Biol. Chem. 263. $8615-8620$.

366 Vallar, L., Biden, T.J. and Wollheim, C.B. (1987) J. Biol. Chem. 262, 5049-5056.

367 Van Blitterswijk, W.J.. Van Der Bend, R.L., Kramer, I., Ver- 
hoeven, A.J., Hilk ann, H. and De Wid, I. (1987) Lipids 22. 842-846.

368 Vander-Meulen, J. and Grinstein, S. (1982) J. Biol. Chem. 257. 5190-5195.

369 Van Der Merwe, F.A., Millar, R.P., Wakefield, I.K. and Davidson. J.S. (1989) Biochem. J. 264, 49.3-498.

370 Van Der Menve, l'.A.. Millar, R.P., Wakefield, I.K. and Davidson, J.S. (1991) Biwchem. J. 275, 399-405.

371 Wagner, P.D. and Vu, N.-D. (1989) J. Biol. Chem. 264, 1961419620.

372 Walsh, C.E., DaChatelet, L.R., Chilton, F.H., Wykle, R.L. and Waite, M. (1983) Biochin. Biophys. Acta 750, 32-40.

373 Weingarten, R., Ransnis, L... Mueller, H., Sklar, L.A. and Bokoch, G.M. (1900) J. Biol. Chem. 265, 11044-11049.

374 Whalley, T., Crossley, I. and Whitaker, M. (1990) J. Cell Biol. 11.3, 76, -778 .

375 Whetton. A., Huang, S. and Monk, P. (1488) Binchem. Bioplyys. Res. Commun. 152, 117, $=1178$.

37 Wilson, B., Desunin, $G$, Slump, R, and Oliver, J. (19KK) FASEB J. 2, A123\%.

377 Wojcieseyn, J.W.. Schlegel, R.A., Lumicy-Sapanski, K. and Jaculesen, K.A. (108,3) , , Cell Bis). 4h, 151-1,50.
378 Wollheim, C.B. Ullrich, S., Meda, P. and Vallar, L. (1987) Bioseci. Reports. 7, 443-454.

379 Wymann, M.P., Von Tscharney, V., Deranleate, D.A. and Baggiolini. M. (1987) J. Biol. Chen. 262. 12048-12053.

380 Yamadis, Y., Natsumeda, Y. and Webur, G. (1988) Biochemistry $27,2193-2196$.

381 Yamamoto, T., Furuki, Y. Guid, S. and Kebabian, J.W. (1987) Biochem. Biophys. Res. Commun. 143, 1076-1084.

382 Yamamoto, T., Furuki. Y., Kebabian, J.W. and Spatz, M. (1987) FEBS Lett. 219, 326-330.

383 Yaseen. M.A., Pedley, K.C. and Howell, S.L. (1982) Biochem. J. $206,81-87$.

384 Yin, H. (1987) Bioessays 7, :76-179.

385 Ypey, D.L. and Clapham, D.E. (1984) Proc. Natl. Acad. Sci. USA $81,30 \times 3-3087$.

386 Zieseniss, E. and Platuer. H. (1985) J. Cell Biol. 101, 202820.35 .

387 Zimmerbegs, J. (1987) Biosei. Reports 7.251-268,

348 Zimmerberg, J., Curran, M., Cohen, F.S. and Brodwick, M. (1U87) Proc. Nall. Acad. Sci. USA 84, 1585-1589.

384) Zurec, R., Musun, W. and Sikdar, S.K. (19k8) J. Gen. Physiol. $11: 12 i n$. 